NASA

$\checkmark$

\title{
A Comparison of Graphite/Epoxy Tape Laminates and 2-D Braided Composites Mechanical Properties
}

Pierre J. Minguet and Christian K. Gunther

(NASA-CR-4610) A COMPARISON DF

GRAPHITE/EPOXY TAPE LAMINATES AND

2-D ORAIDED COMPOSITES MECHANICAL

PROPERTIES Final Report (Boeing

Defense and Space Group) 53 p
N94-37582

Unclas

$\mathrm{H1} / 26 \quad 0018514$ 


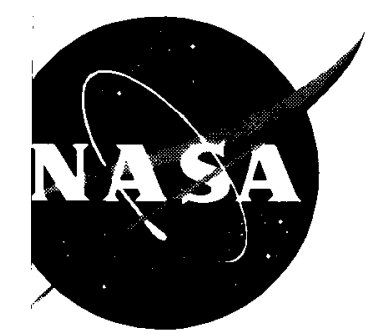

\section{A Comparison of Graphite/Epoxy Tape Laminates and 2-D Braided Composites Mechanical Properties}

'ierre J. Minguet and Christian K. Gunther

oeing Defense \& Space Group • Philadelphia, Pennsylvania 


\begin{abstract}
A comparison of the in-plane mechanical properties of unidirectional composite tape laminates and of 2-dimensional triaxially braided composite was conducted. The tape laminate layups were designed to match the percentage of axial fibers and the angle of the bias tows in the braided composite. The material system used for the laminates is AS4/3501-6 which was chosen as the closest available match to AS4/1895 used for the braids. This report documents the results of the testing of the laminates and compares these results with data previously obtained for the braided composite. The strength and stiffness properties measured here include tension, open-hole tension, filled-hole tension, compression and open-hole compression, all of these in both the longitudinal and transverse direction, in-plane shear and bearing.

Results show that the longitudinal modulus of both material forms is quite similar, but that the transverse modulus of the braids is lower. In terms of strength, the longitudinal unnotched strength of the braids is lower than that of the laminates, while the transverse strength is significantly lower. Similarly, the shear strength of the braids was much lower. For both strength and stiffness, the crimp in the bias tows of the braid is probably the main cause for reduced properties. On the other hand, a very significant increase in open-hole and filled-hole tension strength was observed for the braids compared to the tape laminates. However, this was not observed in compression where all the braid properties are lower than for the laminates. Bolt-bearing strength of the braids was also lower.
\end{abstract}




\section{Table of Contents}

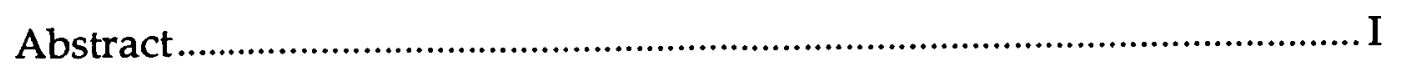

Table of Contents ...................................................................................... II

List of Figures........................................................................................ III

List of Tables ....................................................................................... IV

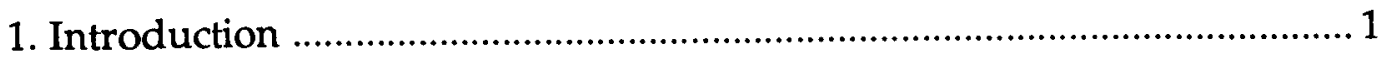

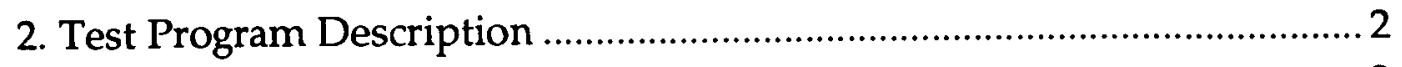

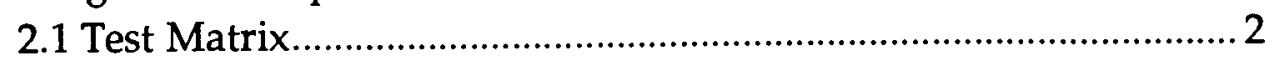

2.2 Test Matrix .................................................................................

2.3 Data Reduction Techniques ...................................................... 4

3. Tension Properties............................................................................... 5

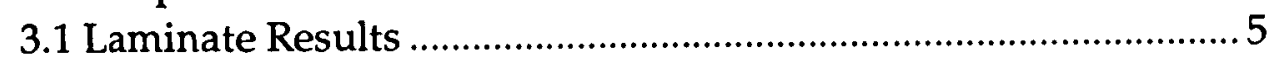

3.2 Comparison with Braided Composite.......................................... 7

4. Compression Properties ........................................................................ 12

4.1 Laminate Results ..................................................................... 12

4.2 Comparison with Braided Composite........................................... 13

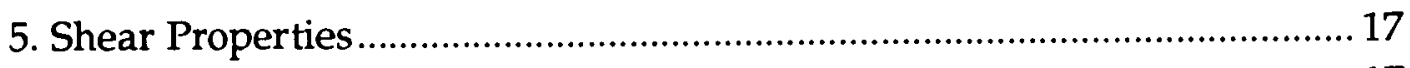

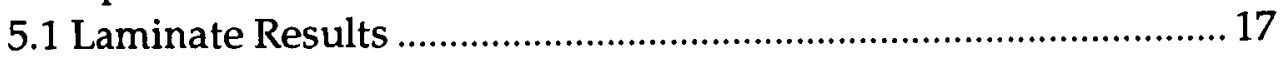

5.2 Comparison with Braided Composite.......................................... 17

6. Bolt Bearing Properties ........................................................................... 19

6.1 Laminate Results ..................................................................... 19

6.2 Comparison with Braided Composite........................................... 19

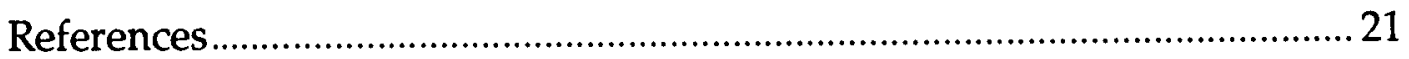

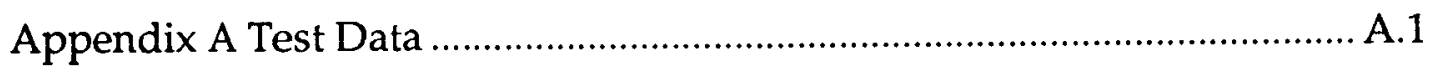

Appendix B Typical Stress-Strain Curves............................................... B.1 


\section{List of Figures}

Figure 2.1 Illustration of 2-D Triaxial Braid Configuration......................................... 3

Figure 3.1 Comparison of Longitudinal and Transverse Tension Modulus............ 8

Figure 3.2.a Comparison of $0^{\circ}$ Tension Strength for Tape Laminate 1, SLL

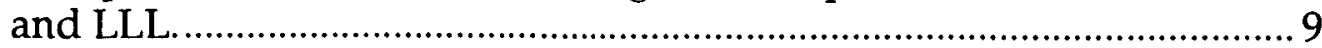

Figure 3.2.b Comparison of $0^{\circ}$ Tension Strength for Tape Laminate 2 and

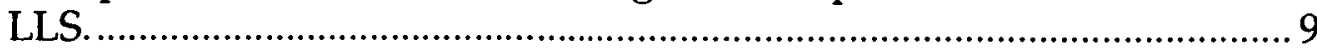

Figure 3.2.c Comparison of $0^{\circ}$ Tension Strength for Tape Laminate 3 and LSS.

Figure 3.2.d Comparison of $0^{\circ}$ Tension Strength for Tape Laminate 4 and B1. 10

Figure 4.1 Comparison of Longitudinal and Transverse Compression Modulus. 14

Figure 4.2.a Comparison of $0^{\circ}$ Compression Strength for Tape Laminate 1, SLL and LLL. 14

Figure 4.2.b Comparison of $0^{\circ}$ Compression Strength for Tape Laminate 2, LLS.

Figure 4.2.c Comparison of $0^{\circ}$ Compression Strength for Tape Laminate 3, LSS

Figure 4.2.d Comparison of $0^{\circ}$ Compression Strength for Tape Laminate 4, B1. 15

Figure 4.3.a Comparison of $90^{\circ}$ Compression Strength for Tape Laminate 1, SLL and LLL

Figure 4.3.b Comparison of $90^{\circ}$ Compression Strength for Tape Laminate 2, LLS. 16

Figure 4.3.c Comparison of $90^{\circ}$ Compression Strength for Tape Laminate 3, LSS. 16

Figure 5.1 Comparison of In-Plane Shear Modulus of Laminates and 2-D Braids

Figure 5.2 Comparison of In-Plane Shear Strength of Laminates and 2-D Braids

Figure 6.1 Comparison of Bearing Strength for Tape Laminate 1, 2 and braids SLL, LLL and LLS. 


\section{List of Tables}

Table 2.1 Description of 2-D braid architectures...........................................................

Table 2.2 Tape Laminates Test Program .....................................................................

Table 3.1 Laminate Longitudinal Tension Properties.................................................... 5

Table 3.2 Laminate Transverse Tension Properties......................................................... 6

Table 4.1 Laminate Longitudinal Compression Properties ......................................... 12

Table 4.2 Laminate Transverse Compression Properties ............................................. 13

Table 5.1 Laminate Shear Properties ............................................................................17

Table 6.1 Laminate Bearing Strength Properties ........................................................ 19 


\section{Introduction}

Carbon/Epoxy composites made from textile fiber preforms manufactured with a Resin-Transfer-Molding (RTM) process have some potential for reducing costs and increasing damage tolerance of aerospace structures. One form of textile preform which is under consideration is a 2-dimensional triaxially braided fabric. A large amount of test data has been generated recently to quantify the mechanical properties of various 2$\mathrm{D}$ braided configurations loaded in tension, with and without holes, compression, with and without holes, shear and bolt bearing [1].

The key question is then to determine and quantify the benefits and drawbacks of this material form. Because of the nature of the triaxial fabric (e.g., no $90^{\circ}$ fibers), little data which could be used for a direct comparison of mechanical performance is available for more conventional material forms (i.e. tape or biaxial fabric laminates). Therefore, tape laminates with the same ply orientation and percentage of $0^{\circ}$ fibers as the previously tested braided composites were manufactured and tested. The objectives of this report are to summarize all the strength and stiffness properties measured for the tape laminates investigated and to compare these properties with those previously determined for 2-D braided composites.

This report describes work accomplished under Contract NAS1-19247 from the National Aeronautics and Space Administration, Langley Research Center, Hampton VA. Mr Clarence C. Poe Jr., NASA LaRC, was the NASA Technical Monitor. The Structures Technology organization of the Boeing Defense \& Space Group, Helicopters Division was responsible for completing this task. All specimen manufacturing and material testing was conducted at Integrated Technologies, Inc. (Intec, Bothell, WA) 


\section{Test Program Description}

\subsection{Test Matrix}

Four configurations of 2-D braided composite were extensively tested in a previous investigation as reported in Reference 1 . The 2-D braided fabric contains two types of tows, the longitudinal (axial, or $0^{\circ}$ ) tow and the braided (or bias) tows oriented at angle $\theta$ of the axial tow as illustrated in Figure 2.1. The braid pattern used is $2 \times 2$ pattern, meaning that each braided tow goes over and under two tows at a time. As shown in Table 2.1, the first three architectures contain a large percentage of axial fiber typical of a composite optimized for a predominantly longitudinal loading. The first architecture, SLL, was braided with small tows to provide a fine architecture, while the third one, LLL, was braided with 2.5 times larger tows, thus allowing one to examine the influence of tow sizes. The second architecture, LLS was braided with a $45^{\circ}$ bias angle, thus allowing one to examine the influence of braid angles. For practical applications, braid angles will often be limited to the $45^{\circ}$ to $70^{\circ}$ range, and the comparison of LLS and LLL allows one to examine both upper and lower bounds on that parameter. Finally, the fourth architecture, LSS, contains a larger amount of $\pm 45^{\circ}$ tows more typical of a composite optimized for shear loading. In addition, a fifth configuration, B1, is considered which is used in the fuselage frame for NASA/Boeing ATCAS crown panel. Only limited data were available for this material system in Reference 2. Results from this Reference were scaled up to the common $60 \%$ fiber volume fraction used in this report.

Four laminates were designed to match the bias angle and percentage of axial fibers of these braids. Two of the braids, SLL and LLL, have the same layup with different tow sizes and thus will be compared with the same laminate. The material system used is AS4/3501-6 (4.4 oz/ $\left.\mathrm{yd}^{2}\right)$ which closely matches the AS4/1895 system used for the braids. The following four laminates were used:

Laminate 1: $\quad\left[(45 / 0 /-45 / 0)_{2} / 45 / 0 /-45\right]_{S}$

22 Plies Total, $100^{\circ}$ Plies (45.4\%), $1245^{\circ}$ Plies, to match LLS.

Laminate 2: $\quad\left[(70 / 0 /-70 / 0)_{2} / 70 / 0 /-70\right]_{S}$

22 Plies Total, $100^{\circ}$ Plies (45.4\%), $\left.12 ; \cdot\right)^{\circ}$ Plies, to match SLL and LLL.

Laminate 3: $\quad\left[( \pm 45)_{2} / 0 /( \pm 45)_{3} / 0( \pm 45)_{3} / 0 /( \pm 45)_{2}\right]_{\mathrm{t}}$

23 Plies Total, $30^{\circ}$ Plies (13.0\%), $2045^{\circ}$ Plies, to match LSS.

Laminate 4: $\quad\left[(66 / 0 /-66)_{4} / 0\right]_{S}$

26 Plies Total, $100^{\circ}$ Plies (38.5\%), $166^{\circ}$ Plies, to match B1. 
Table 2.1 Description of 2-D braid architectures.

\begin{tabular}{||c|c|c|c|c|c|c||}
\hline \hline Name & $\begin{array}{c}\text { Longitudinal } \\
\text { Tow Size }\end{array}$ & $\begin{array}{c}\text { Braided Tow } \\
\text { Size }\end{array}$ & $\begin{array}{c}\text { \% Longitudinal } \\
\text { Tow }\end{array}$ & $\begin{array}{c}\text { Braid } \\
\text { Angle [ }{ }^{\circ} \text { ] }\end{array}$ & $\begin{array}{c}\text { Unit Cell } \\
\text { Width [in] }\end{array}$ & $\begin{array}{c}\text { Unit Cell } \\
\text { Length [in] }\end{array}$ \\
\hline SLL & $30 \mathrm{~K}$ & $6 \mathrm{~K}$ & 46 & 70 & 0.458 & 0.083 \\
\hline LLS & $36 \mathrm{~K}$ & $15 \mathrm{~K}$ & 46 & 45 & 0.415 & 0.207 \\
\hline LLL & $75 \mathrm{~K}$ & $15 \mathrm{~K}$ & 46 & 70 & 0.829 & 0.151 \\
\hline LSS & $6 \mathrm{~K}$ & $15 \mathrm{~K}$ & 12 & 45 & 0.415 & 0.207 \\
\hline B1 & $18 \mathrm{~K}$ & $6 \mathrm{~K}$ & 37 & 66 & 0.105 & 0.046 \\
\hline
\end{tabular}

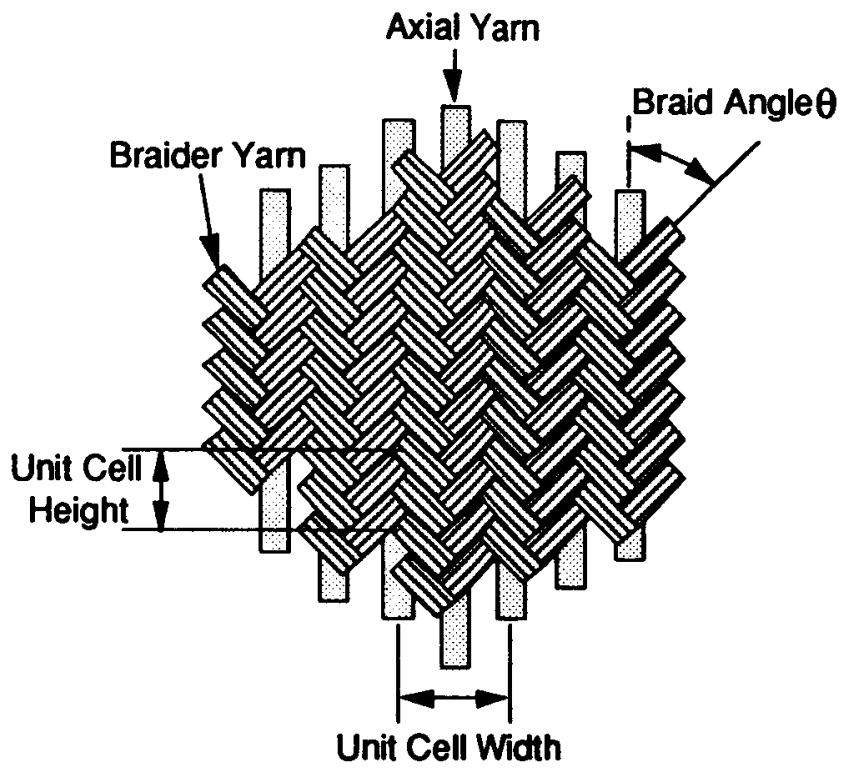

Figure 2.1 Illustration of 2-D Triaxial Braid Configuration.

\subsection{Iest Matrix}

The complete test matrix for this program is shown in Table 2.2. A total of 180 specimens were used. All the in-plane material properties considered in Ref. 1 were considered here. Standard size specimen, 12" long and 1.5" wide, were used for the tension tests. Modified IITRI specimens, 1.5" long by $1.5^{\prime \prime}$ wide test section, were used for the compression tests. The laminate thickness was doubled for the compression specimen to insure specimen stability. A hole diameter of $0.188^{\prime \prime}$ was mistakenly used in the compresssion test instead of the standard $0.250^{\prime \prime}$. 
Table 2.2 Tape Laminates Test Program

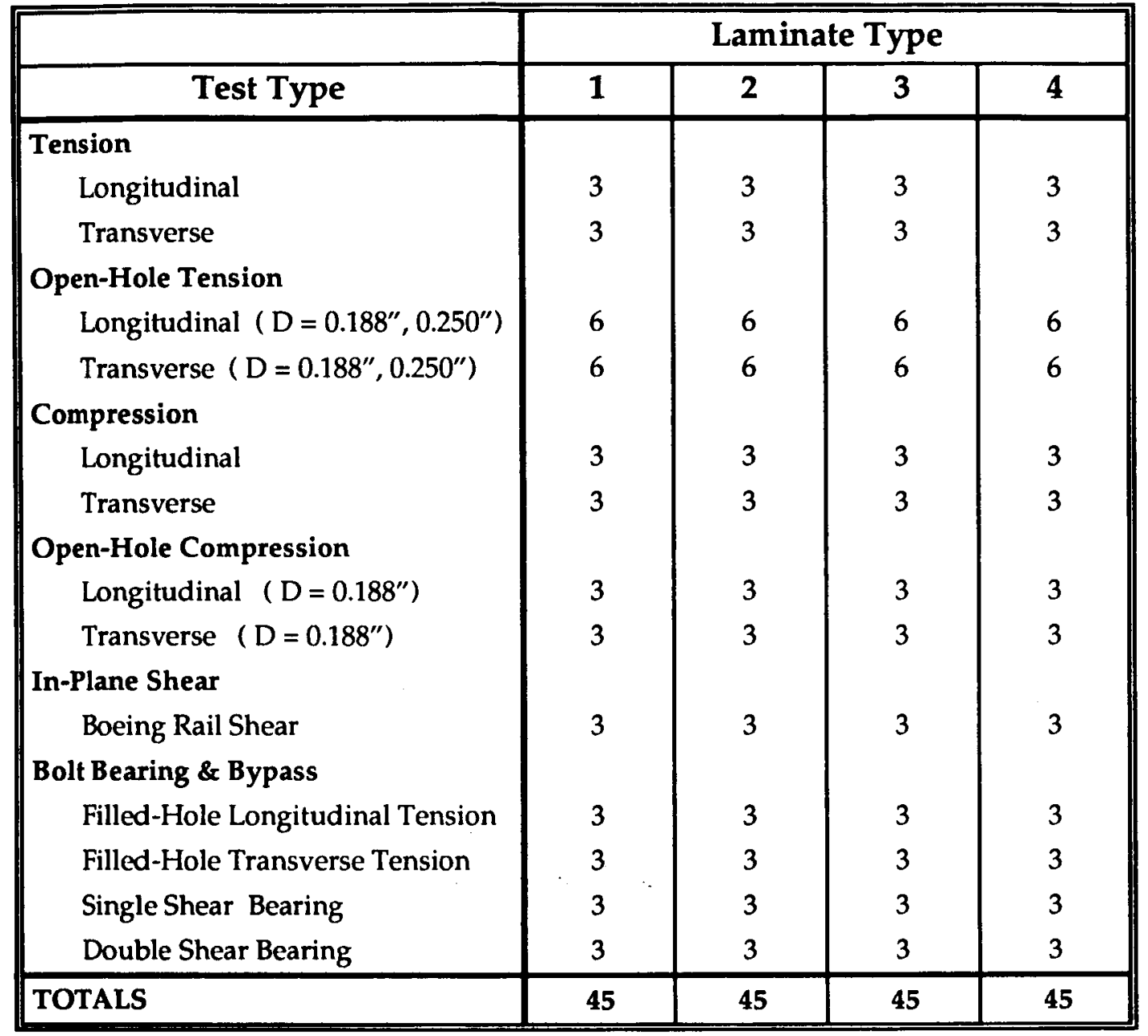

\subsection{Data Reduction Techniques}

The same approach used in Reference 1 was used here to make all results directly comparable. All results are normalized to a $60 \%$ fiber volume fraction. Fiber volume fraction and thickness were measured on all manufactured panels. After averaging these data over all panels, a nominal ply thickness of $\mathbf{0 . 0 0 5 4 " ~ w a s ~ c a l c u l a t e d . ~ A l l ~}$ stiffness moduli and Poisson's coefficients are the initial value of these properties and were measured with a linear regression between 0.001 and 0.003 strain levels. Wherever a nominal strain is reported, it is equal to the strength divided by the initial modulus. Actual strain is the last reading obtained from a strain gage prior to failure. Strength is always calculated as load divided by actual width and nominal thickness.

Open-hole and filled-hole strength results were corrected to infinite plate width with the following formula for a hole diameter $\mathrm{d}$ and a plate width $\mathrm{w}$ :

$$
\sigma_{\infty}=\left[\frac{2+\left(1-\frac{d}{w}\right)^{3}}{3\left(1-\frac{d}{w}\right)}\right] \cdot \frac{P}{w t_{\text {nom }}}
$$




\section{Tension Properties}

Tension properties for all four laminates were measured in both the longitudinal $\left(0^{\circ}\right)$ and transverse $\left(90^{\circ}\right)$ directions. Properties included stiffness modulus, Poisson's coefficient, open-hole strength (01.88" and 0.250" diameters) and filled-hole strength using a fully-torqued $0.25^{\prime \prime}$ titanium hilock fastener.

\subsection{Laminate Results}

All the tension properties measured in the longitudinal $\left(0^{\circ}\right)$ direction are shown in Table 3.1, while all the properties measured in the transverse $\left(90^{\circ}\right)$ direction are shown in Table 3.2. Individual test results and typical stress-strain curves can be found in Appendix A and $B$ respectively.

Table 3.1 Laminate Longitudinal Tension Properties

\begin{tabular}{|c|c|c|c|c|}
\hline Property & Laminate 1 & Laminate 2 & Laminate 3 & Laminate 4 \\
\hline Modulus [msi] & 10.33 & 9.63 & 4.92 & 8.23 \\
\hline CoV [\%] & 0.8 & 2.8 & 0.5 & 2.0 \\
\hline Poisson's Coefficient & 0.663 & 0.157 & 0.713 & 0.190 \\
\hline $\operatorname{CoV}[\%]$ & 2.3 & 3.7 & 0.8 & 0.1 \\
\hline Unnotched Strength [ksi] & 131 & 132 & 63 & 105 \\
\hline Nominal Strain [ $\mu \mathrm{s}]$ & 12,690 & 13,750 & 12,840 & 12,720 \\
\hline $\operatorname{CoV}[\%]$ & 12.5 & 6.3 & 1.8 & 5.3 \\
\hline Actual Strain [ $\mu s]$ & 12,300 & 13,400 & 15,200 & 12,800 \\
\hline $0.188^{\prime \prime}$ OHT Strength [ksi] & 72 & 66 & 42 & 61 \\
\hline OHT Nom. Strain $[\mu s]$ & 6,960 & 6,860 & 8,460 & 7,450 \\
\hline $\operatorname{CoV}[\%]$ & 4.4 & 1.0 & 2.0 & 3.7 \\
\hline $0.250^{\prime \prime}$ OHT Strength [ksi] & 69 & 66 & 40 & 60 \\
\hline OHT Nom. Strain [ $\mu \mathrm{s}]$ & 6,640 & 6,820 & 8,080 & 7,340 \\
\hline $\operatorname{CoV}[\%]$ & 3.8 & 3.6 & 1.2 & 1.7 \\
\hline $0.250^{\prime \prime}$ FHT Strength [ksi] & 60 & 49 & 42 & 47 \\
\hline FHT Strain [ $\mu s]$ & 5,820 & 5,090 & 8,560 & 5,710 \\
\hline $\operatorname{CoV}[\%]$ & 2.1 & 1.8 & 2.7 & 3.6 \\
\hline
\end{tabular}

Note: Laminate $1\left[(45 / 0 /-45 / 0)_{2} / 45 / 0 /-45\right]_{S}$

Laminate $2\left[(70 / 0 /-70 / 0)_{2} / 70 / 0 /-70\right]_{\mathrm{s}}$

Laminate $3\left[( \pm 45)_{2} / 0 /( \pm 45)_{3} / 0 /( \pm 45)_{3} / 0 /( \pm 45)_{2}\right]_{\mathrm{t}}$

Laminate $4[(66 / 0 /-66) 4 / 0]_{S}$

Coefficients of variation were generally quite low and well within the typical values obtained when testing composites. The only exception was the unnotched $0^{\circ}$ strength of L1 for which one specimen failed prematurely. If that data point was excluded, L1 strength would be $141 \mathrm{ksi}(13,600 \mu \mathrm{s})$. Laminate 1,2 and 4 were linear to failure, as 
indicated by the fact that actual and nominal strains are virtually equal, while laminate 3 (with a high percentage of $\pm 45^{\circ}$ plies) had a softening behavior with the actual strain much higher than nominal. Failure for L1 and L2 occured close to the tabs, and for L4 occured under the tabs. L3 exhibited a large amount of delamination.

Somewhat different failure modes were observed in the $90^{\circ}$ unnotched tension tests. Laminates 1 and 2 exhibited a clean straigth break well inside the test section. Laminate 3 also failed inside the test section and showed mostly an in-plane shear failure mode, along with some visible edge delaminations. Laminate 4 exhibited a large amount of delamination initiating from the edges. Laminate 1 and 3 had a softening behavior because of their $45^{\circ}$ ply angle. The strain levels in L2 and L4 were much below that in the $0^{\circ}$ tests, indicating that pure fiber fracture was not the dominant failure mode.

All laminates but L3 show a strong sensitivity to the presence of a fully torque fastener in the longitudinal tension test. Strength reductions were $13 \%$ for $\mathrm{L} 1,26 \%$ for L2, 22\% for L4. In the transverse direction, the influence of the fastener was quite different. A strength increase was observed for L1 $(+18 \%)$ and L2 $(+3 \%)$, while a strength decrease was observed for L2 $(-10 \%)$ and L4 $(-7 \%)$. Note that the strength increase was observed for the two laminates with a low transverse modulus.

Table 3.2 Laminate Transverse Tension Properties

\begin{tabular}{|c|c|c|c|c|}
\hline Property & Laminate 1 & Laminate 2 & Laminate 3 & Laminate 4 \\
\hline Modulus [msi] & 3.37 & 8.96 & 3.48 & 8.88 \\
\hline $\operatorname{CoV}[\%]$ & 0.9 & 0.6 & 1.5 & 1.9 \\
\hline Poisson's Coefficient & 0.225 & 0.147 & 0.513 & 0.223 \\
\hline $\operatorname{CoV}[\%]$ & 9.4 & 3.9 & 1.1 & 2.6 \\
\hline Unnotched Strength [ksi] & 35 & 72 & 35 & 73 \\
\hline Nominal Strain [ $\mu \mathrm{s}]$ & 10,480 & 8,020 & 10,030 & 8,180 \\
\hline $\mathrm{CoV}[\%]$ & 1.8 & 3.3 & 0.9 & 4.6 \\
\hline Actual Strain $[\mu s]$ & 15,600 & 8,300 & 14,800 & 8,600 \\
\hline $0.188^{\prime \prime}$ OHT Strength [ksi] & 31 & 59 & 33 & 58 \\
\hline OHT Nom. Strain [us] & 9,210 & 6,580 & 9,520 & 6,550 \\
\hline $\operatorname{CoV}[\%]$ & 1.2 & 3.5 & 0.6 & 3.6 \\
\hline $0.250^{\prime \prime}$ OHT Strength [ksi] & 28 & 53 & 32 & 54 \\
\hline OHT Nom. Strain $[\mu s]$ & 8,359 & 5,910 & 9,140 & 6,110 \\
\hline $\operatorname{CoV}[\%]$ & 2.7 & 3.4 & 0.8 & 0.5 \\
\hline $0.250^{\prime \prime}$ FHT Strength [ksi] & 33 & 50 & 33 & 52 \\
\hline FHT Strain $[\mu \mathrm{s}]$ & 9,660 & 5,580 & 9,430 & 5,810 \\
\hline $\operatorname{CoV}[\%]$ & 2.3 & 3.1 & 0.5 & 3.1 \\
\hline
\end{tabular}

Note: Laminate $1\left[(45 / 0 /-45 / 0)_{2} / 45 / 0 /-45\right]_{S}$ Laminate $2\left[(70 / 0 /-70 / 0)_{2} / 70 / 0 /-70\right]_{S}$ Laminate $3\left[( \pm 45)_{2} / 0 /( \pm 45)_{3} / 0 /( \pm 45)_{3} / 0 /( \pm 45)_{2}\right]_{\mathrm{t}}$ Laminate $4\left[(66 / 0 /-66)_{4} / 0\right]_{S}$ 


\subsection{Comparison with Braided Composite}

The first comparison, shown in Figure 3.1, is for longitudinal modulus. Minimal differences were found between braids and tape laminates: $+0.4 \%$ for SLL, $-4.6 \%$ for LLL, $-0.9 \%$ for LLS, and $-0.6 \%$ for LSS. Considering experimental scatter and the slight differences in percentage of $0^{\circ}$, it is fair to say that there is no difference between longitudinal moduli for the two material forms. The slight reduction for LLL is probably due to the additional tow waviness introduced by the use of large tow sizes.

The comparison is quite different for the transverse modulus. As shown in Figure 3.1, the braided material is substantially less stiff: $-19 \%$ for SLL, $-24 \%$ for LLL, $-22 \%$ for LLS, and $-16 \%$ for LSS. The primary cause for this reduction is the crimp in the bias tows.

The comparison for unnotched longitudinal tension strength is show in Figure 3.2.a to 3.2.d. A notably lower strength was obtained for all the braids: $-17 \%$ for SLL, $-34 \%$ for LLL, $-31 \%$ for LLS, and $-16 \%$ for LSS. Once again, the tow waviness is a probable contributor to this loss of strength. However, it is somewhat surprising that there was so little difference in modulus and such difference in strength. Another possible contributor is the matrix material. Although 1895 and 3501-6 are rather similar epoxys, it is possible that 1895 is more brittle or has a lower strain to failure than 3501-6.

The open-hole tension strength comparison is based on the standard 1/4" diameter hole which is often used in developing material allowables. In Reference 1, several hole diameters were tested for each braided material. A log-log best fir curve of strength versus hole diameter was then calculated. This procedure showed that the data at some of the hole diameters did not follow the overall trend due to experimental scatter. This was the case for the $1 / 4^{\prime \prime}$ hole in the SLL and LLS architecture. Thus, instead of using the data for the $1 / 4^{\prime \prime}$ hole, the strength is calculated with the following best fit equations:

$$
\begin{array}{ll}
\text { SLL: } \sigma=72.2 * \mathrm{~d}^{-} .165 & \text { LLL: } \sigma=53.0 * \mathrm{~d}-.315 \\
\text { LLS: } \sigma=61.3 * \mathrm{~d}^{-} \cdot 208 & \text { LLS: } \sigma=28.8 * \mathrm{~d}^{-} \cdot 265
\end{array}
$$

Results in Figure 3.2 show a clear strength advantage for the braided materials. The relative differences between braid and laminate strength were $+37 \%$ for SLL, $+24 \%$ for LLL, $+20 \%$ for LLS, and $+4 \%$ for LSS. Since moduli are quite similar for each braid and equivalent laminate, the differences in term of nominal strain are about the same.

This strength difference is further magnified in the filled-hole tension test. As mentioned above, the laminated material was quite sensitive to the presence of a fastener, while the data in Ref. 1 showed that the braids were not. The relative differences in term of strength were: $+72 \%$ for SLL, $+47 \%$ for LLL, and $+19 \%$ for LLS (no data is available for LSS).

Post-failure examination of the braided specimens revealed extensive matrix failure between the axial and bias tows which would tend to reduce the stress concentration for 
axial yarns. On the other hand, examination of the laminated specimen showed a fairly clean fracture surface across the specimen net section. Thus, 2D braids may have advantages over tape laminates with regard to open- and filled-hole tension strengths.

Strength measured along the transverse direction for these materials is shown in Figure 3.3.a to 3.3.d. For the unnotched case, the braided material show a severe strength reduction compared to the tape laminates: $-51 \%$ for SLL, $-57 \%$ for LLL, $-57 \%$ for LLS, and $-29 \%$ for LSS. Once again, the crimp in the bias tows is the likely cause for the strength reduction.

Only a limited set of data is available for the transverse open-hole tension strength of the braided material. A single hole size of $1 / 4^{\prime \prime}$ was tested and is used for comparison. Somewhat surprisingly, these materials exhibited no notch sensitivity, and in some cases, the strength was slightly higher than that for the unnotched case. The data is probably too limited at this point to draw any definite conclusion. The tape laminates did show some notch sensitivity, and thus the differences in strength between the two material forms are reduced compared to the unnotched case: $-36 \%$ for SLL, $-43 \%$ for LLL, $-46 \%$ for LLS, and $-16 \%$ for LSS.
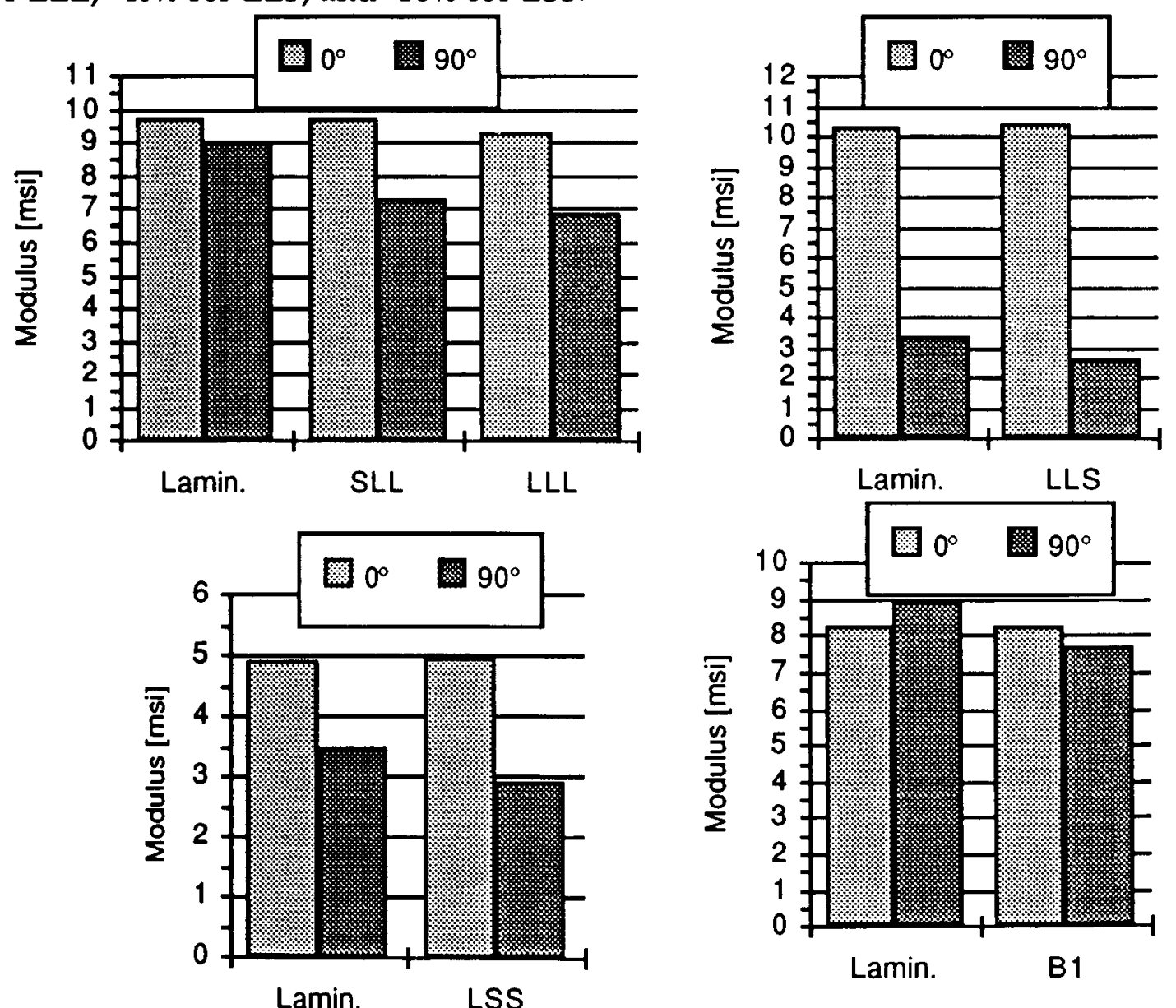

Figure 3.1 Comparison of Longitudinal and Transverse Tension Modulus. 

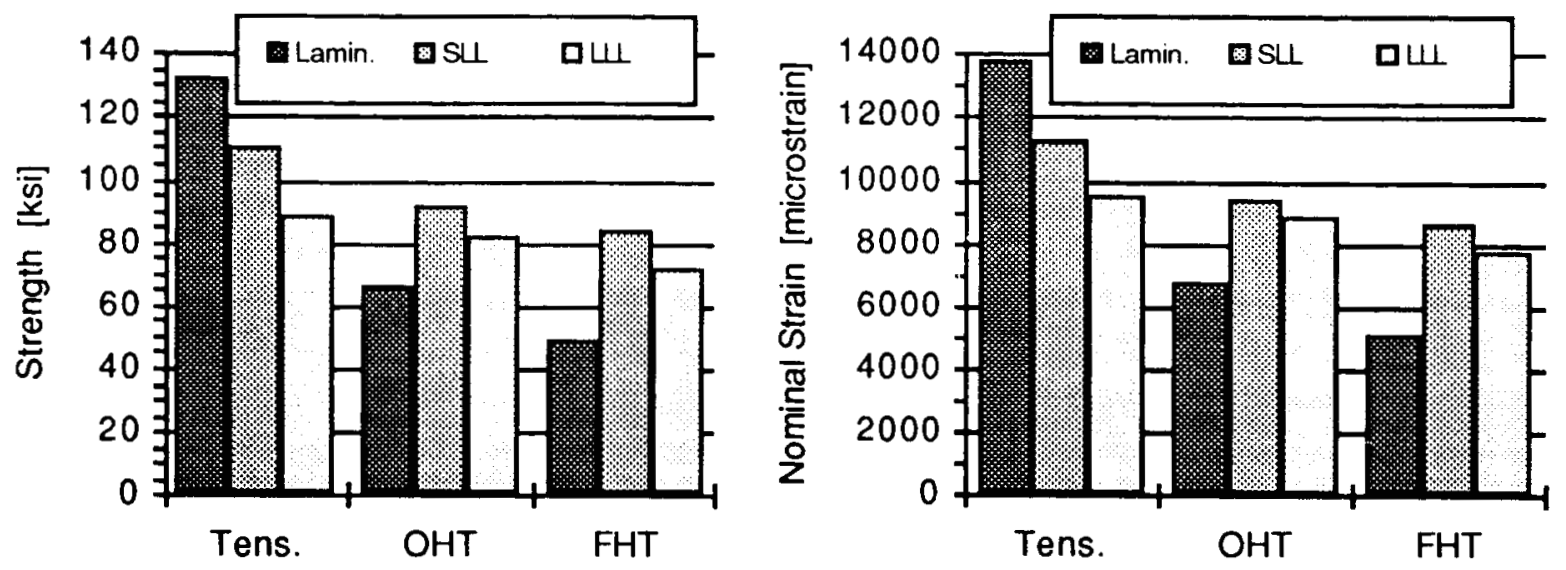

Figure 3.2.a Comparison of $0^{\circ}$ Tension Strength for Tape Laminate 1, SLL and LLL.
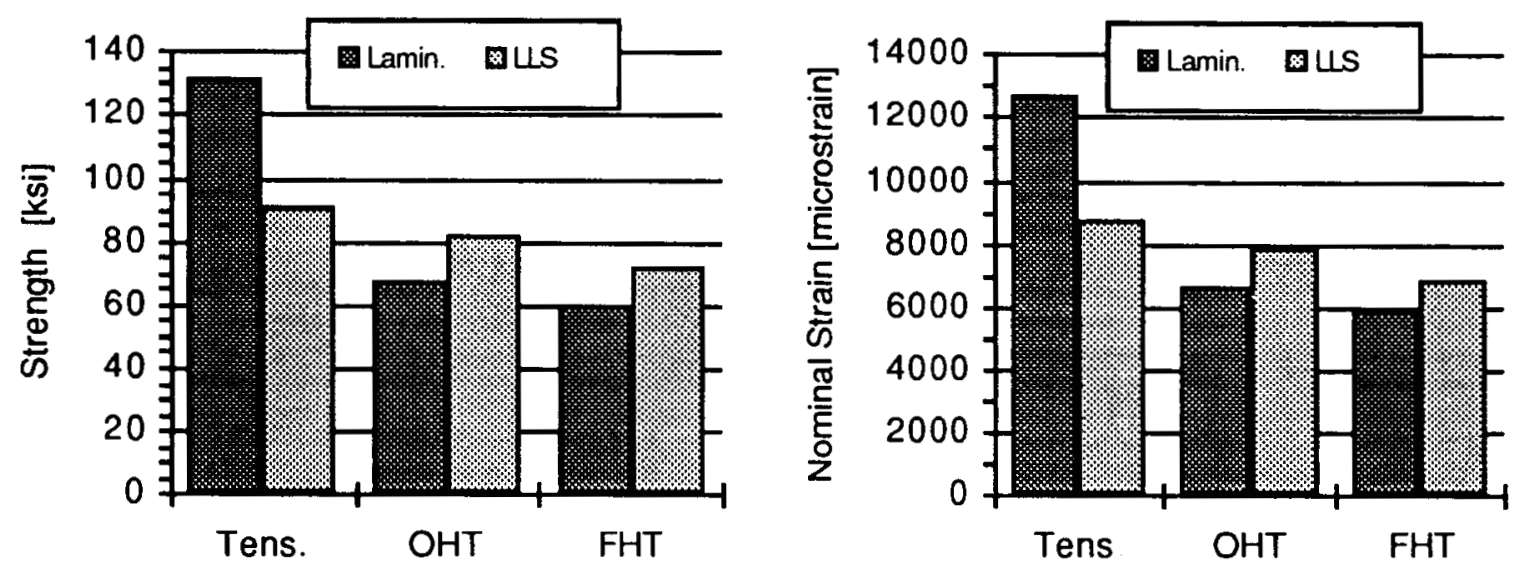

Figure 3.2.b Comparison of $0^{\circ}$ Tension Strength for Tape Laminate 2 and LLS.
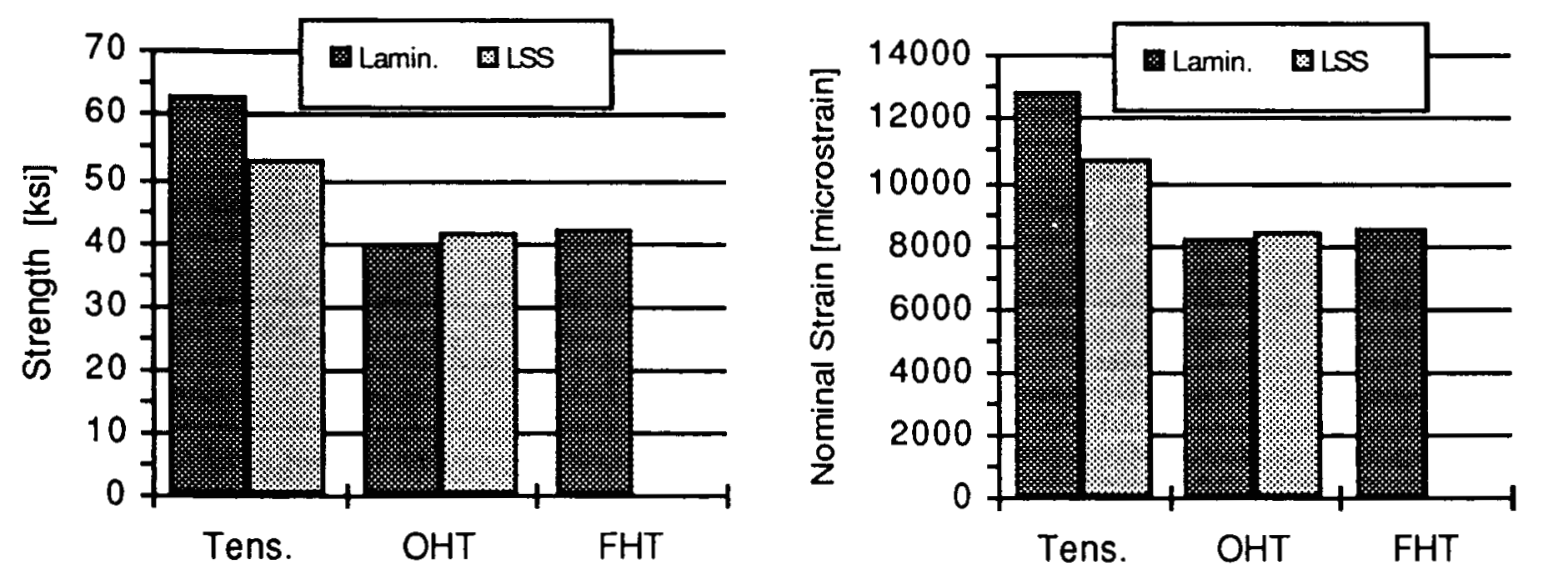

Figure 3.2.c Comparison of $0^{\circ}$ Tension Strength for Tape Laminate 3 and LSS. 

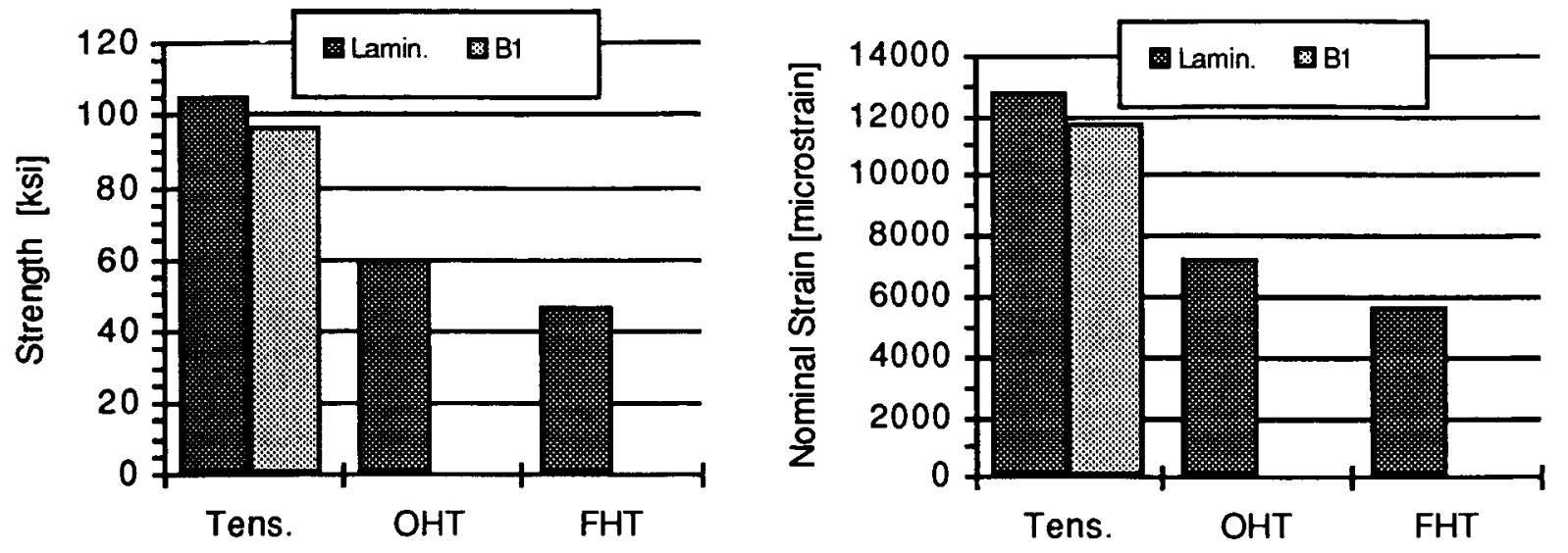

Figure 3.2.d Comparison of $0^{\circ}$ Tension Strength for Tape Laminate 4 and B1.

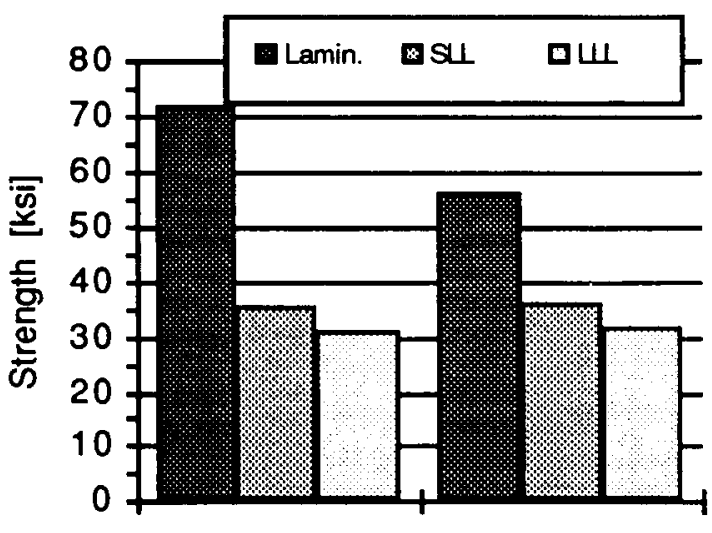

Tr.Tens

Tr. OHT

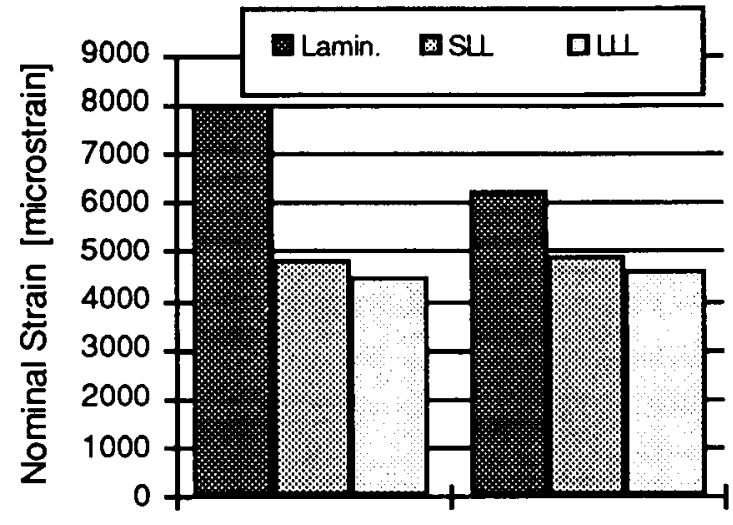

Tr.Tens

Tr. OHT

Figure 3.3.a Comparison of $90^{\circ}$ Tension Strength for Tape Laminate 1, SLL and LLL.
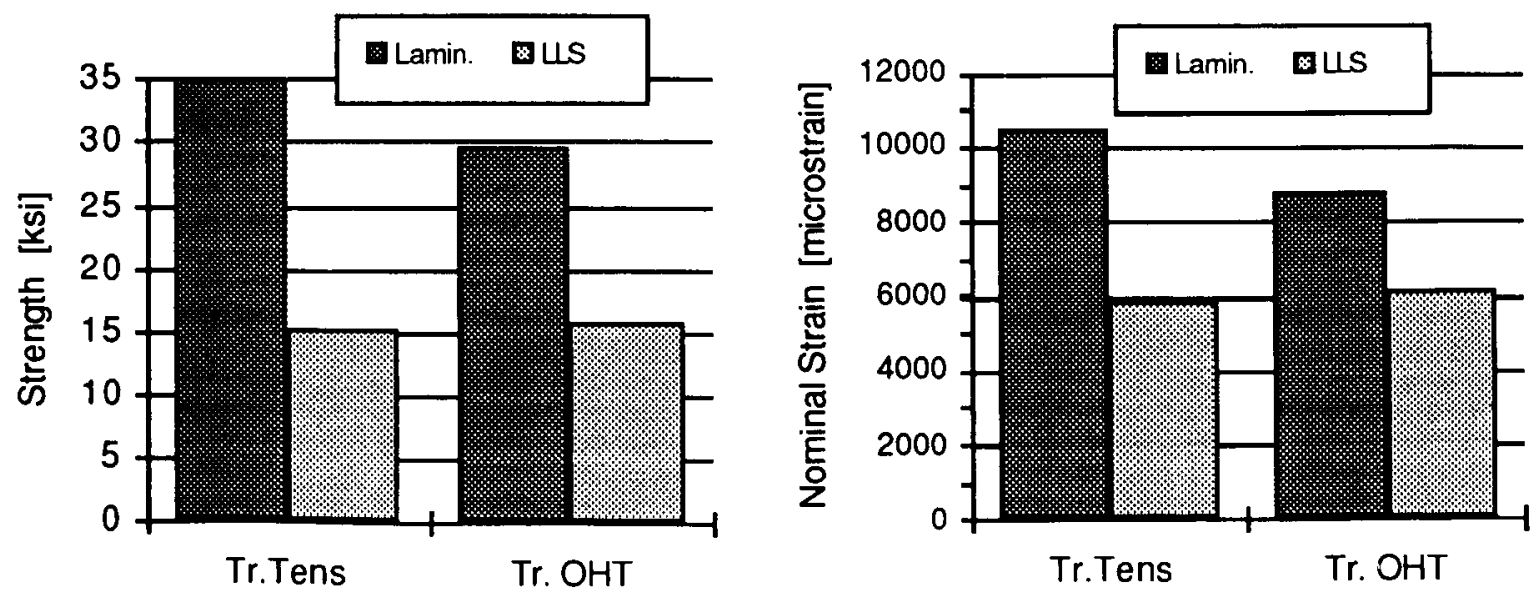

Figure 3.3.b Comparison of $90^{\circ}$ Tension Strength for Tape Laminate 2 and LLS. 


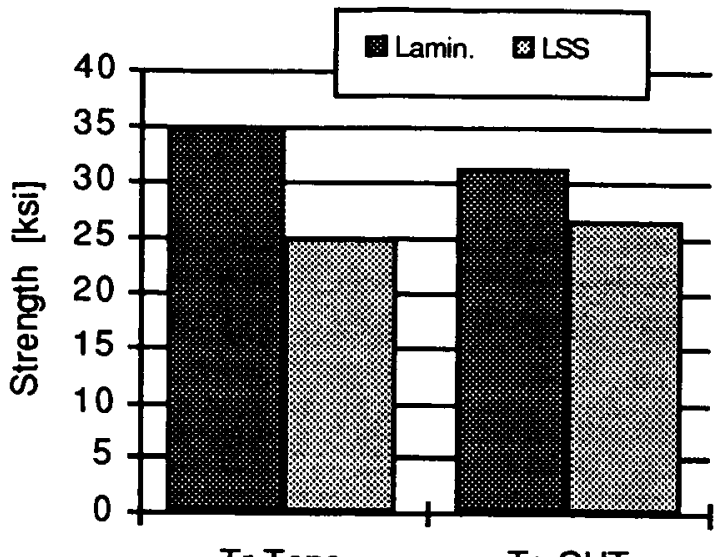

Tr.Tens

Tr. OHT

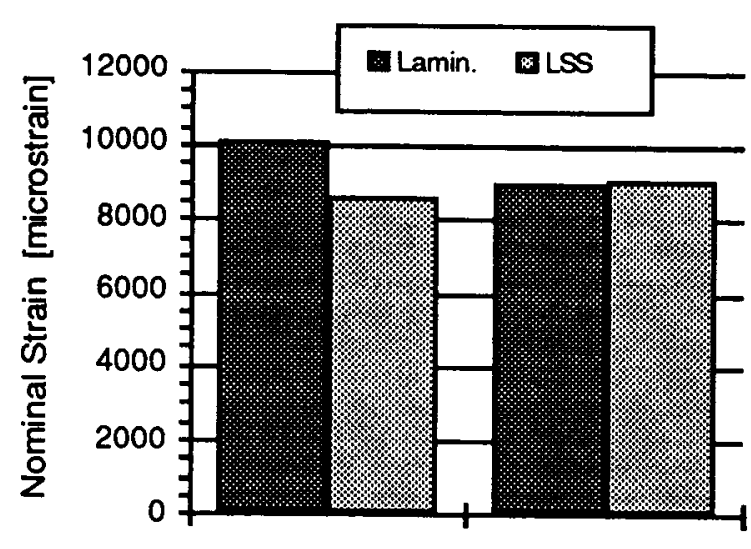

Tr.Tens

Tr. OHT

Figure 3.3.c Comparison of $90^{\circ}$ Tension Strength for Tape Laminate 3 and LSS.

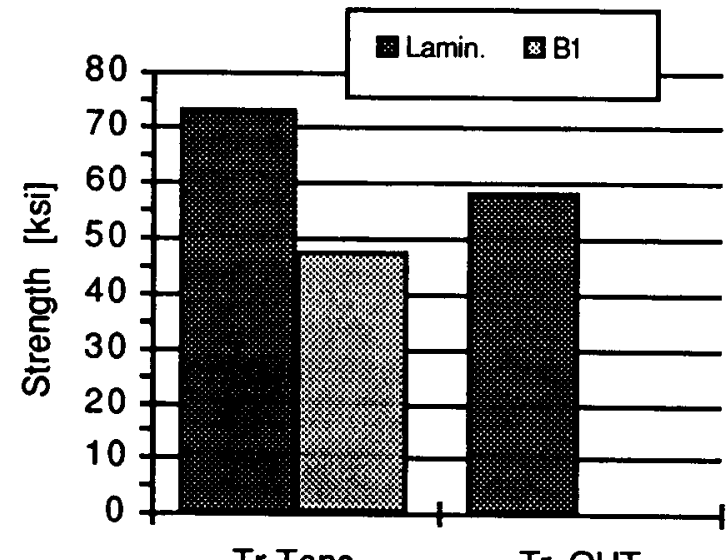

Tr.Tens

Tr. OHT

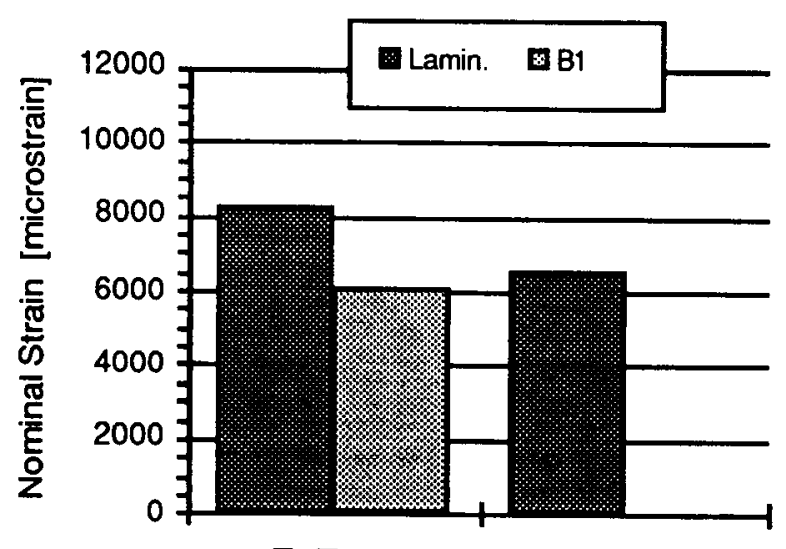

Tr.Tens

Tr. OHT

Figure 3.3.d Comparison of $90^{\circ}$ Tension Strength for Tape Laminate 4 and B1. 


\section{Compression Properties}

Compression properties for all four laminates were also measured in both the longitudinal $\left(0^{\circ}\right)$ and transverse $\left(90^{\circ}\right)$ directions. Properties included stiffness modulus, Poisson's coefficient and open-hole strength ( $0.188^{\prime \prime}$ diameter). A modified IITRI test specimen [1] with a test section of $1.5^{\prime \prime}$ by $1.5^{\prime \prime}$ was used for all tests.

\subsection{Laminate Results}

All the compression properties measured in the longitudinal $\left(0^{\circ}\right)$ direction are shown in Table 4.1, while all the properties measured in the transverse $\left(90^{\circ}\right)$ direction are shown in Table 4.2. Individual test results and typical stress-strain curves can be found in Appendix A and B respectively. Coefficients of variation were generally quite low and well within the typical values obtained when testing composites. Some of the exceptions were the unnotched $0^{\circ}$ strength of L1, notched $90^{\circ}$ strength of L1 and unotched $90^{\circ}$ strength of L2. The nominal strains reported in this section were always calculated with the compression modulus. When comparing the compression moduli to the ones measured in tension, significant differences were observed, $17 \%$ lower for L1, $13 \%$ for L2, $16 \%$ for L3 and 14\% L4. A similar observation can me made for the transverse modulus: $8 \%$ lower for $\mathrm{L} 1,14 \%$ for $\mathrm{L} 2,13 \%$ for $\mathrm{L} 3$ and $18 \%$ for $\mathrm{L} 4$. Although it is typical for composites to be softer in compression, these differences are slightly higher than expected. The test specimen itself, with a short and wide test section, is believed to be partly responsible for this effect. Longitudinal fiber strains at failure were fairly typical of this type of material, ranging from $0.95 \%$ to $1.1 \%$. High strains to failure were measured wherever there was a large percentage of $\pm 45^{\circ}$ fibers, such as in the $0^{\circ}$ and $90^{\circ}$ test of L3 and in the $90^{\circ}$ test of L1.

Table 4.1 Laminate Longitudinal Compression Properties

\begin{tabular}{|c|c|c|c|c|}
\hline Property & Laminate 1 & Laminate 2 & Laminate 3 & Laminate 4 \\
\hline Modulus [msi] & 8.84 & 8.53 & 4.25 & 7.22 \\
CoV [\%] & 1.0 & 2.1 & 1.6 & 1.5 \\
\hline Poisson's Coefficient & 0.704 & 0.172 & 0.712 & 0.227 \\
CoV [\%] & 3.0 & 1.8 & 3.2 & 2.9 \\
\hline Unnotched Strength [ksi] & 84 & 82 & 58 & 79 \\
Nominal Strain [ $\mu \mathrm{s}]$ & 9,500 & 9,640 & 13,560 & 10,880 \\
CoV [\%] & 9.9 & 5.5 & 5.1 & 1.1 \\
\hline $0.188^{\prime \prime}$ OHT Strength [ksi] & 65 & 75 & 43 & 69 \\
OHT Nom. Strain [ $\mu \mathrm{s}]$ & 7,330 & 8,770 & 10,210 & 9,550 \\
CoV [\%] & 1.5 & 2.0 & 1.4 & 1.9 \\
\hline
\end{tabular}

Note: Laminate $1\left[(45 / 0 /-45 / 0)_{2} / 45 / 0 /-45\right]_{S}$

Laminate $2\left[(70 / 0 /-70 / 0)_{2} / 70 / 0 /-70\right]_{S}$

Laminate $3\left[( \pm 45)_{2} / 0 /( \pm 45)_{3} / 0 /( \pm 45)_{3} / 0 /( \pm 45)_{2}\right]_{t}$

Laminate $4\left[(66 / 0 /-66)_{4} / 0\right]_{S}$ 
Table 4.2 Laminate Transverse Compression Properties

\begin{tabular}{|c|c|c|c|c|}
\hline Property & Laminate 1 & Laminate 2 & Laminate 3 & Laminate 4 \\
\hline Modulus [msi] & 3.13 & 7.84 & 3.08 & 7.52 \\
\hline $\operatorname{CoV}[\%]$ & 0.6 & 1.3 & 1.5 & 1.9 \\
\hline Poisson's Coefficient & 0.237 & 0.151 & 0.525 & 0.226 \\
\hline $\operatorname{CoV}[\%]$ & 2.1 & 6.7 & 2.5 & 4.0 \\
\hline Unnotched Strength [ksi] & 50 & 70 & 48 & 74 \\
\hline Nominal Strain $[\mu \mathrm{s}]$ & 15,880 & 8,930 & 15,720 & 9,780 \\
\hline $\operatorname{CoV}[\%]$ & 4.9 & 12.3 & 1.5 & 1.4 \\
\hline $0.188^{\prime \prime}$ OHT Strength [ksi] & 42 & 61 & 44 & 59 \\
\hline OHT Nom. Strain $[\mu \mathrm{s}]$ & 13,520 & 7,830 & 14,220 & 7,850 \\
\hline $\operatorname{CoV}[\%]$ & 7.6 & 1.3 & 0.4 & 2.6 \\
\hline
\end{tabular}

Note: Laminate $1\left[(45 / 0 /-45 / 0)_{2} / 45 / 0 /-45\right]_{S}$

Laminate $2\left[(70 / 0 /-70 / 0)_{2} / 70 / 0 /-70\right]_{S}$

Laminate $3\left[( \pm 45)_{2} / 0 /( \pm 45)_{3} / 0 /( \pm 45)_{3} / 0 /( \pm 45)_{2}\right]_{\mathrm{t}}$

Laminate $4[(66 / 0 /-66) 4 / 0]_{s}$

\subsection{Comparison with Braided Composite}

The first comparison, shown in Figure 4.1, is for modulus. Small differences were found between braids and tape laminates for the longitudinal modulus, $+4.6 \%$ for SLL, $-1.9 \%$ for LLL, $-0.2 \%$ for LLS, and $3.1 \%$ for LSS, and for the transverse modulus, $+7.5 \%$ for SLL, $-5.4 \%$ for LLL, $-3.2 \%$ for LLS, and $-1.6 \%$ for LSS. The differences for the transverse modulus are less than those observed in the tension case. Based on these observations, it would appear that the modulus measured in the laminated specimen might be somewhat under-estimated, although no precise cause was found for this effect.

The comparison for unnotched longitudinal compression strength is shown in Figure 4.2.a to 4.2.d. As anticipated, a lower strength was obtained for all the braids: $-14 \%$ for SLL, $-28 \%$ for LLL, $-31 \%$ for LLS, and $-16 \%$ for LSS. Once again, the tow waviness is a probable contributor to this loss of strength. 

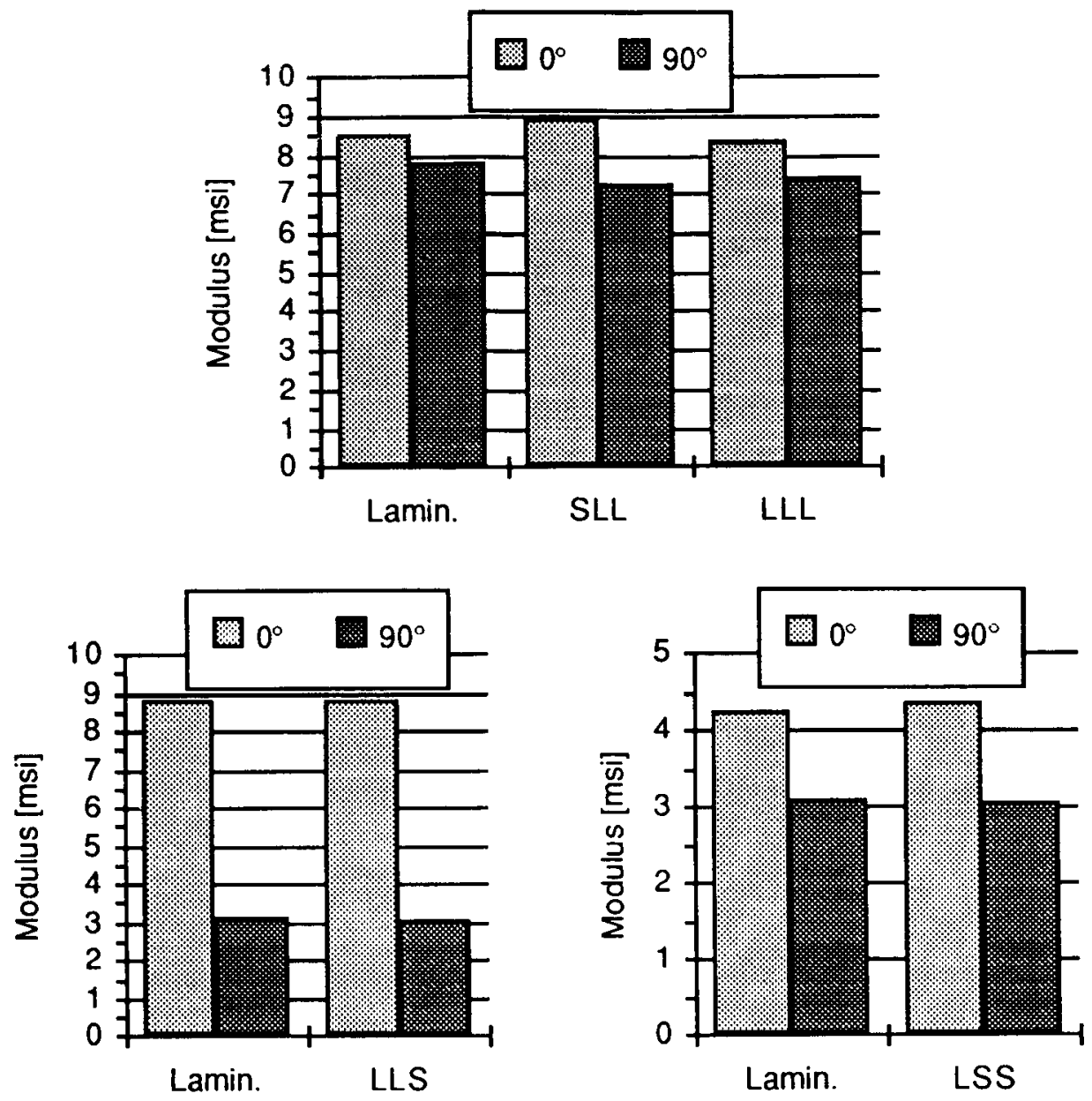

Figure 4.1 Comparison of Longitudinal and Transverse Compression Modulus.
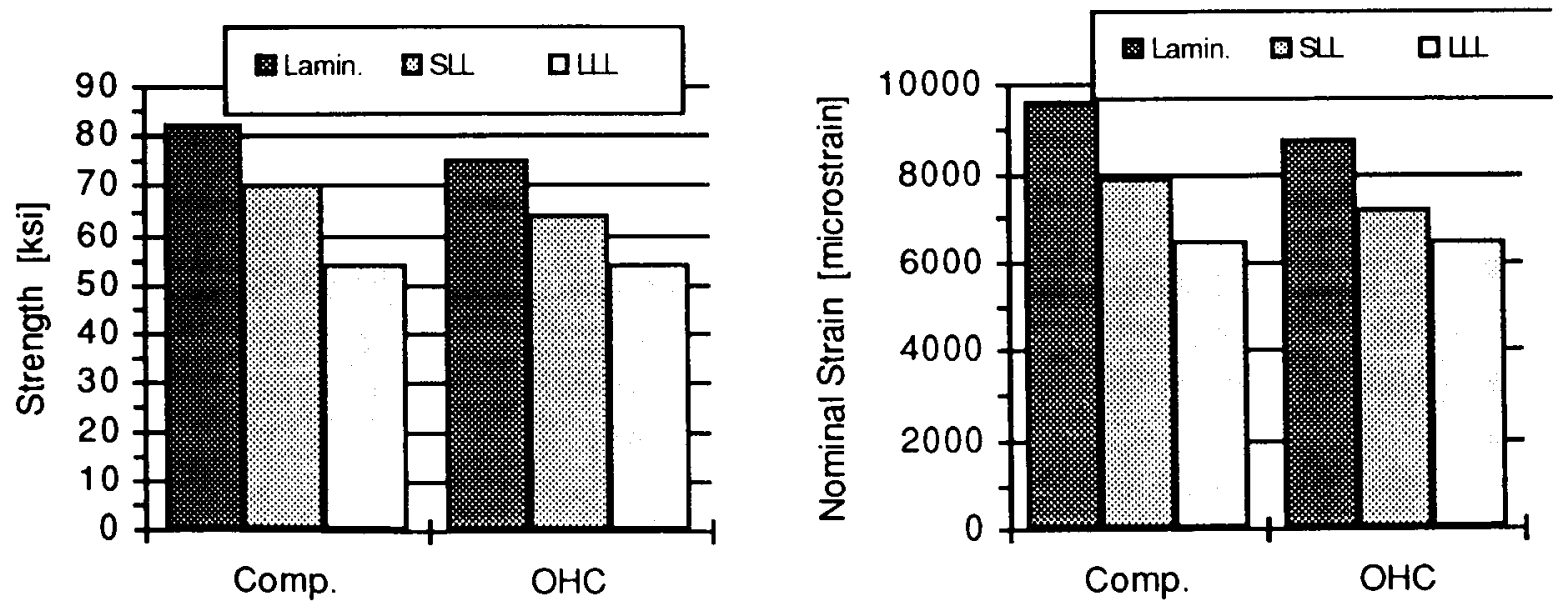

Figure 4.2.a Comparison of $0^{\circ}$ Compression Strength for Tape Laminate 1, SLL and LLL. 

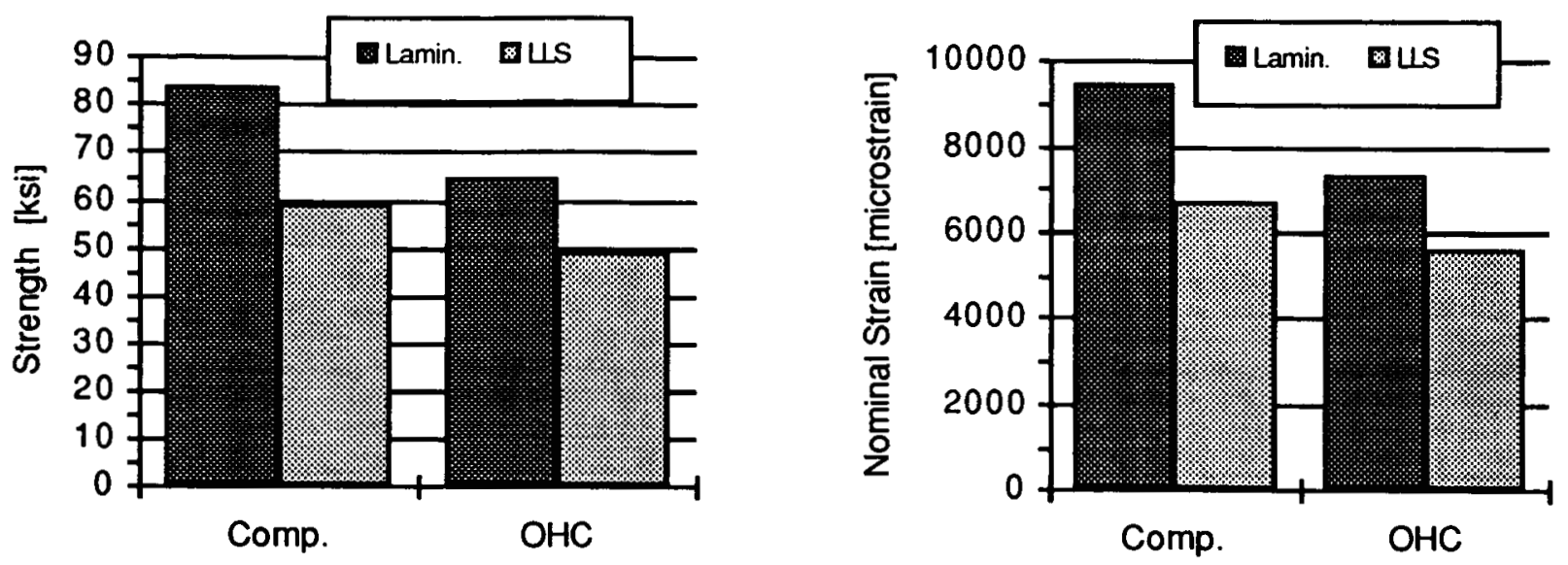

Figure 4.2.b Comparison of $0^{\circ}$ Compression Strength for Tape Laminate 2, LLS.
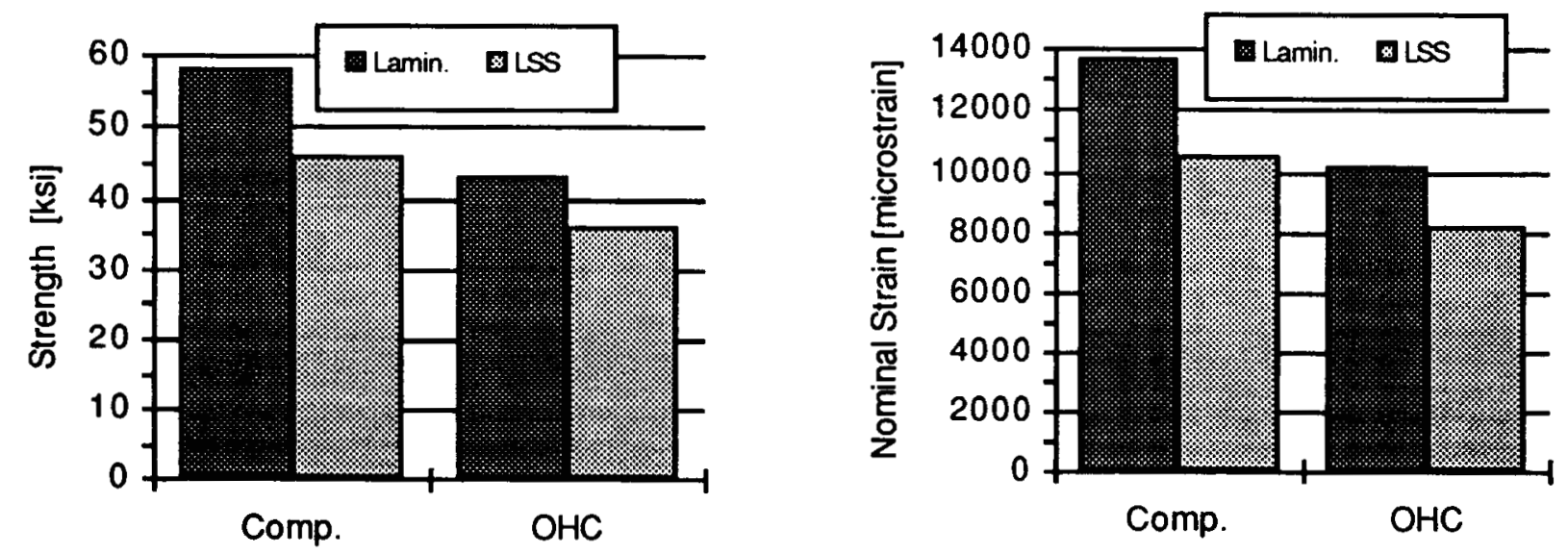

Figure 4.2.c Comparison of $0^{\circ}$ Compression Strength for Tape Laminate 3, LSS.

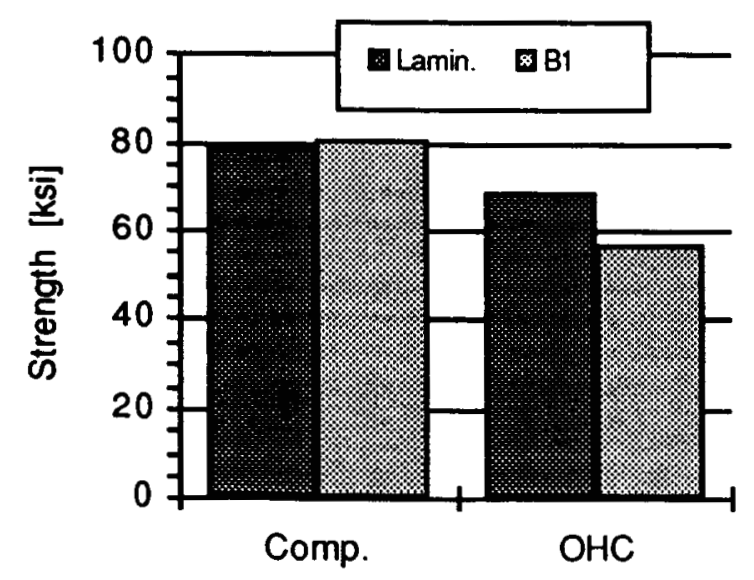

Figure 4.2.d Comparison of $0^{\circ}$ Compression Strength for Tape Laminate 4, B1. 

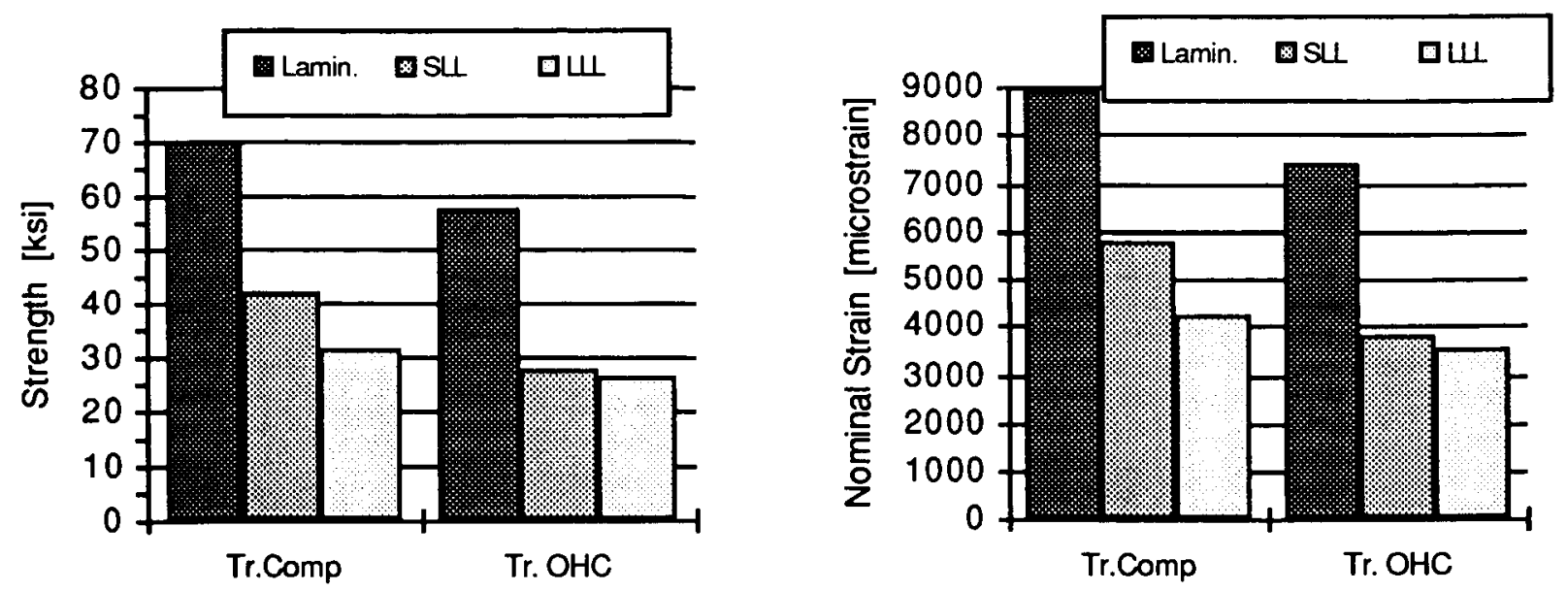

Figure 4.3.a Comparison of $90^{\circ}$ Compression Strength for Tape Laminate 1, SLL and LLL.
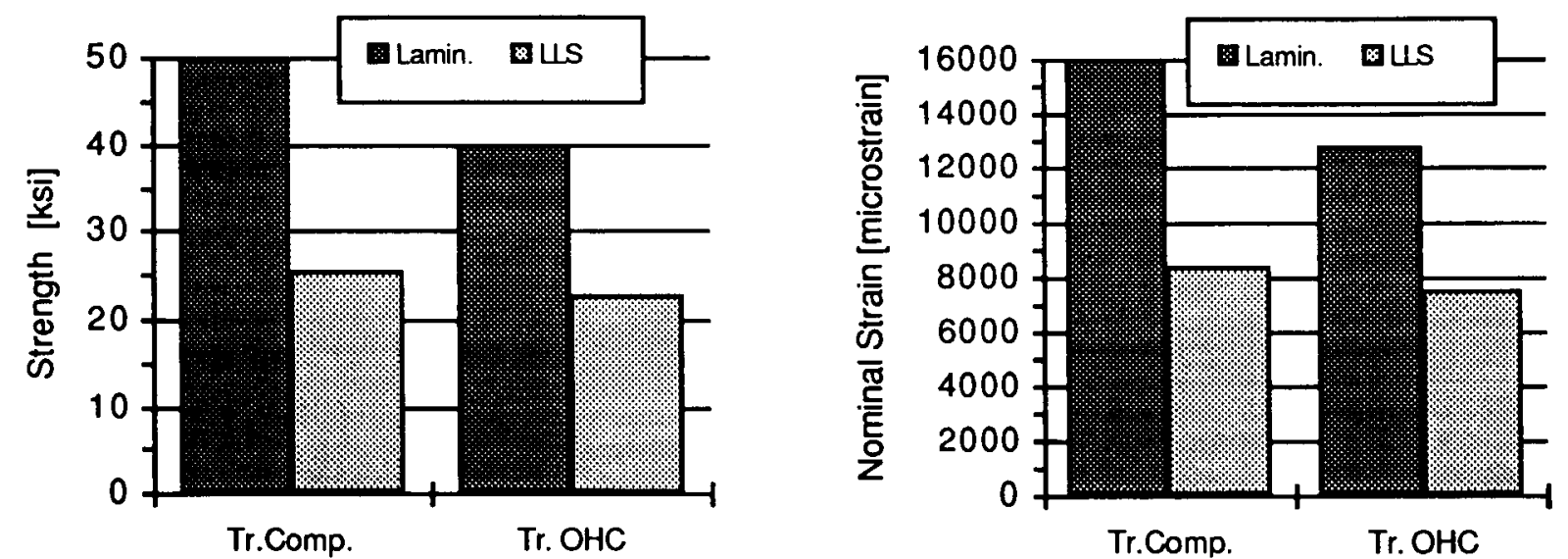

Figure 4.3.b Comparison of $90^{\circ}$ Compression Strength for Tape Laminate 2, LLS.
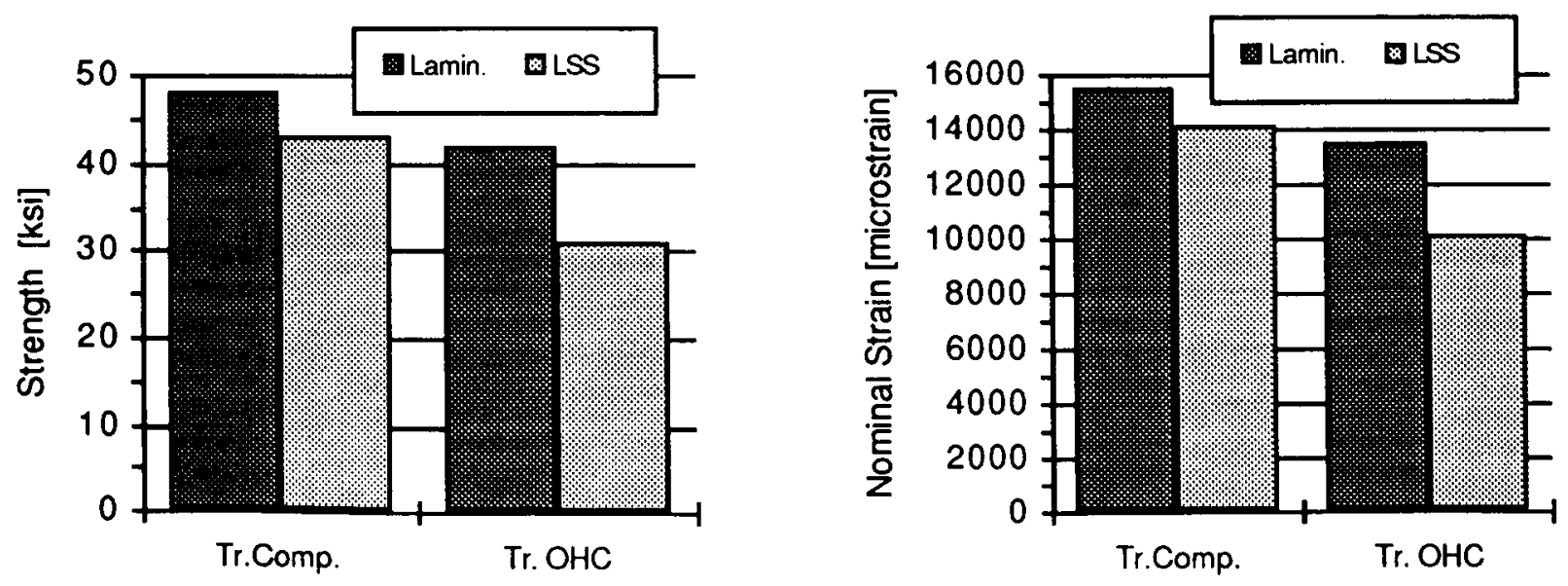

Figure 4.3.c Comparison of $90^{\circ}$ Compression Strength for Tape Laminate 3, LSS. 


\section{Shear Properties}

In-plane strength was measured for all four laminates using the rail shear test method. All specimens were tabbed with $0.125^{\prime \prime}$ thick quasi-isotropic graphite/epoxy tabs to avoid the bearing failures encountered in Reference 1.

\subsection{Laminate Results}

Stiffness and strength results are shown in Table 5.1. Individual test results can be found in Appendix A. Unfortunately, bearing failures were experienced in all the laminates except L2. Thus, the reported strength is actually a lower bound to the actual shear strength of these laminates.

Table 5.1 Laminate Shear Properties

\begin{tabular}{|c|c|c|c|c||}
\hline Property & Laminate 1 & Laminate 2 & Laminate 3 & Laminate 4 \\
\hline Modulus [msi] & 2.74 & 1.68 & 4.05 & 2.13 \\
CoV [\%] & 3.2 & 6.5 & 2.9 & 2.7 \\
\hline Shear Strength [ksi] & 35 & 36 & 36 & 32 \\
CoV [\%] & 7.1 & 4.7 & 4.1 & 4.8 \\
\hline
\end{tabular}

Note: Laminate $1[(45 / 0 /-45 / 0) 2 / 45 / 0 /-45] \mathrm{s}$

Laminate $2[(70 / 0 /-70 / 0) 2 / 70 / 0 /-70] \mathrm{s}$

Laminate $3[( \pm 45) 2 / 0 /( \pm 45) 3 / 0 /( \pm 45) 3 / 0 /( \pm 45) 2] \mathbf{t}$

Laminate $4[(66 / 0 /-66) 4 / 0] \mathrm{s}$

\subsection{Comparison with Braided Composite}

The comparison of shear moduli is shown in Figure 5.1, and of the shear strength in Figure 5.2. For the 2-D braids, the results of the rail shear testing in Reference 1 were used in the comparison. Results show that the measured moduli are fairly comparable, but that there is a significant difference in strength. That difference is consistant with the low transverse strength observed in the transverse tension and transverse compression tests. Because of the bearing failures encountered in the tape laminate tests and the LSS tests, it is not possible to put an exact figure on the difference between the two material forms. Based on the results for Laminate 2 (which failed in shear), SLL and LLL, the shear strength reduction could be as high as $50 \%$. However, that layup is not well suited to carry shear loads. Laminate 3 and LSS were optimized for shear. Data show that the fiber strain level was about $-8,000$ microstrain in L3 when bearing failure occured. If one assumes a compression failure in the $45^{\circ}$ plies as the failure mode if no premature bearing failure had occured, results in Section 4 show that at least $-9,500$ microstrain can be achieved along the fiber direction (see L1 in Table 4.1). This would translate to a minimum shear strength of $43 \mathrm{ksi}$ for L3, or about 33\% more than LSS. 


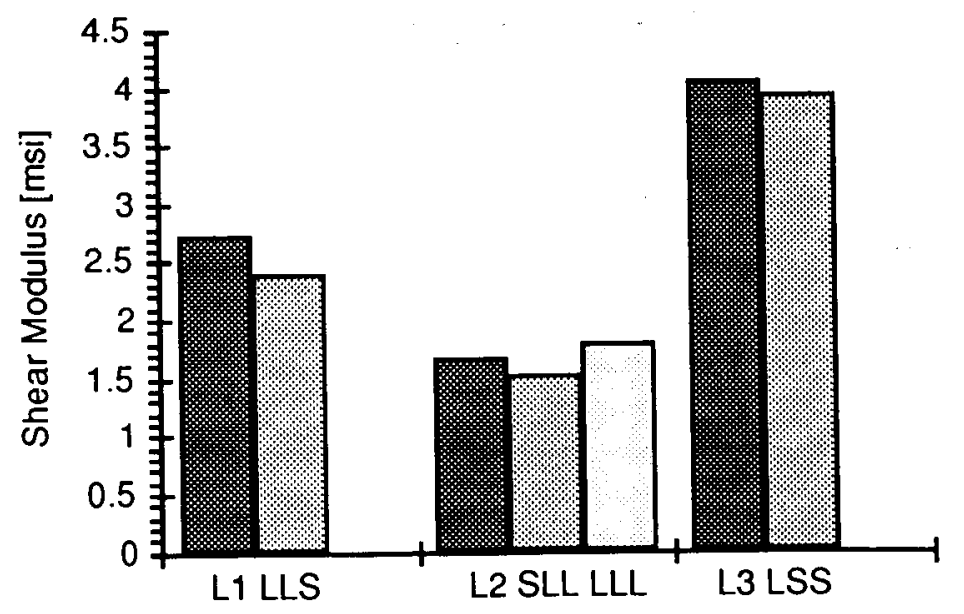

Figure 5.1 Comparison of In-Plane Shear Modulus of Laminates and 2-D Braids.

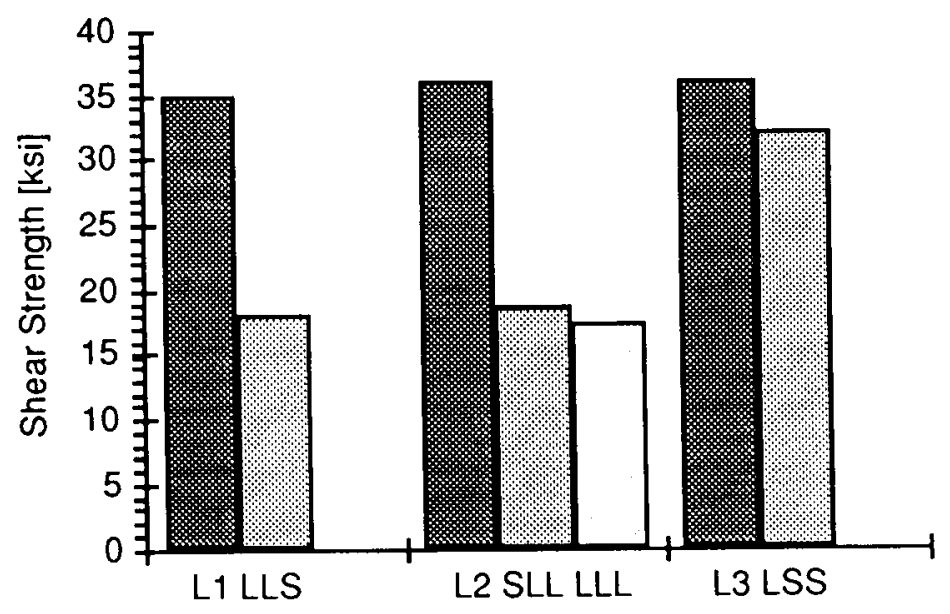

Figure 5.2 Comparison of In-Plane Shear Strength of Laminates and 2-D Braids. 


\section{Bolt Bearing Properties}

Bolt bearing strength was measured for all four laminates using two test configurations, the stabilized single shear specimen and the double shear specimen [1]. A fully torqued $1 / 4^{\prime \prime}$ titanium HiLock fastener was installed in both cases, and the standard values of W/D of 6 and e/D of 3 were used for both configurations.

\subsection{Laminate Results}

Bolt bearing strength was measured for all four laminates using two test configurations, the stabilized single shear specimen and the double shear specimen. Ultimate bearing strength results are reported in Table 6.1. Individual test results can be found in Appendix A. Interestingly, the strength is almost identical for all four layups in both types of test. As expected, the double shear test always produced higher bearing strength by about 20 to $30 \%$.

Table 6.1 Laminate Bearing Strength Properties

\begin{tabular}{|c|c|c|c|c|}
\hline Property & Laminate 1 & Laminate 2 & Laminate 3 & Laminate 4 \\
\hline Single Shear Strength [ksi] & 119 & 122 & 118 & 119 \\
CoV [\%] & 4.1 & 1.3 & 2.0 & 2.5 \\
\hline Double Shear Strength [ksi] & 143 & 154 & 144 & 158 \\
CoV [\%] & 3.9 & 1.9 & 5.0 & 4.5 \\
\hline
\end{tabular}

Note: Laminate $1[(45 / 0 /-45 / 0) 2 / 45 / 0 /-45] \mathrm{s}$

Laminate $2[(70 / 0 /-70 / 0) 2 / 70 / 0 /-70] \mathrm{s}$

Laminate $3[( \pm 45) 2 / 0 /( \pm 45) 3 / 0 /( \pm 45) 3 / 0 /( \pm 45) 2] \mathrm{t}$

Laminate $4[(66 / 0 /-66) 4 / 0] \mathrm{s}$

\subsection{Comparison with Braided Composite}

The comparison with the braided material is shown in Figure 6.1, but data from Reference 1 or 2 was not available for both test methods and all braids. Lower strength were obtained with the braids in all cases where data was available. In single shear, reductions were $-16 \%$ for SLL, $-25 \%$ for LLL and $-30 \%$ for LLS, while in double shear, the reductions were $-12 \%$ for SLL and $-13 \%$ for LLS. 

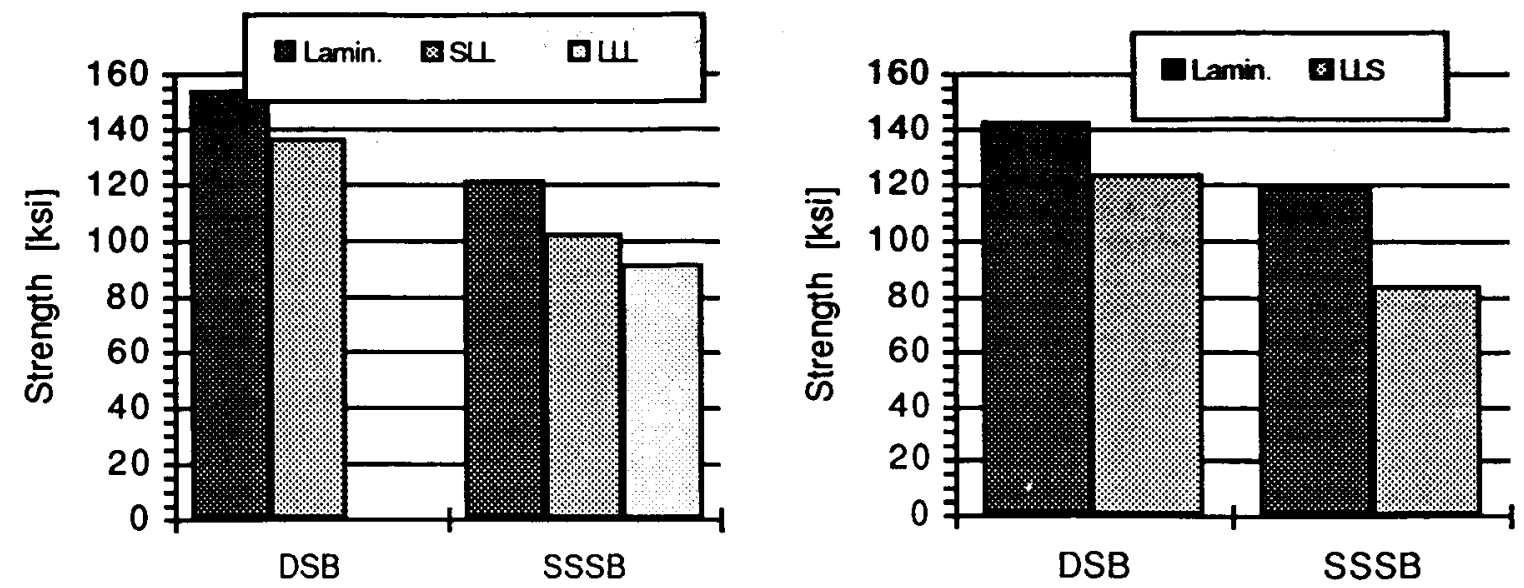

Figure 6.1 Comparison of Bearing Strength for Tape Laminate 1, 2 and braids SLL, LLL and LLS. 


\section{References}

1. Minguet, P.J., Fedro, M.J., Gunther, C.K., "Test Methods for Textile Composites", NASA CR-4609, 1994.

2 Masters, J.E., Foye, R.L., Pastore, C.M., Gowayed, Y.A., "Mechanical Properties of Triaxially Braided Composites: Experimental and Analytical Results," Proceedings of the Ninth DoD/NASA/FAA Conference on Fibrous Composites in Structural Design, Lake Tahoe, Nevada, November 1991. 
Appendix A Test Data 


\section{Appendix A Test Data}

All the individual test data are included in this appendix as reported by Intec. Note that stresses in these spreadsheets are normalized by the actual specimen thickness. 


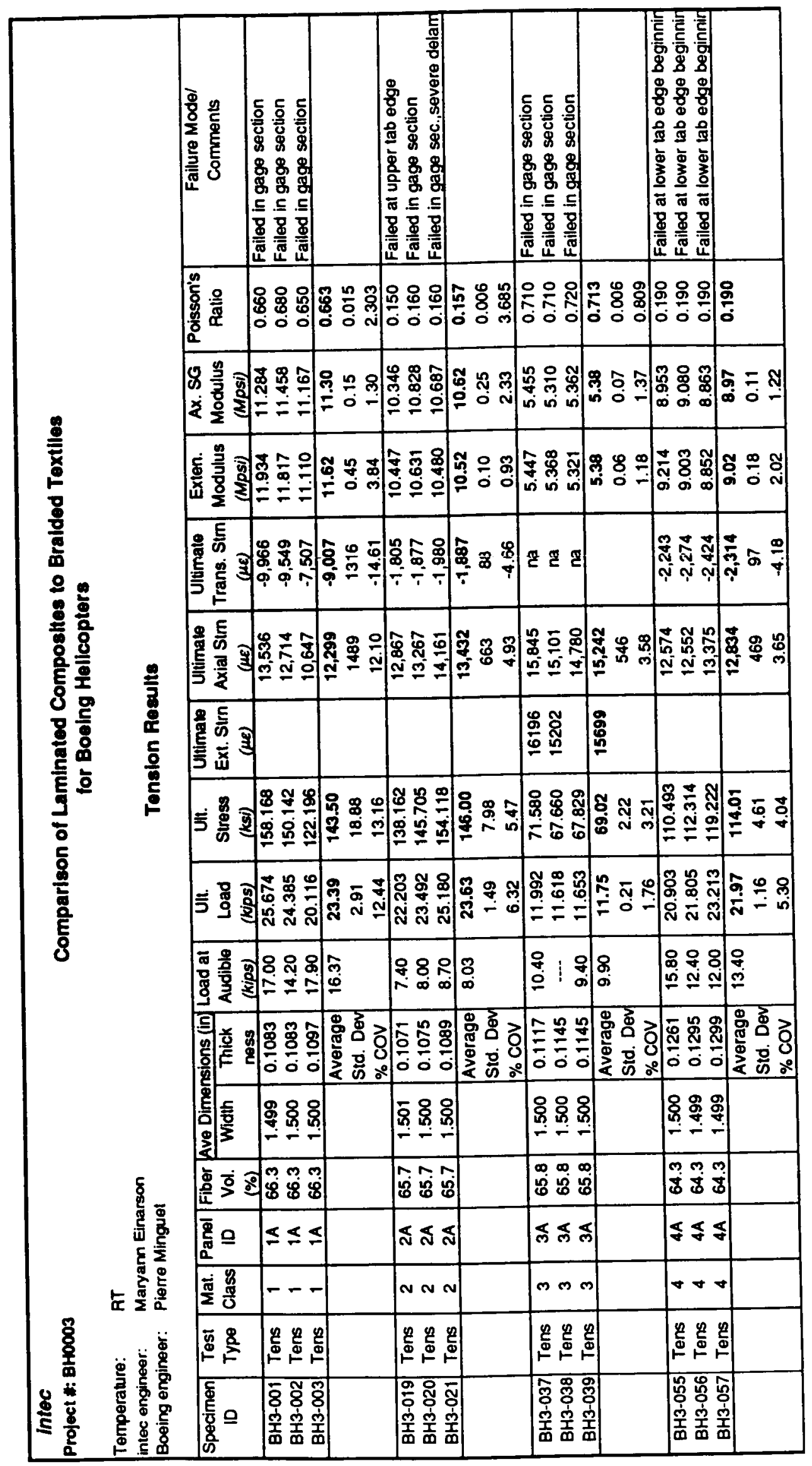




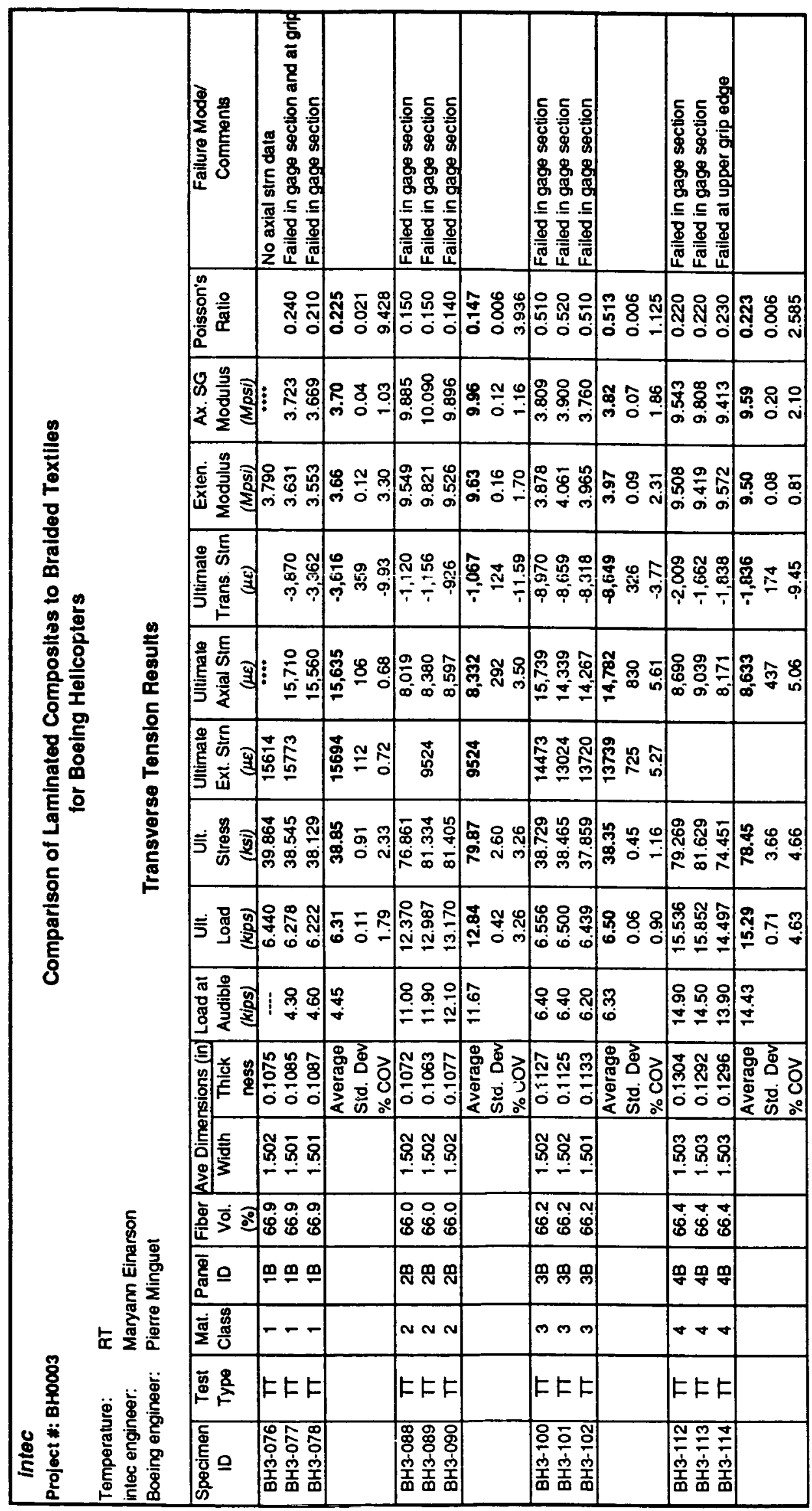




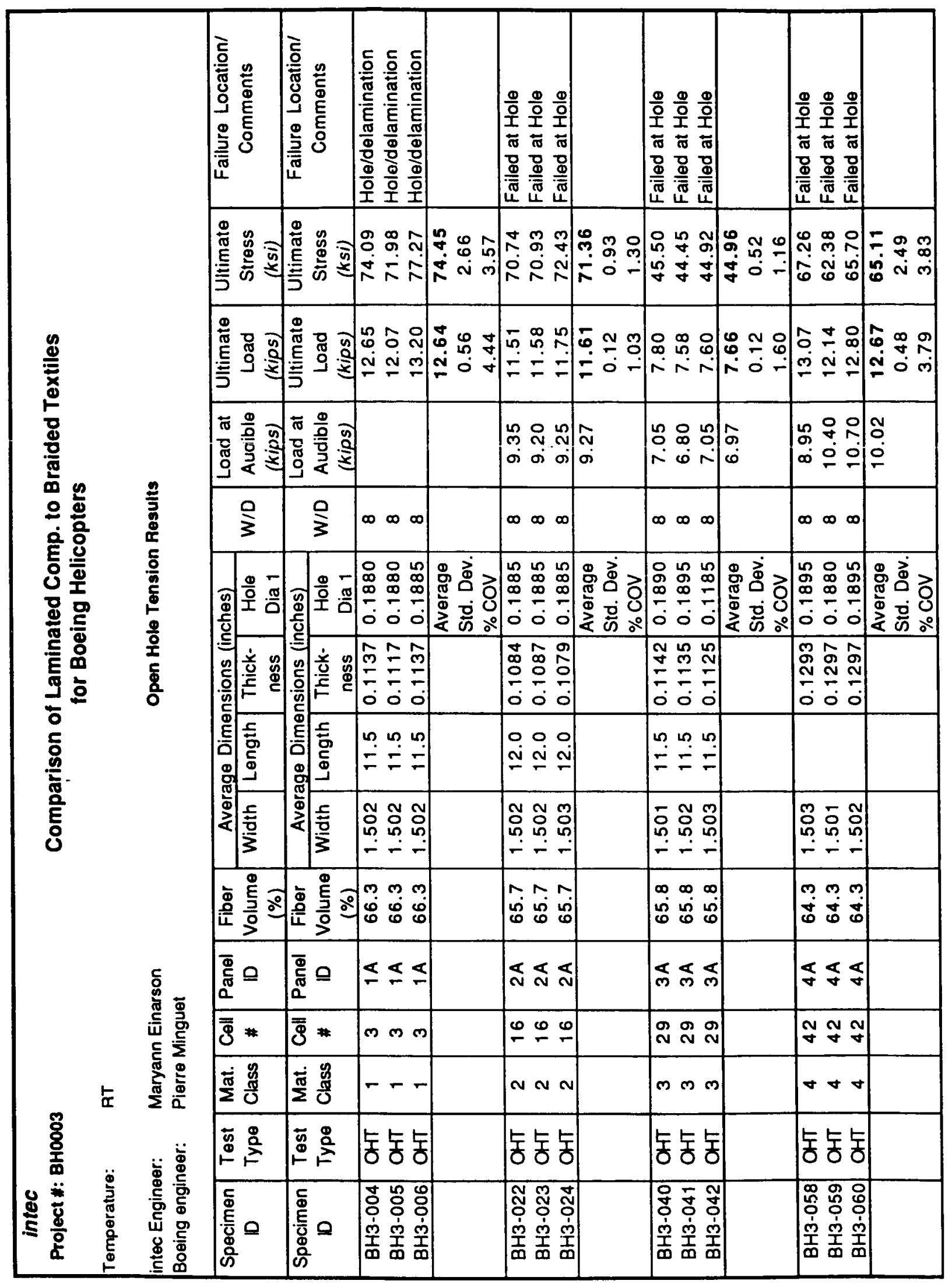




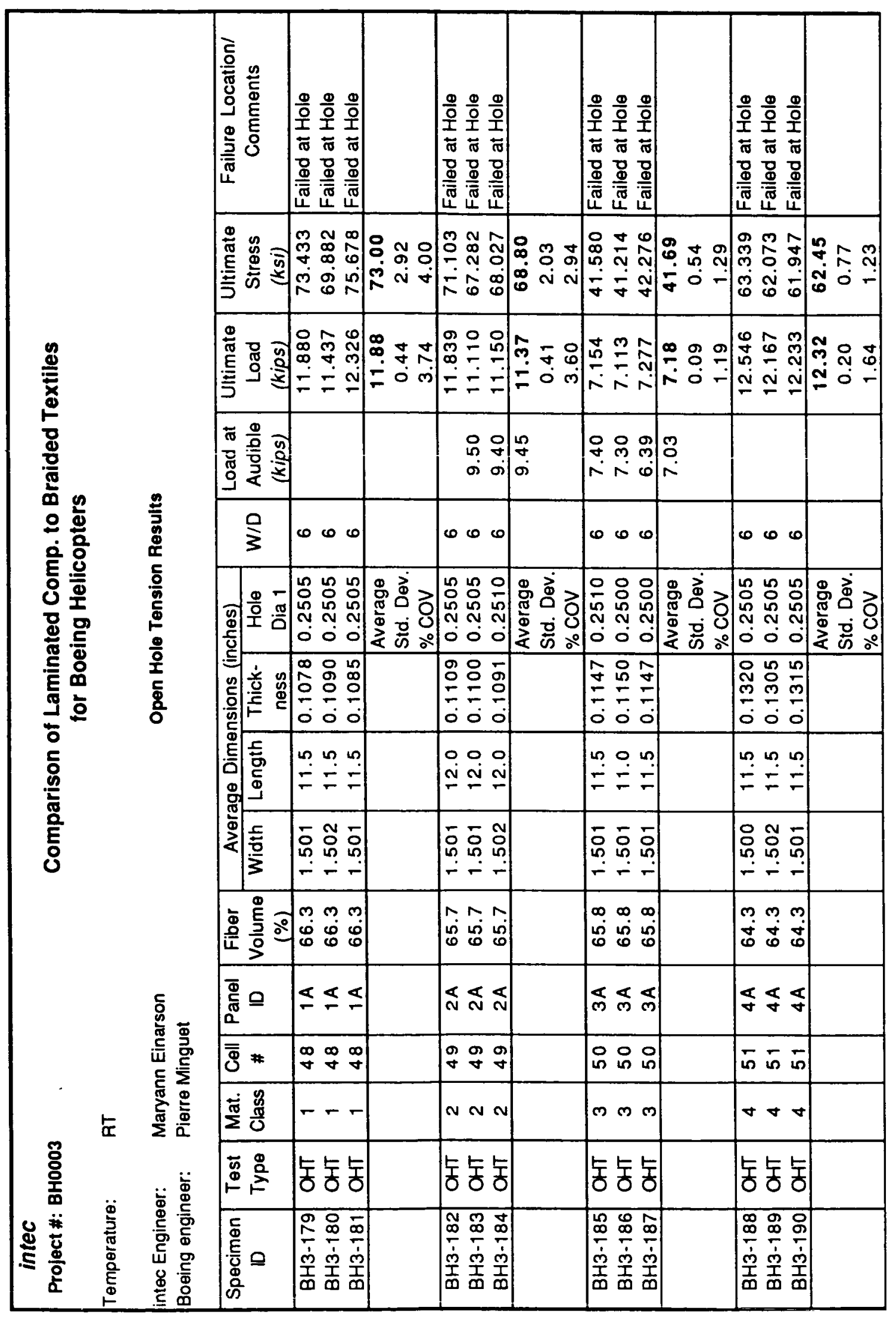




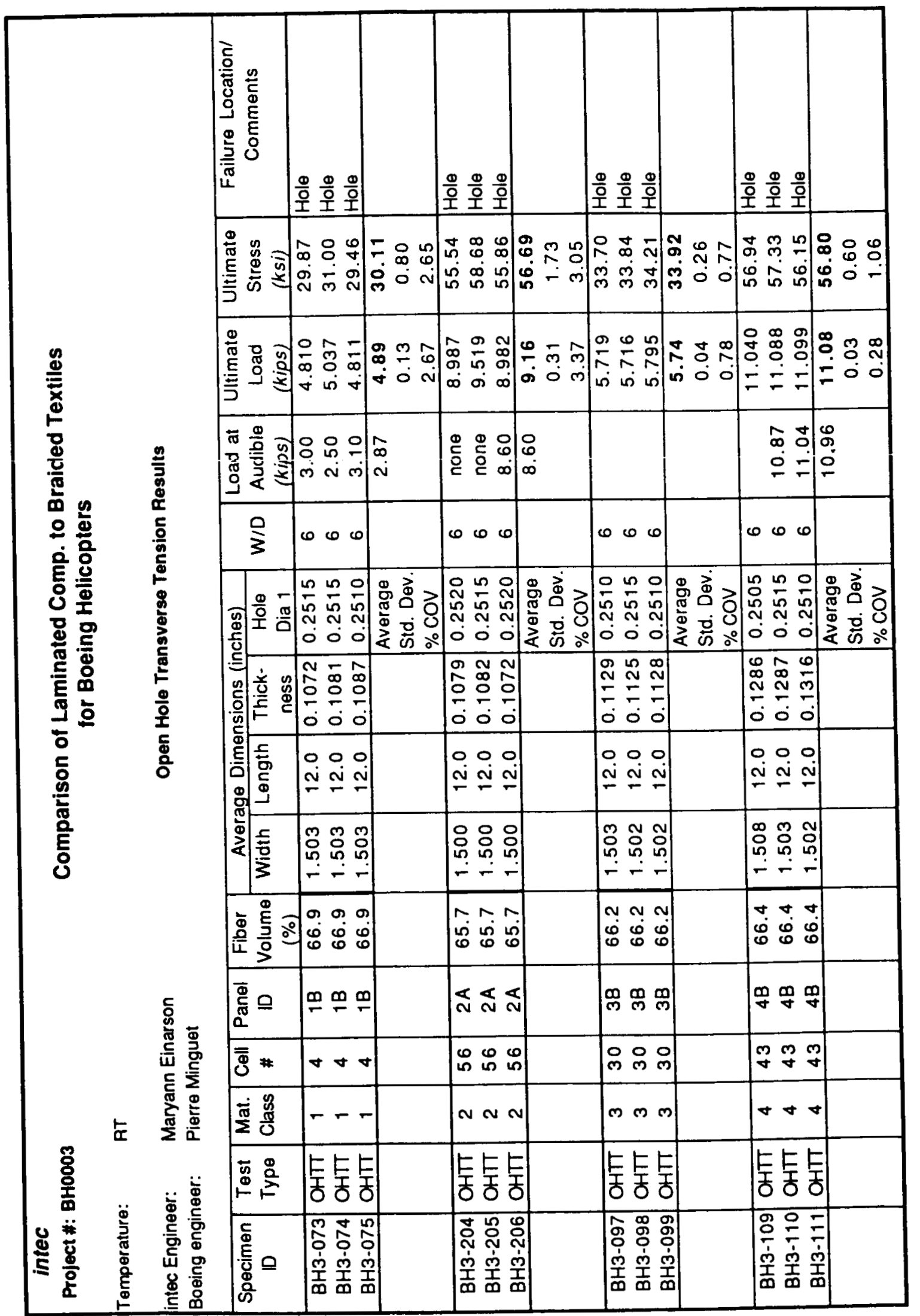




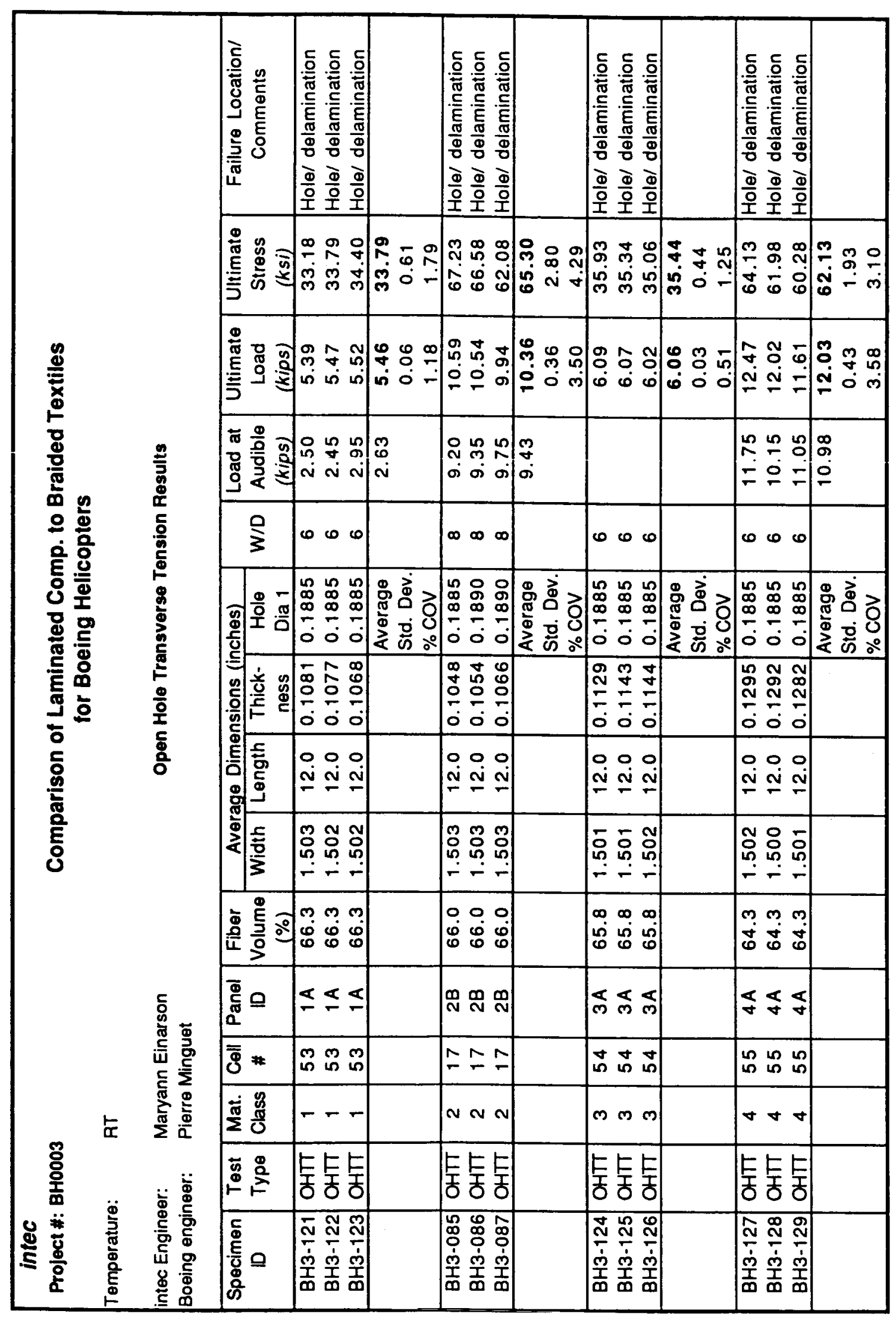




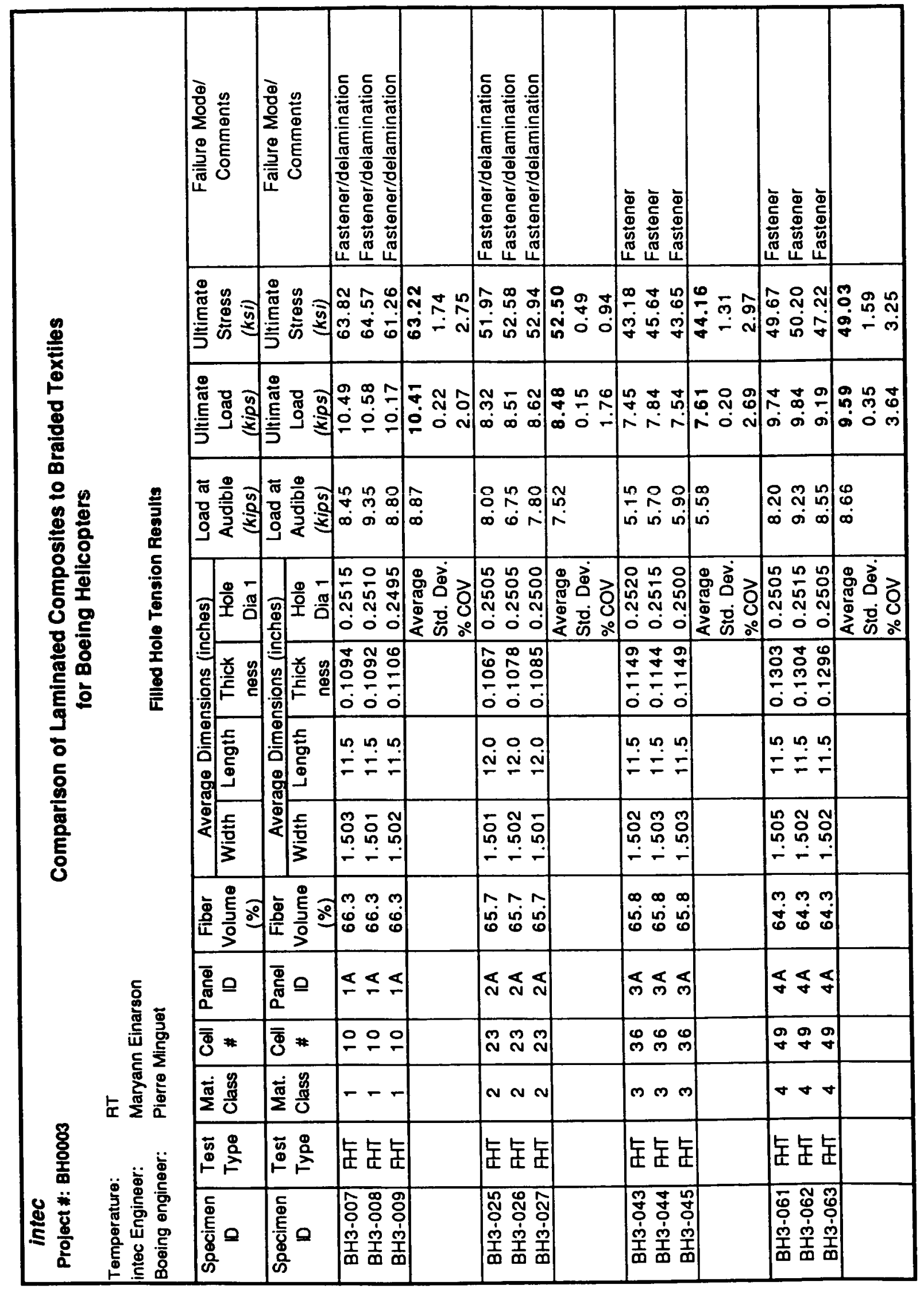




\begin{tabular}{|c|c|c|c|c|c|c|c|c|c|c|}
\hline \multirow{14}{*}{ 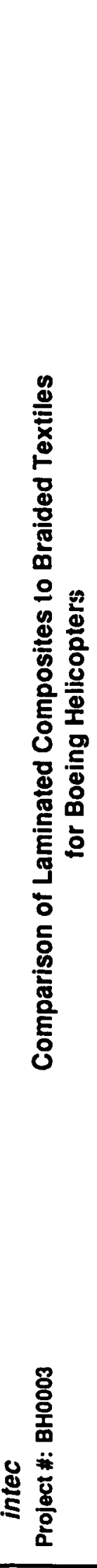 } & & 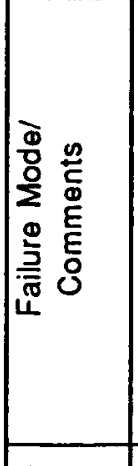 & 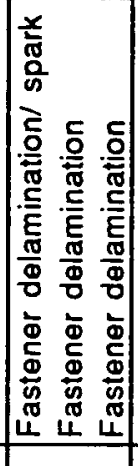 & & 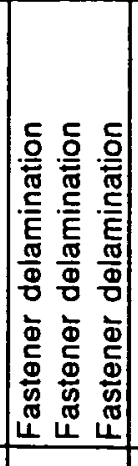 & & 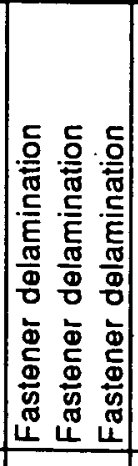 & & 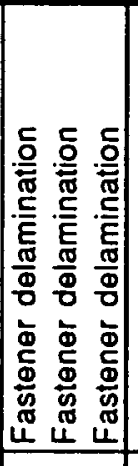 & \\
\hline & & 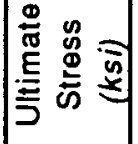 & $\left|\begin{array}{lll}0 & F & \infty \\
m & F & + \\
n & 10 & \dot{+} \\
m & m & m\end{array}\right|$ & 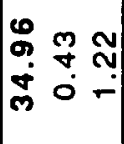 & 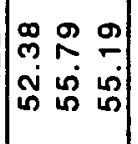 & 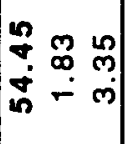 & 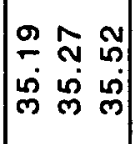 & 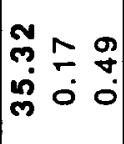 & 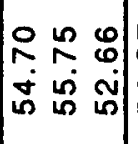 & 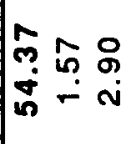 \\
\hline & & 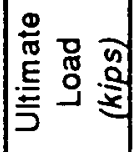 & $\left\{\begin{array}{lll}n & \bar{N} & 0 \\
\dot{N} & \omega & 6\end{array}\right.$ & $\begin{array}{lll}\infty & m & 0 \\
0 & 2 & 8 \\
\text { in } & 0 & 0 \\
\sim\end{array}$ & $\left|\begin{array}{ccc}\infty & 0 & \infty \\
\infty & \infty & \infty \\
\infty & \infty & \infty\end{array}\right|$ & 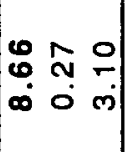 & $\left|\begin{array}{lll}\bar{\sigma} & \bar{\sigma} & 0 \\
\omega & \omega & 0 \\
\omega & \omega\end{array}\right|$ & $\begin{array}{lll}N & m & \infty \\
\sigma & 0 & q \\
\sim & 0 & 0\end{array}$ & $\left|\begin{array}{lll}0 & 0 & 0 \\
0 & \stackrel{0}{0} & 0 \\
0 & 0 & 0 \\
\hdashline & 0 & 0\end{array}\right|$ & 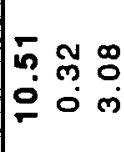 \\
\hline & 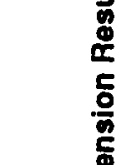 & 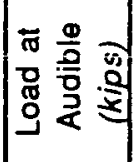 & $\left|\begin{array}{lll}n & 0 & n \\
0 & 8 & 0 \\
m & \dot{m} & \infty\end{array}\right|$ & 官 & 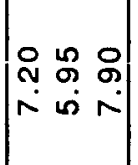 & ro & $\left|\begin{array}{ccc}0 & \omega & n \\
\hdashline & \infty & N \\
\dot{\nabla} & \dot{m} & \bar{n}\end{array}\right|$ & के & 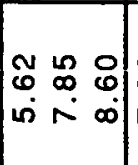 & 弟 \\
\hline & 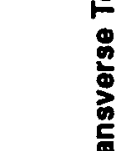 & 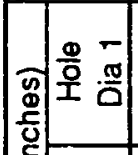 & 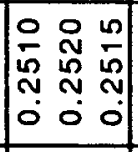 & 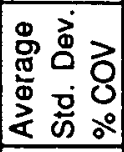 & $\left|\begin{array}{ccc}n & 0 & 0 \\
0 & \frac{1}{0} & 0 \\
n & n & 0 \\
N & N & 0 \\
0 & 0 & 0\end{array}\right|$ & 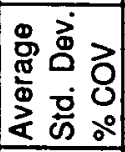 & 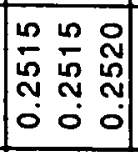 & 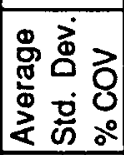 & $\left|\begin{array}{lll}n & n & 0 \\
n & n & 0 \\
N & n & N \\
0 & 0 & 0\end{array}\right|$ & 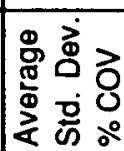 \\
\hline & $\begin{array}{l}\text { ब } \\
\text { 은 } \\
\text { 옹 }\end{array}$ & 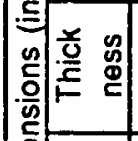 & $\mid$\begin{tabular}{ccc}
0 & $m$ & - \\
$\infty$ & $\infty$ & 0 \\
0 & 0 & 0 \\
\hdashline & - & $\sigma$ \\
0 & 0 & 0 \\
0 & 0 & 0 \\
\end{tabular} & & 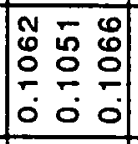 & & $\begin{array}{lll}1 & w & 0 \\
\approx & 5 & \sigma \\
\sigma & 5 & \sigma \\
0 & 0 & 0\end{array}$ & & 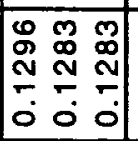 & \\
\hline & $\stackrel{\underline{\underline{t}}}{\bar{i}}$ & 密|c & 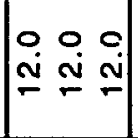 & & $\left|\begin{array}{ccc}0 & 0 & 0 \\
\dot{N} & \stackrel{i}{N} & \stackrel{\sim}{N}\end{array}\right|$ & & $\left|\begin{array}{lll}0 & 0 & 0 \\
& \stackrel{N}{N} & \cdots\end{array}\right|$ & & $\begin{array}{lll}0 & 0 & 0 \\
& \stackrel{N}{*} & \stackrel{\sim}{*}\end{array}$ & \\
\hline & & 帝点 & $\left|\begin{array}{ccc}3 & 0 & 9 \\
0 & 0 & 0 \\
i n & 0 & 0 \\
- & - & 0 \\
- & -\end{array}\right|$ & & 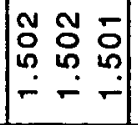 & & 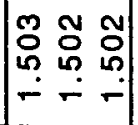 & & 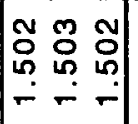 & \\
\hline & & 迹害 & $\left|\begin{array}{lll}0 & 9 & 9 \\
\dot{0} & 0 & 0 \\
0 & 0 & 0\end{array}\right|$ & & $\left|\begin{array}{lll}0 & 0 & 0 \\
\dot{0} & 0 & \vdots \\
0 & 0 & 0\end{array}\right|$ & & 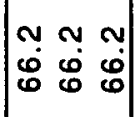 & & $\left|\begin{array}{lll}\nabla & \nabla & \nabla \\
\dot{0} & \dot{0} & \dot{0} \\
0 & 0 & 0\end{array}\right|$ & \\
\hline & $\stackrel{5}{\circ}$ & 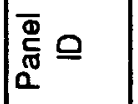 & $\stackrel{\oplus}{\circ} \stackrel{m}{\sim}$ & & $\stackrel{m}{\sim} \stackrel{\infty}{\sim} \underset{\sim}{N} \mid$ & & 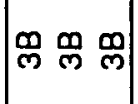 & & $q q q$ & \\
\hline & 悹亭 & $\overline{\bar{D}}$ & $=\mp=$ & & $\mid \begin{array}{lll}\Delta & \dot{N} & \mathbf{N}\end{array}$ & & $\hat{n}$ के & & 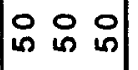 & \\
\hline & 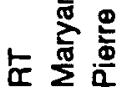 & 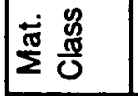 & --- & & 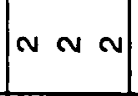 & & $m \infty m$ & & $\forall \forall \forall$ & \\
\hline & $\ddot{\infty} \ddot{\oplus} \dot{\Phi}$ & 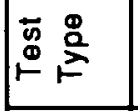 & 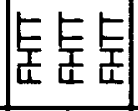 & & 砉愛言 & & 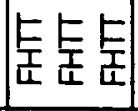 & & 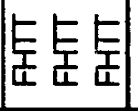 & \\
\hline & 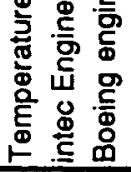 & 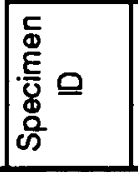 & 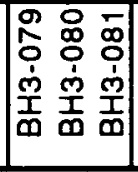 & & 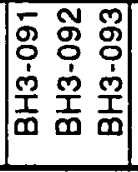 & & 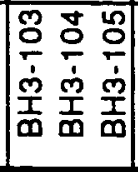 & & 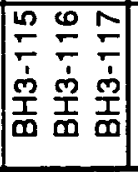 & \\
\hline
\end{tabular}




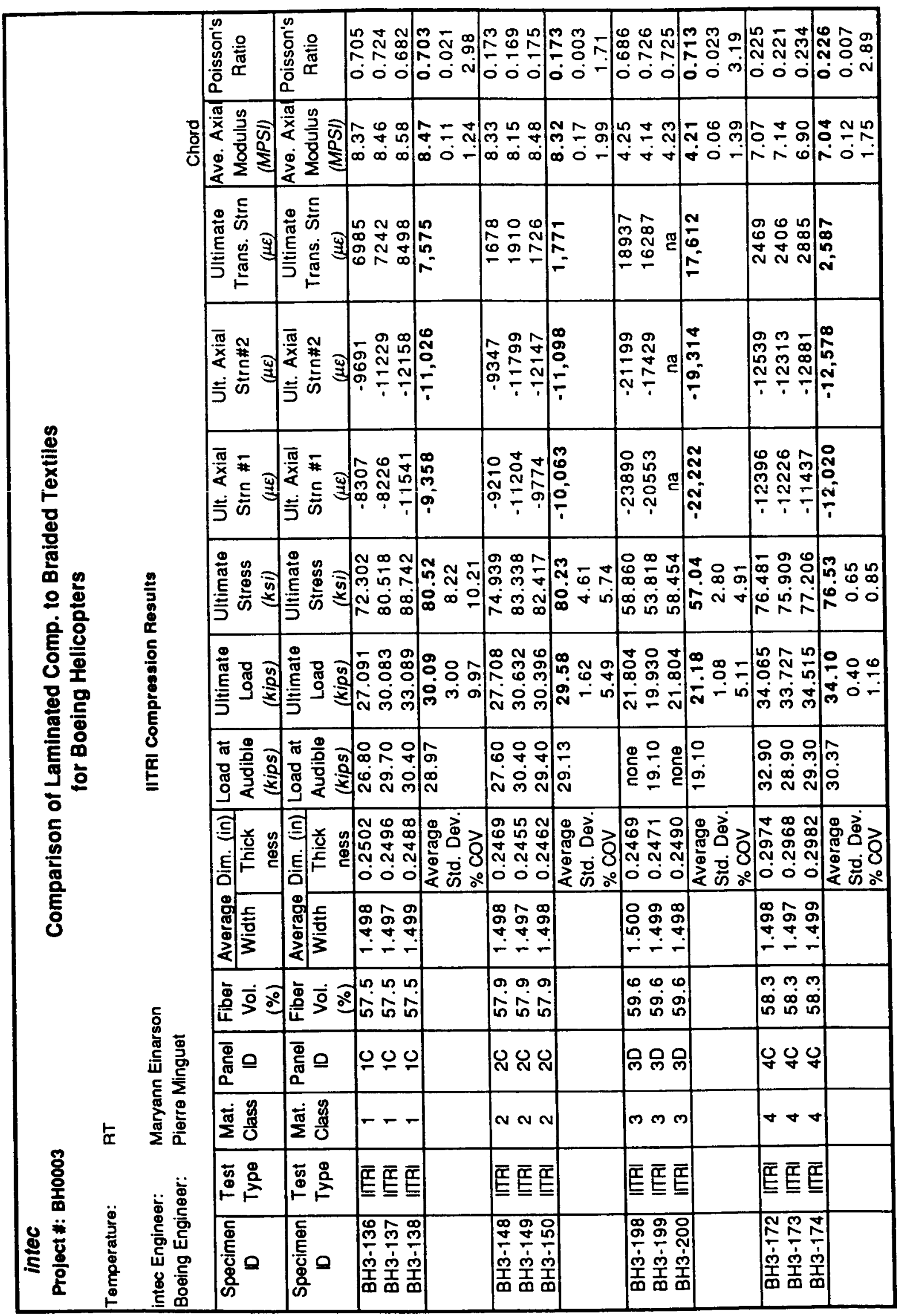




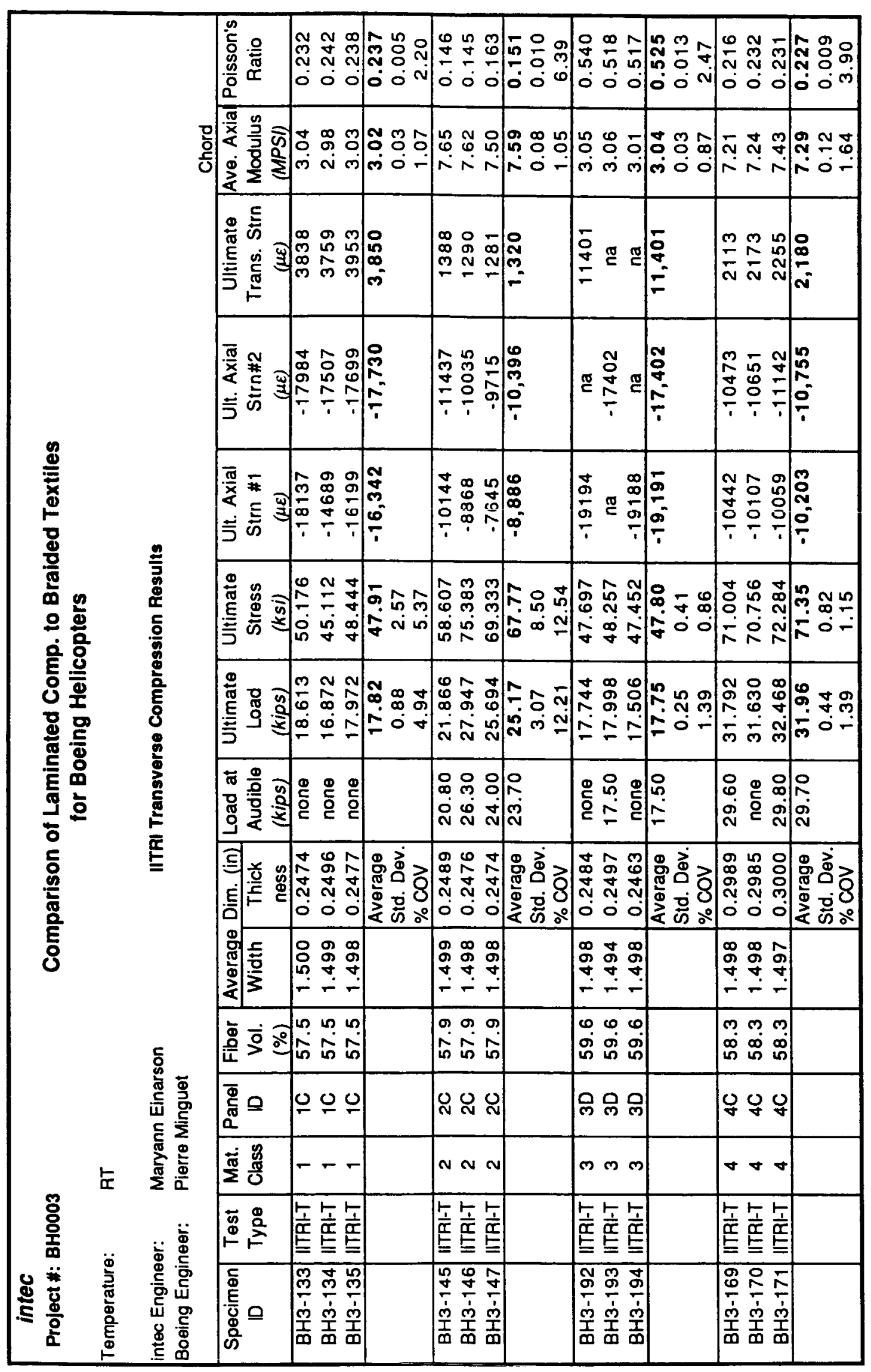




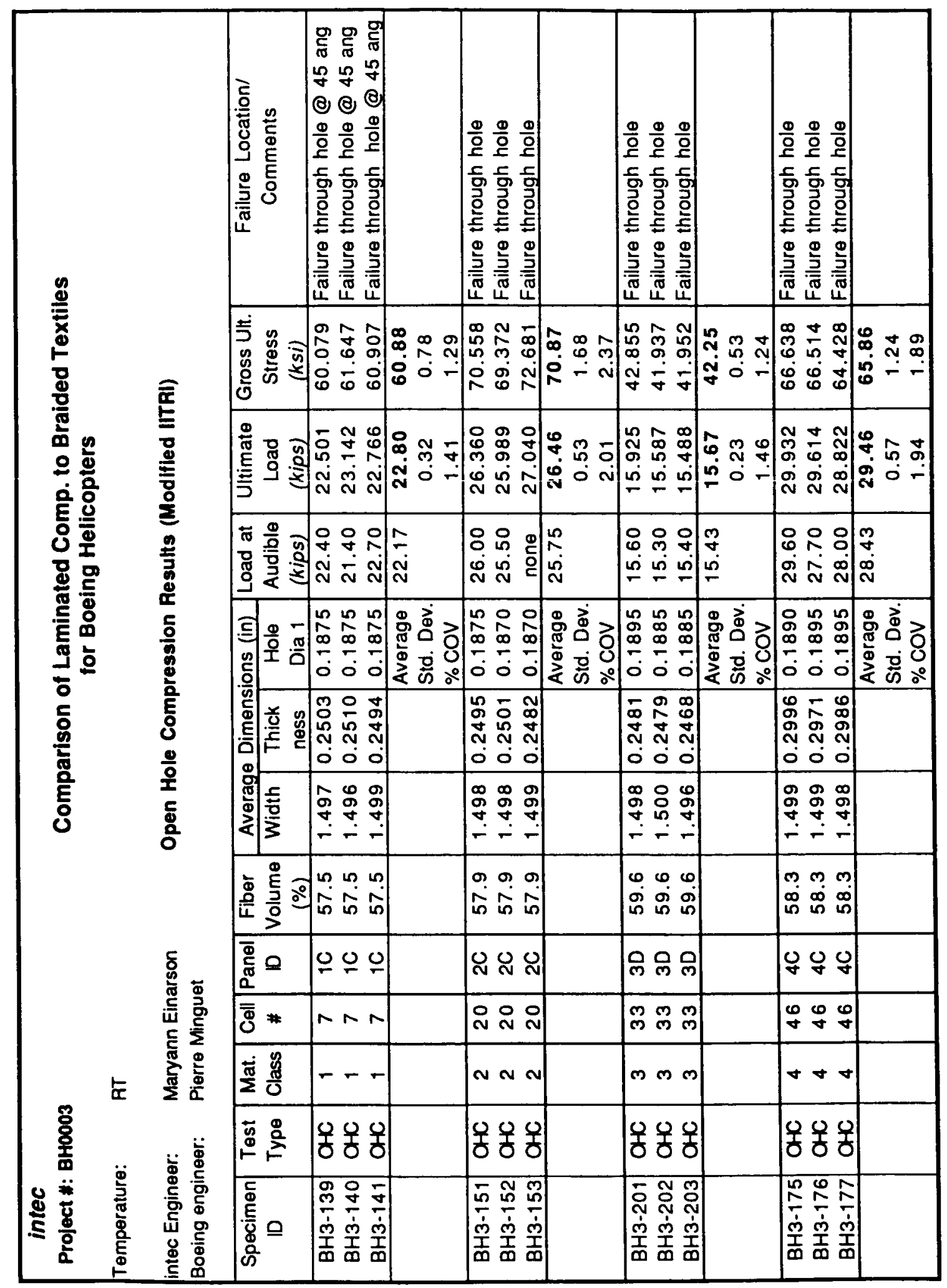




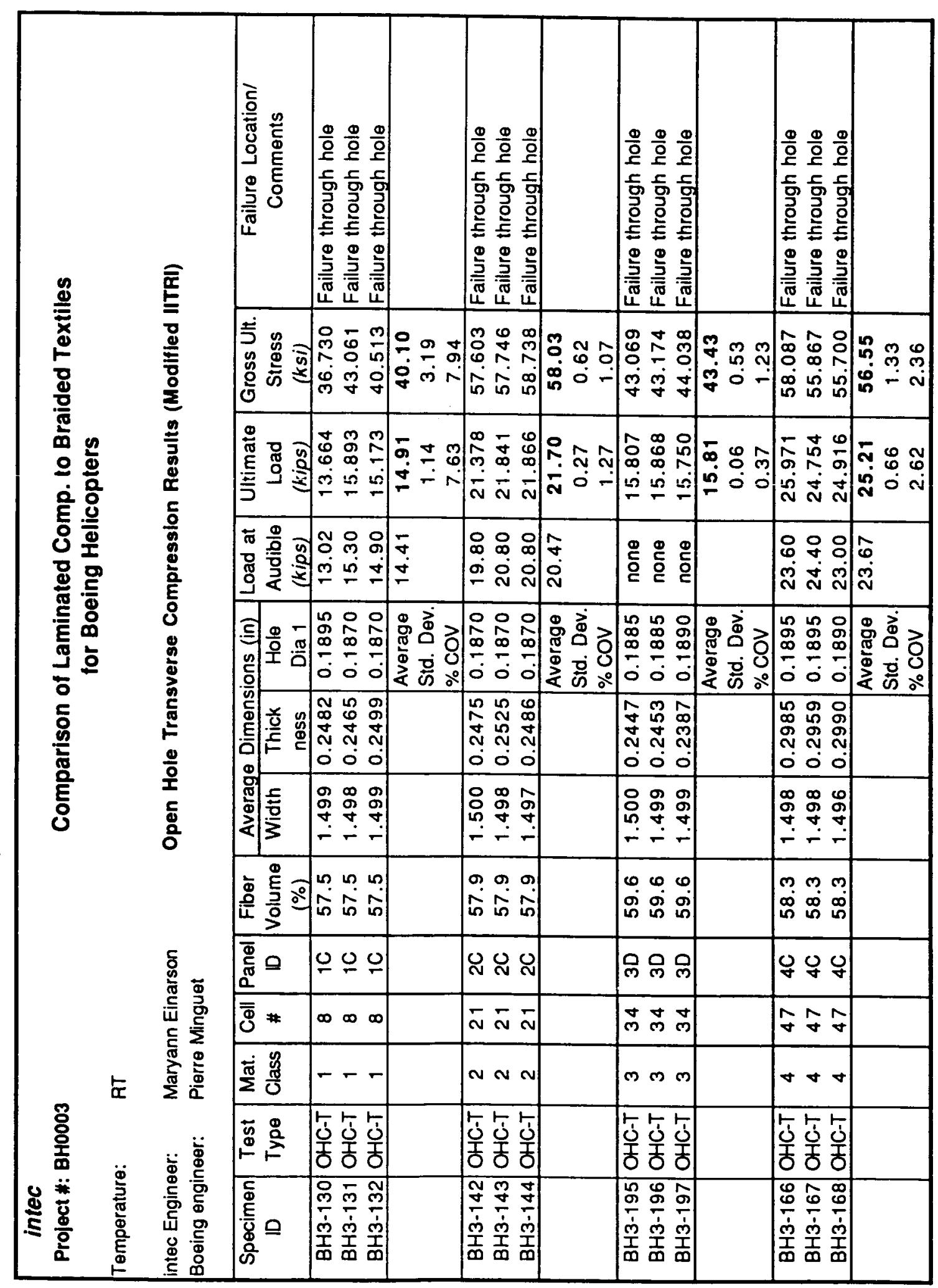




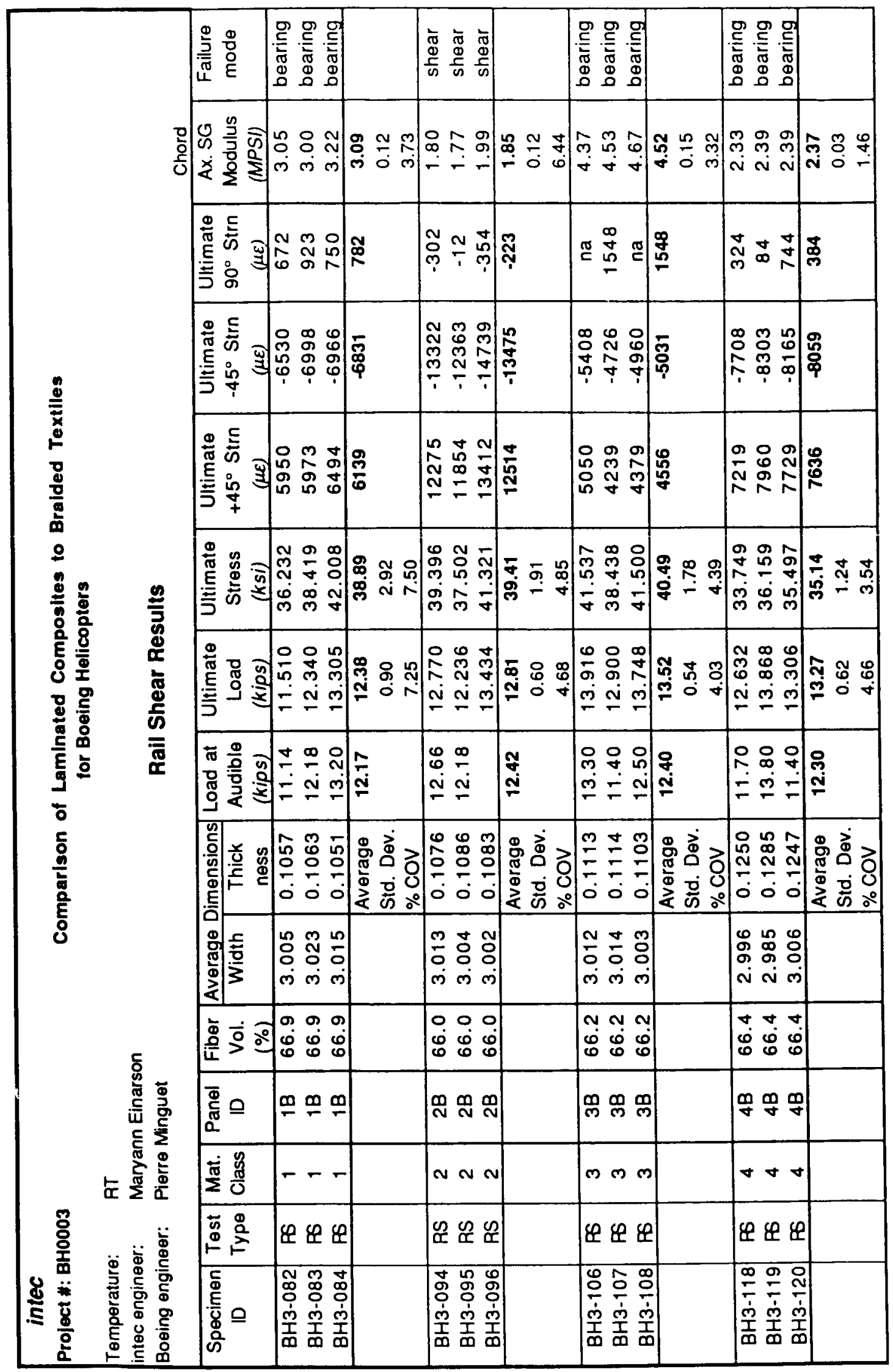




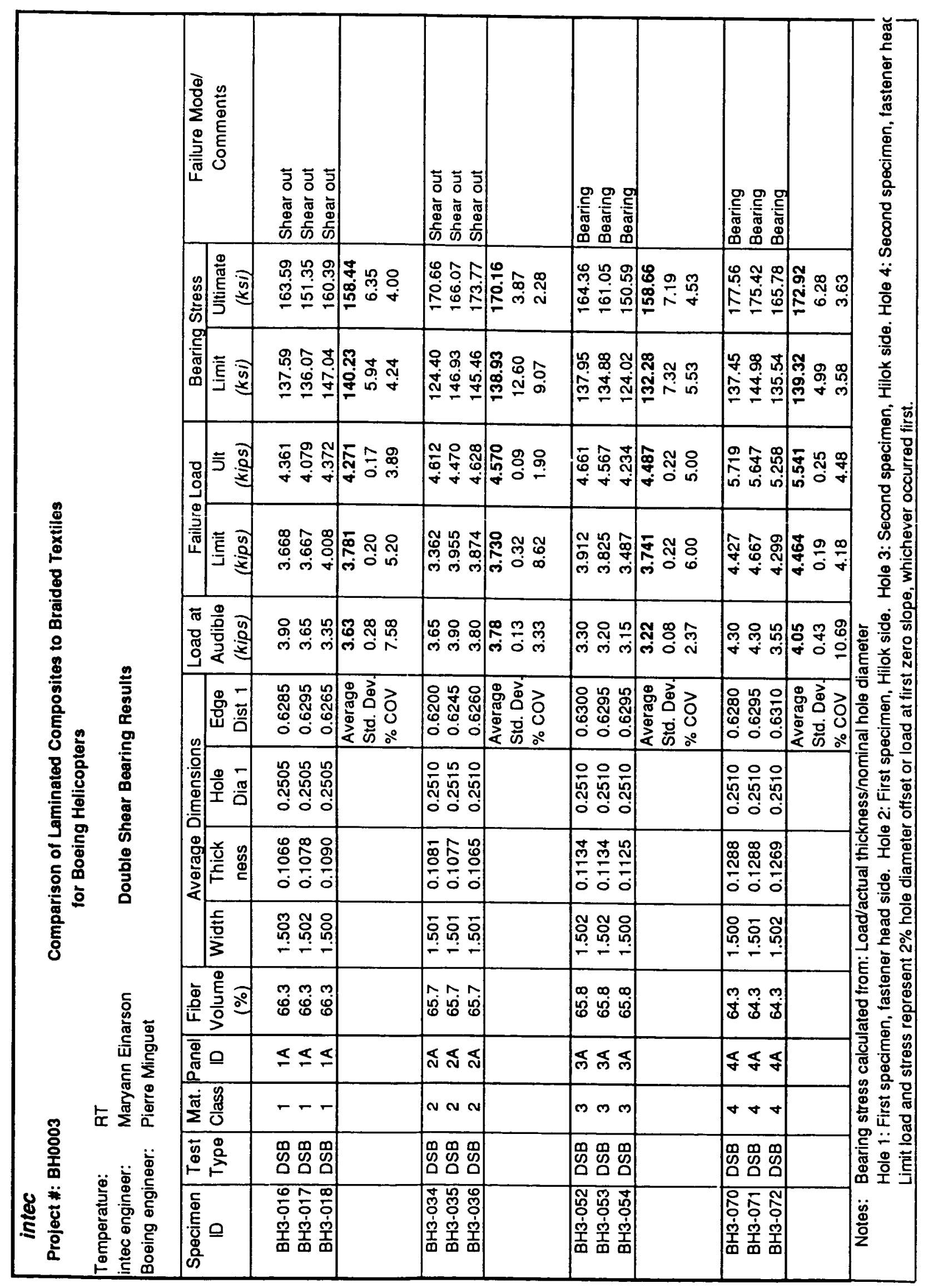




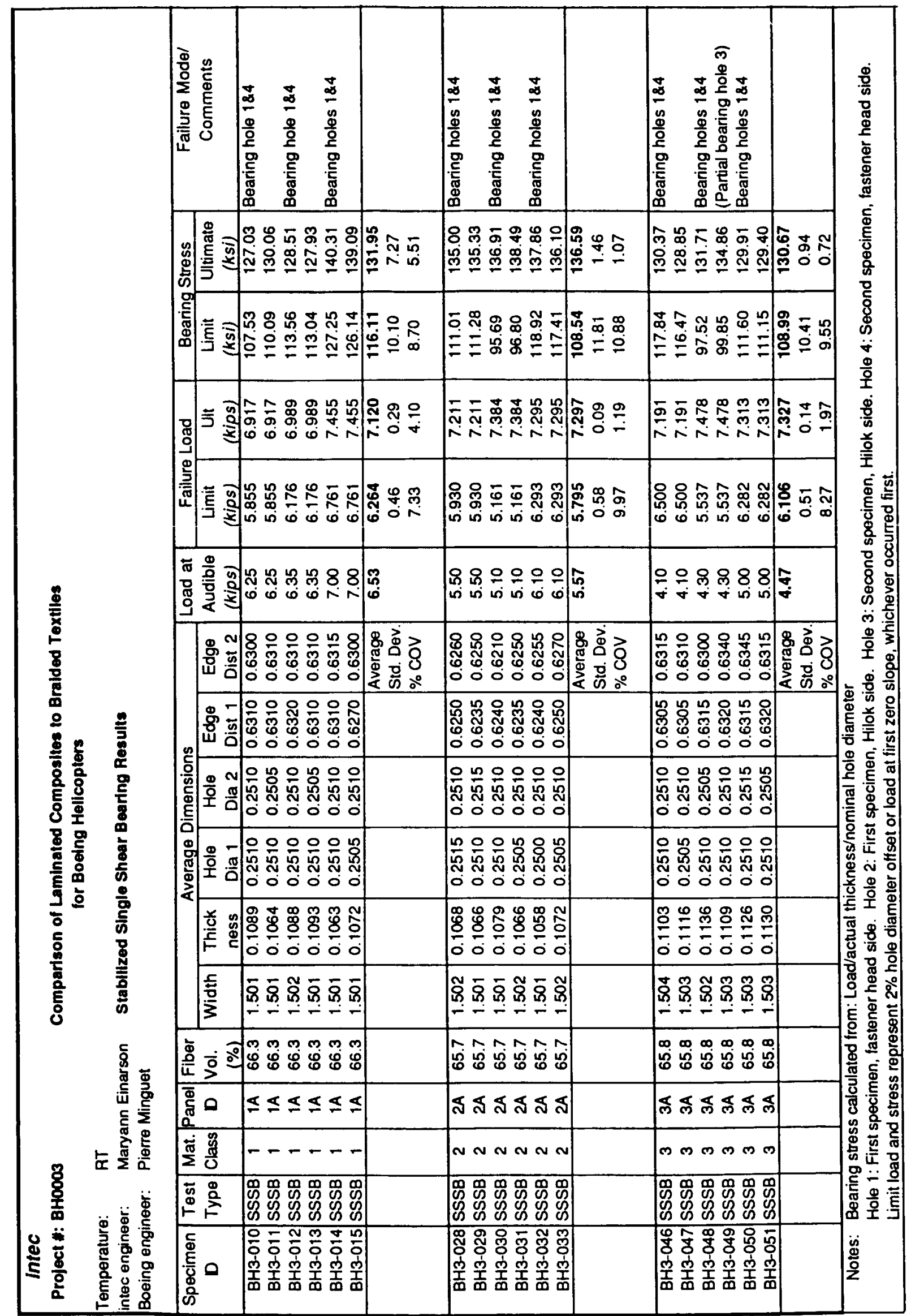




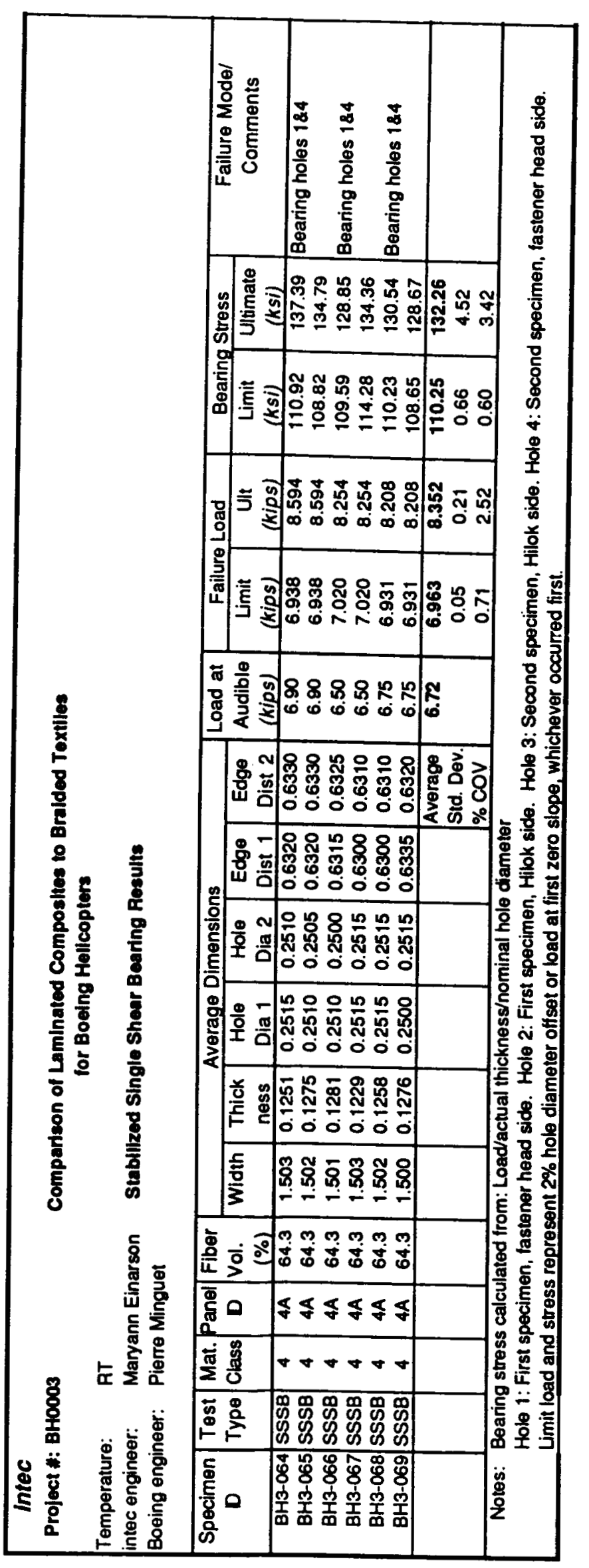




\section{Appendix B Typical Stress-Strain Curves}

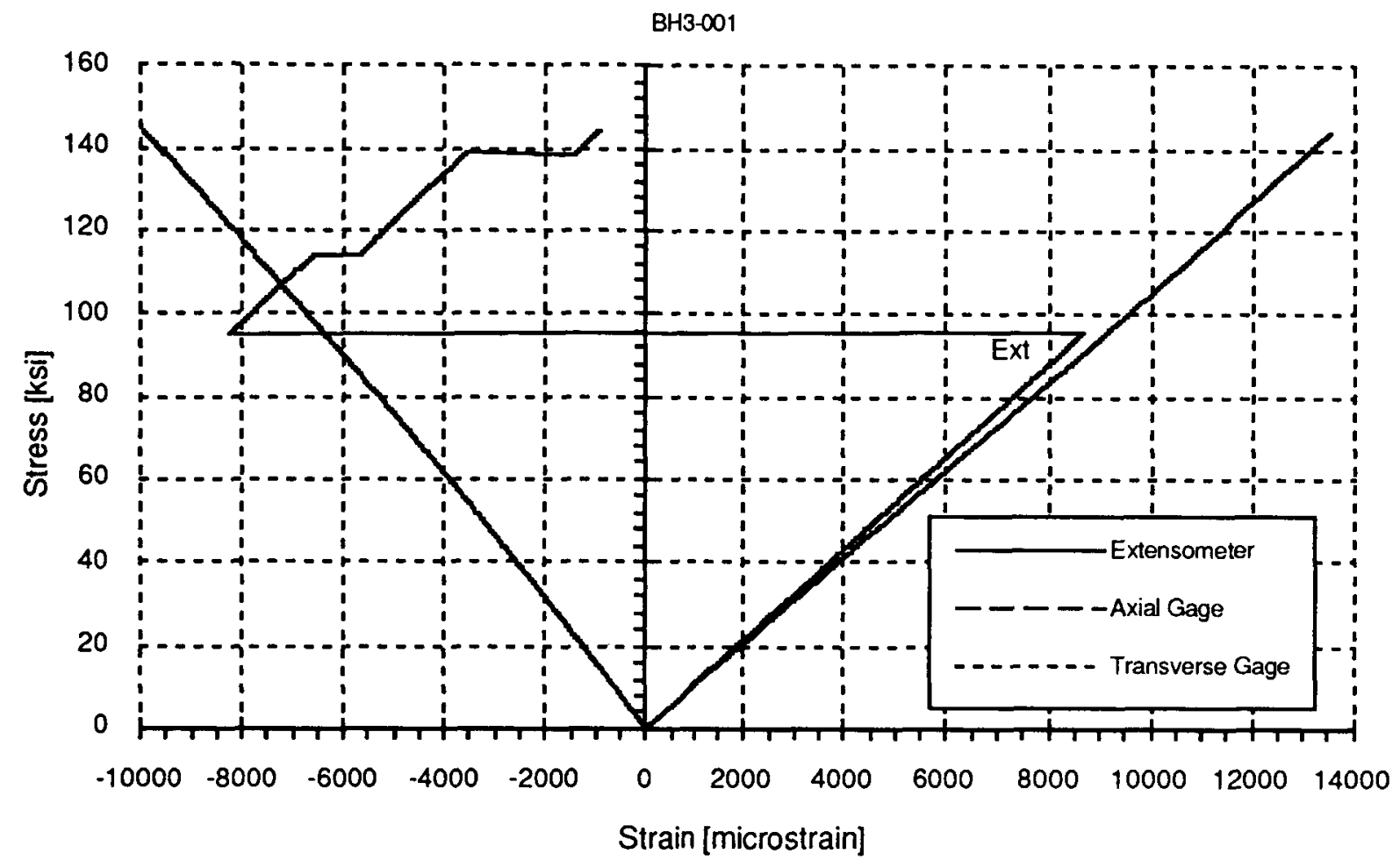

Figure B.1 Typical Longitudinal Tension Test Strain Data for Laminate L1.

BH3-019

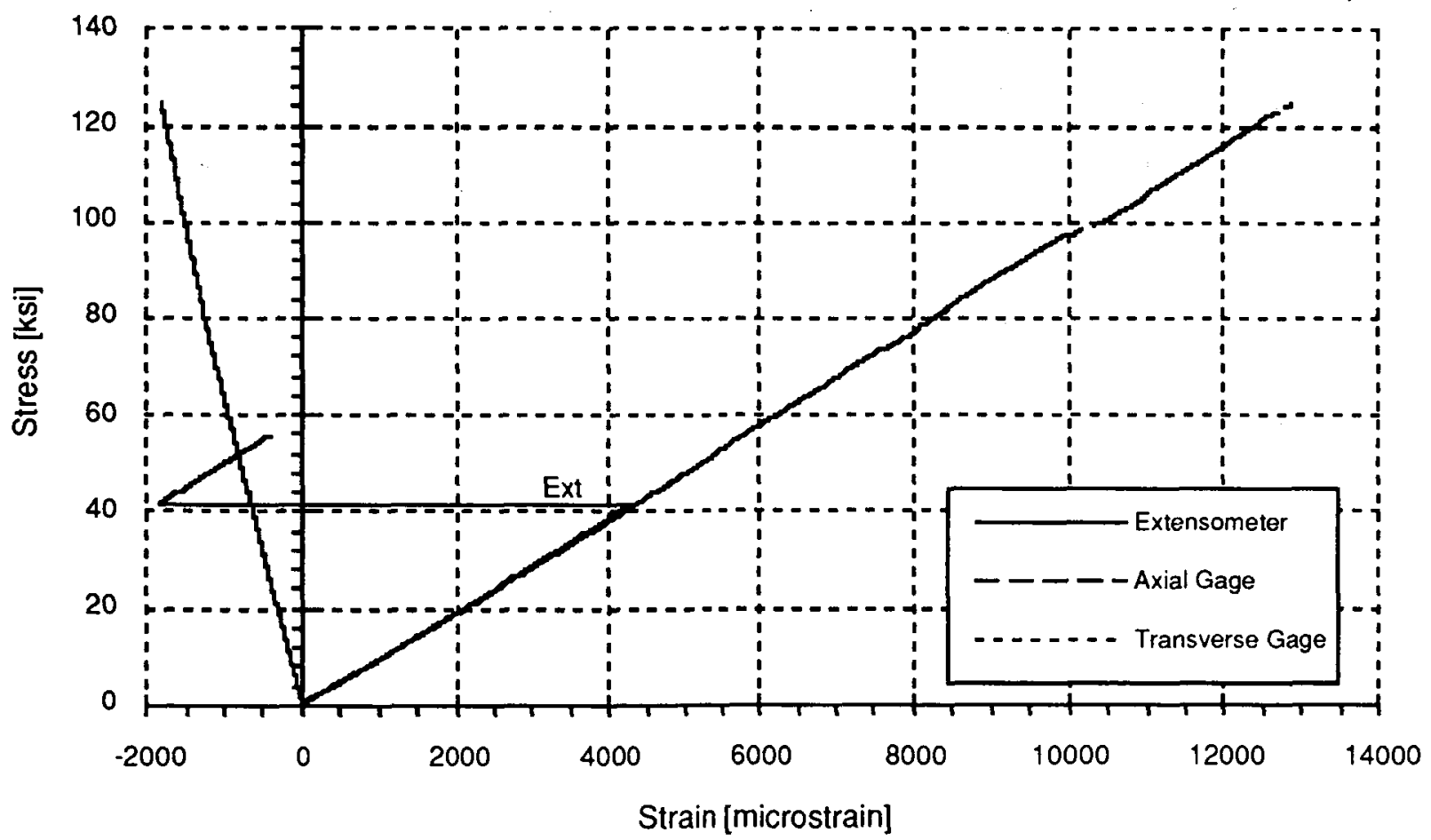

Figure B.2 Typical Longitudinal Tension Test Strain Data for Laminate L2. 
ВН3-037

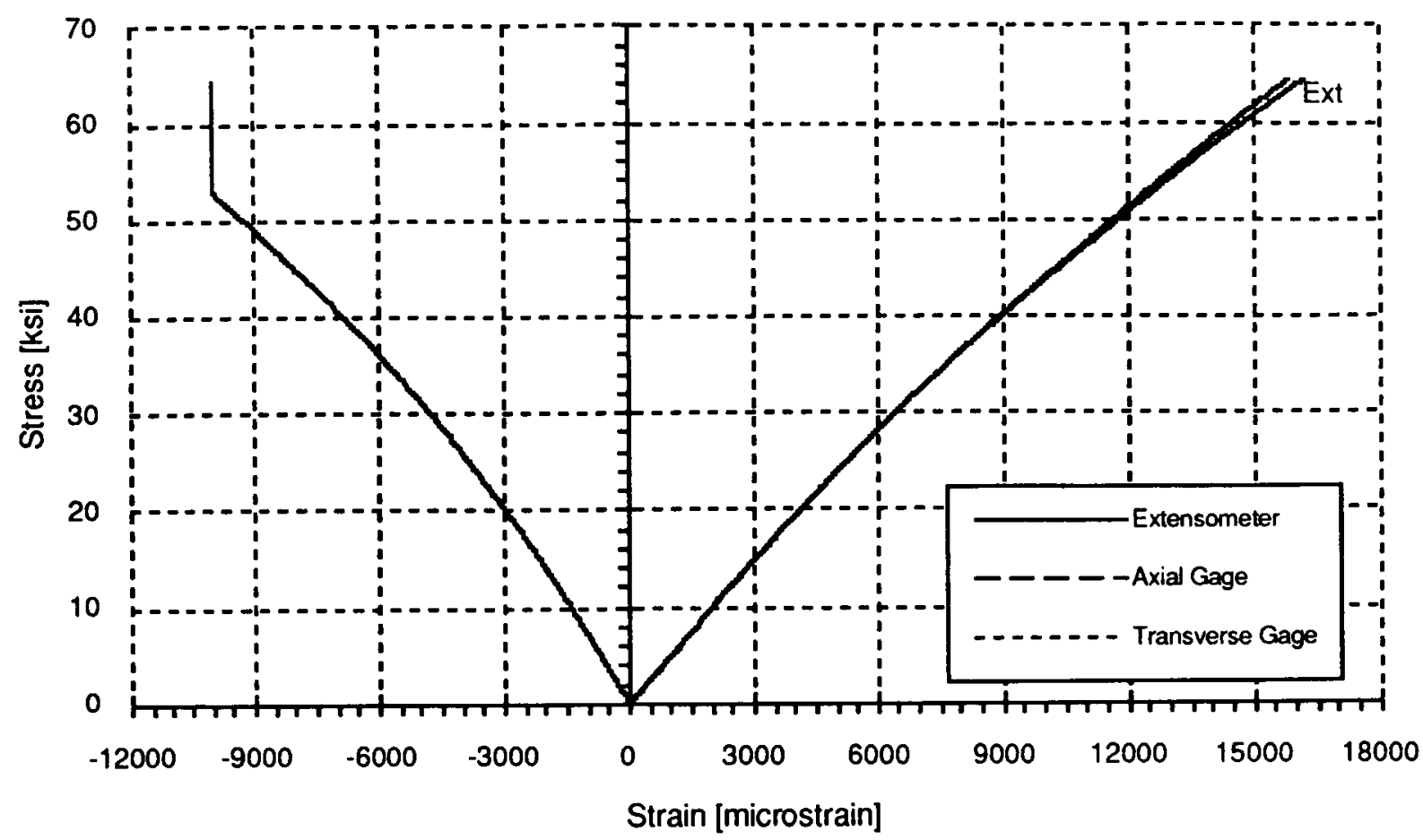

Figure B.3 Typical Longitudinal Tension Test Strain Data for Laminate L3.

BH3-055

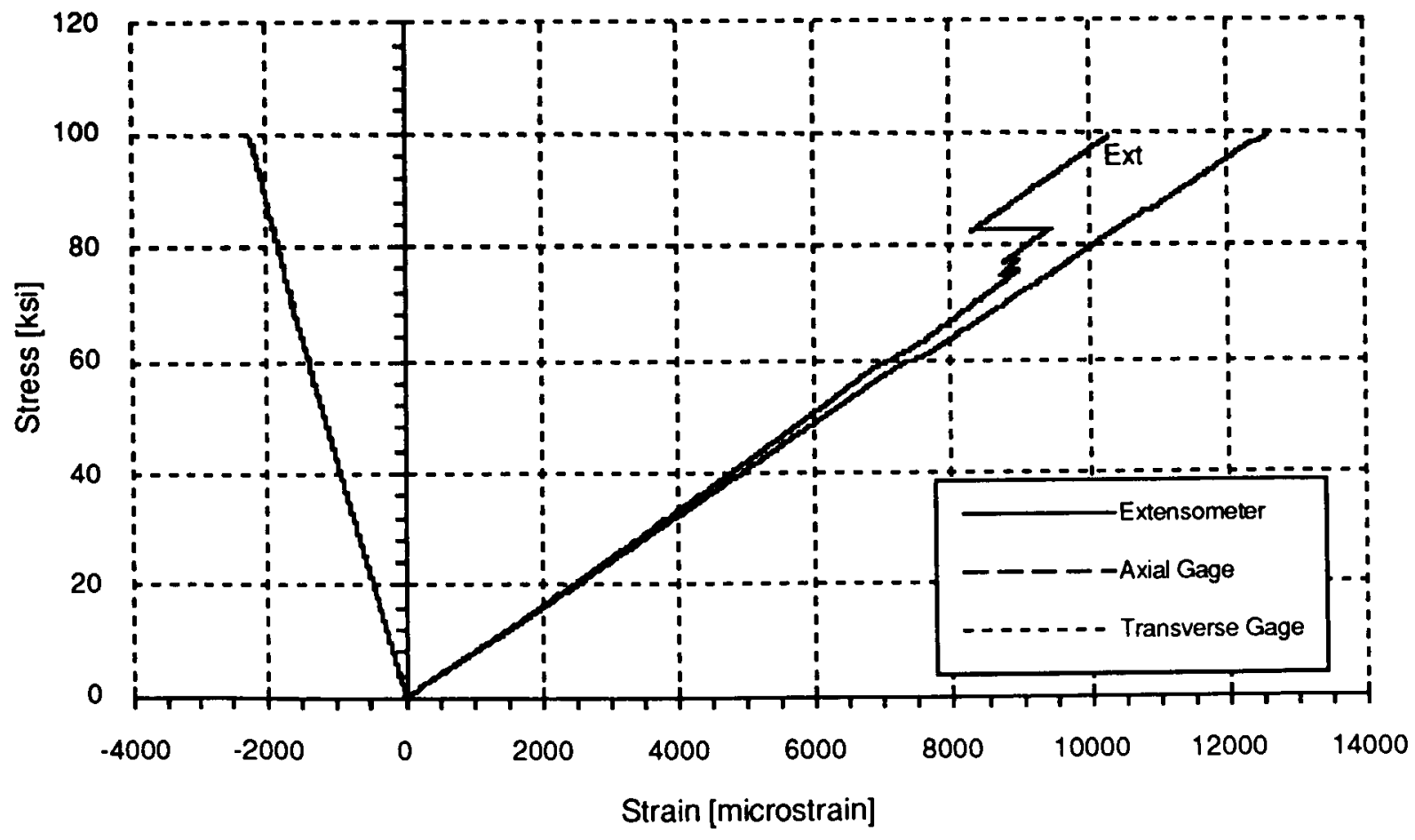

Figure B.4 Typical Longitudinal Tension Test Strain Data for Laminate L4. 


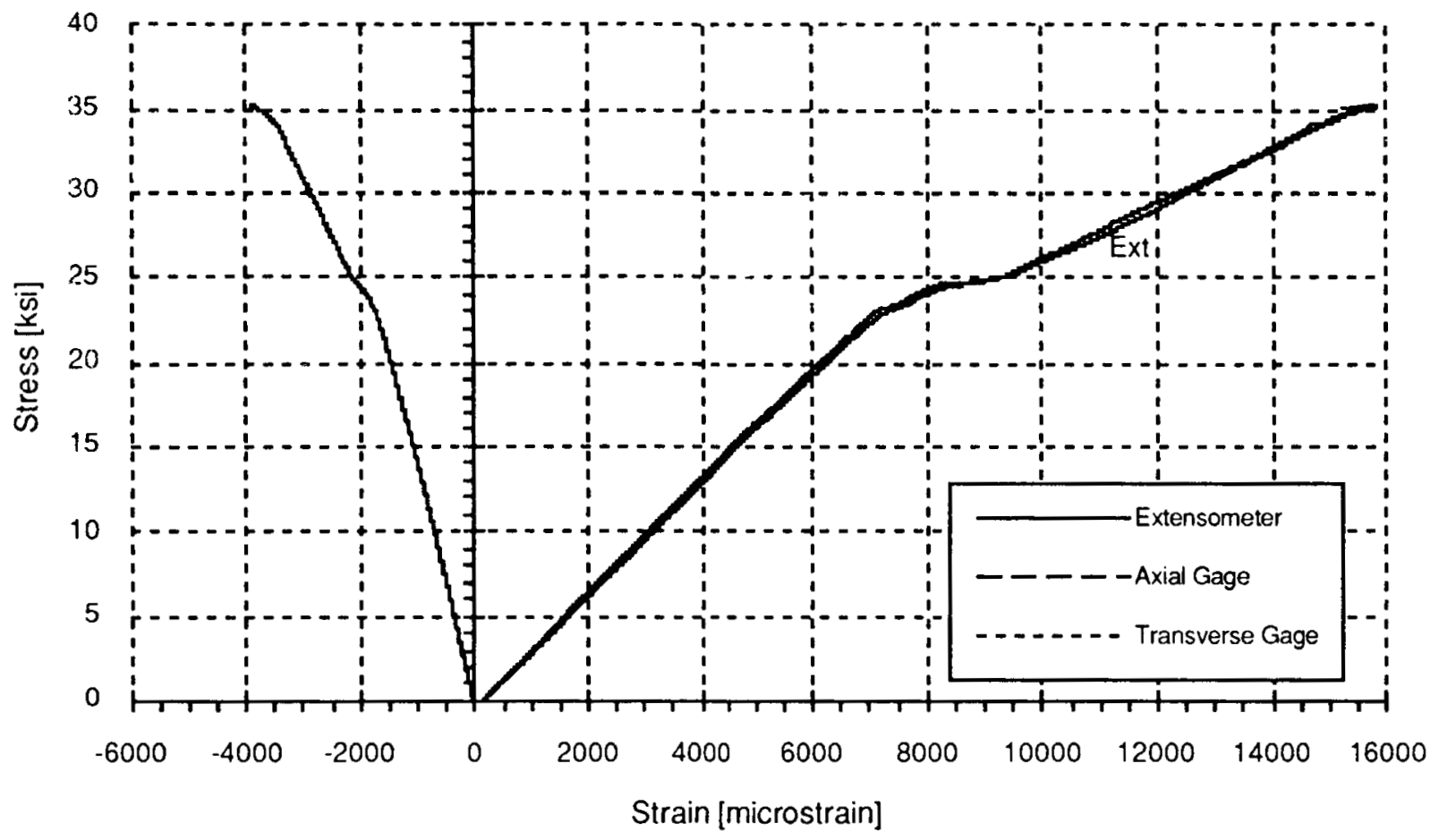

Figure B.5 Typical Transverse Tension Test Strain Data for Laminate L1.

BHЗ-088

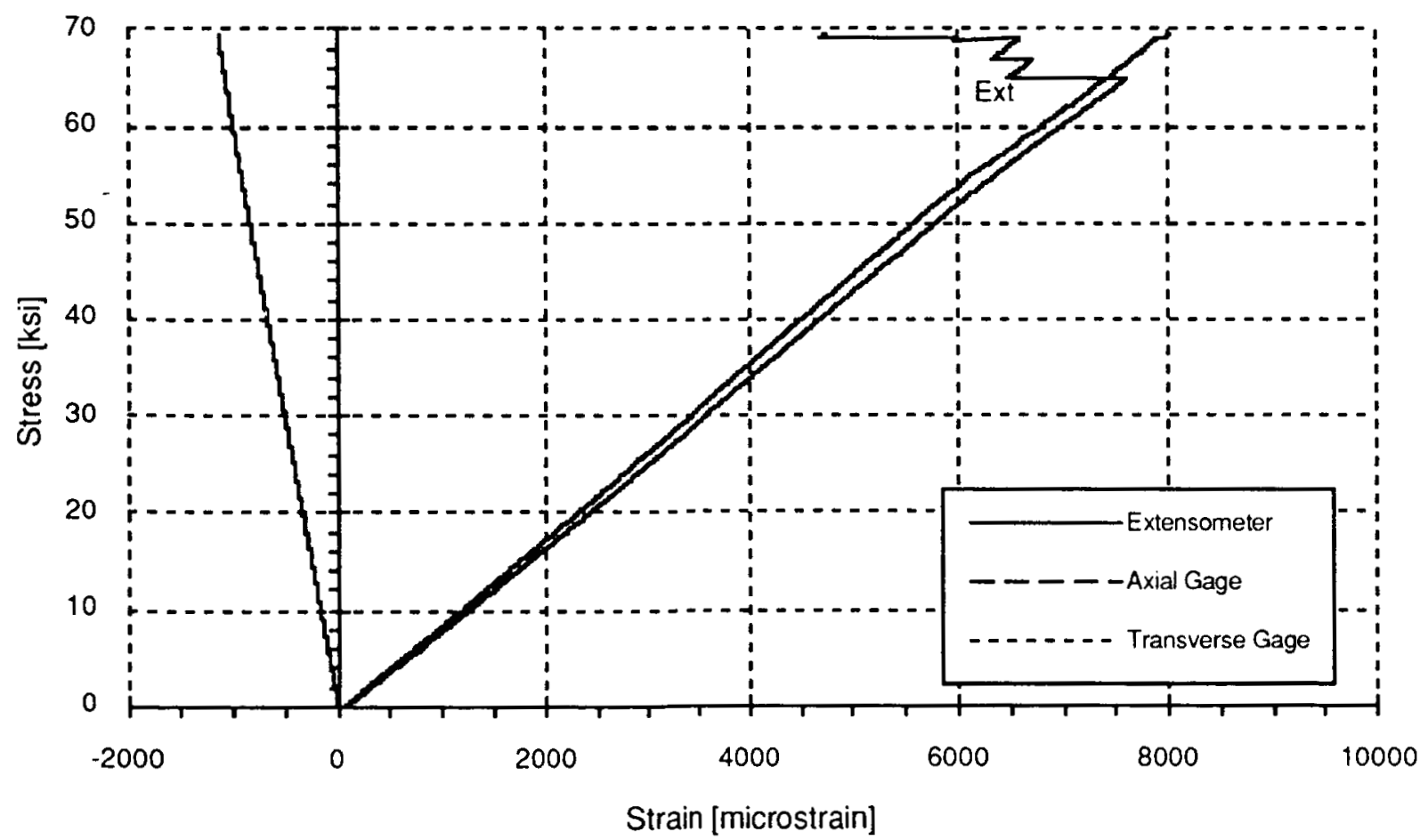

Figure B.6 Typical Transverse Tension Test Strain Data for Laminate L2. 
$\mathrm{BH}-100$

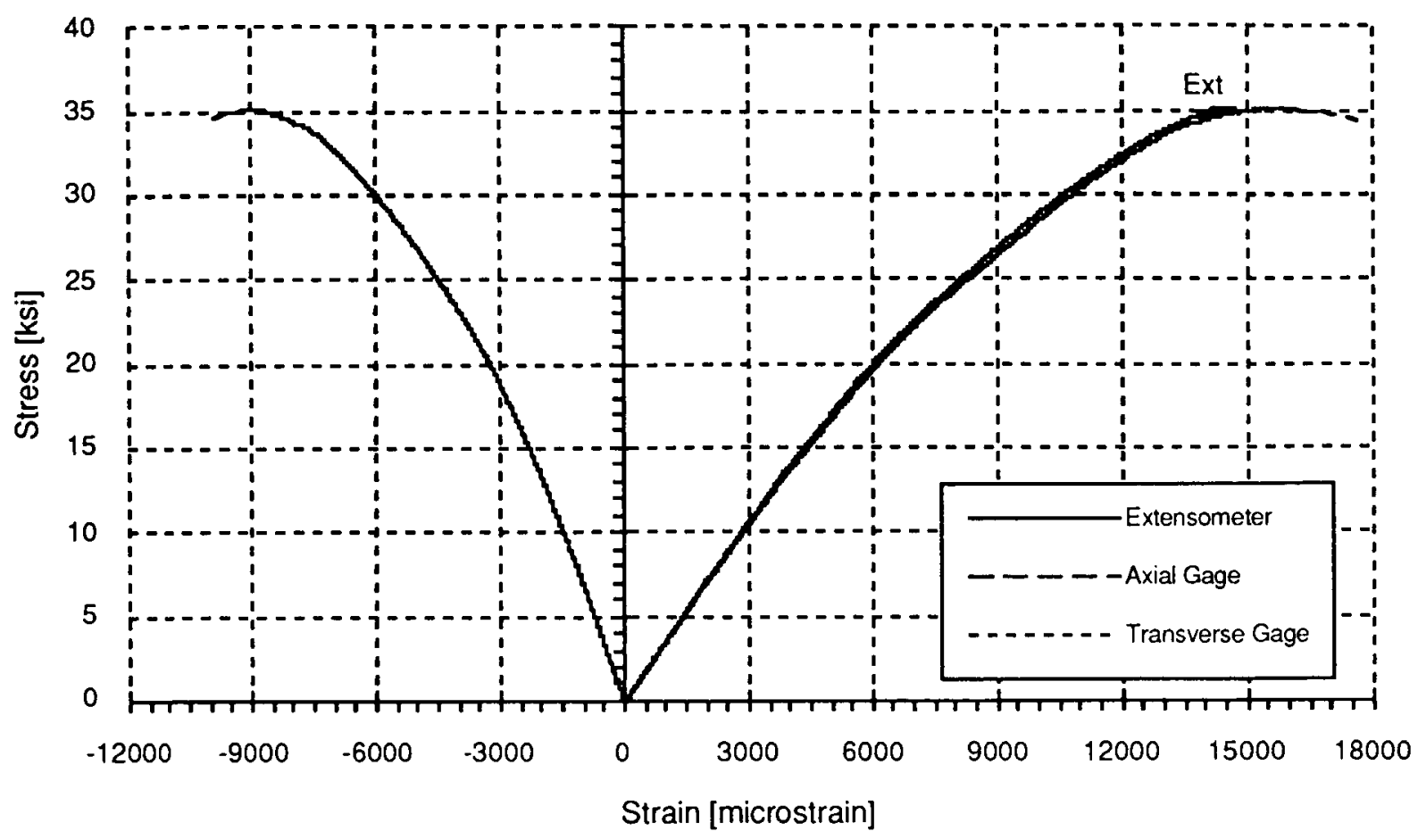

Figure B.7 Typical Transverse Tension Test Strain Data for Laminate L3.

BH3-112

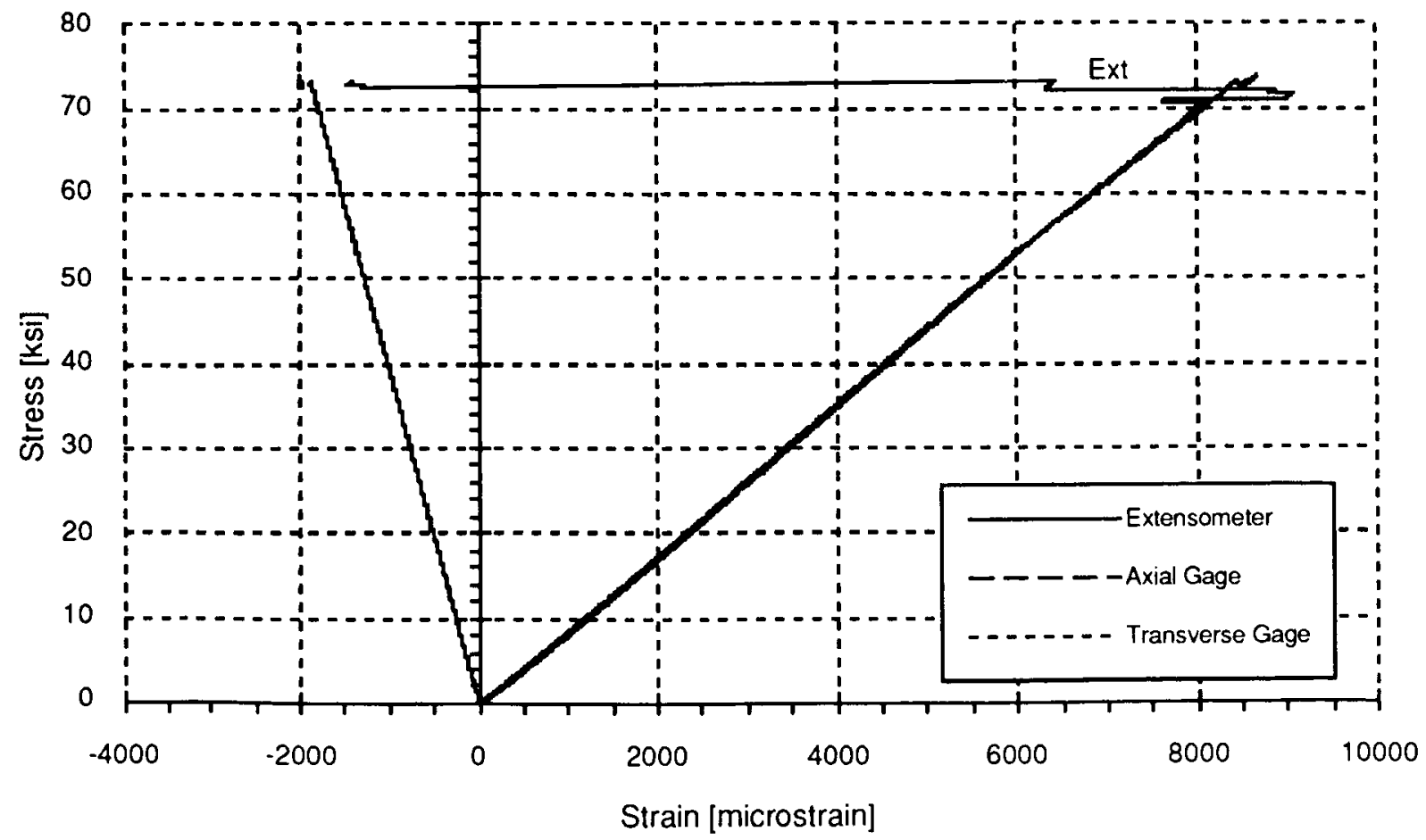

Figure B.8 Typical Transverse Tension Test Strain Data for Laminate L4. 
BH3-136

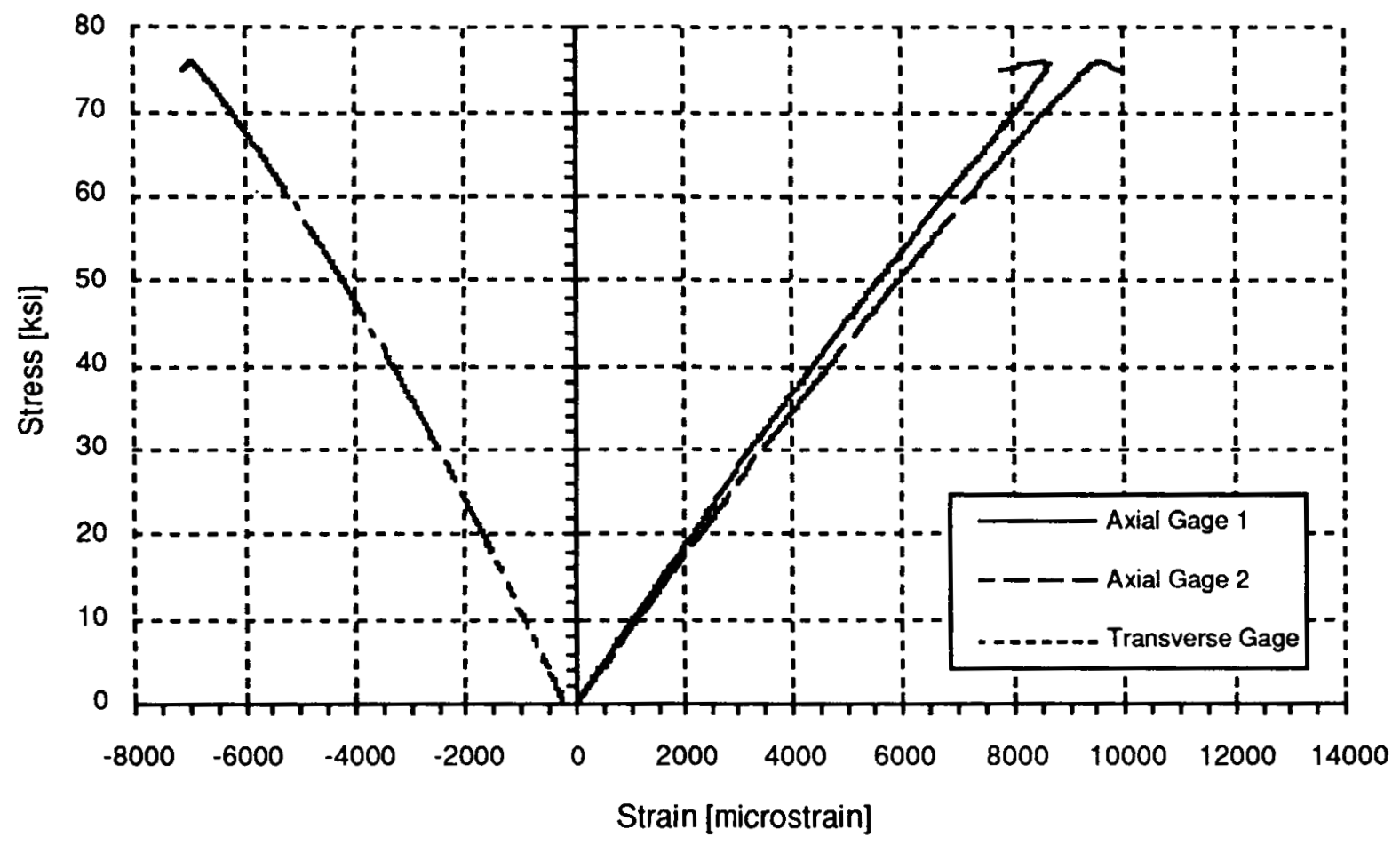

Figure B.9 Typical Longitudinal Compression Test Strain Data for Laminate L1.

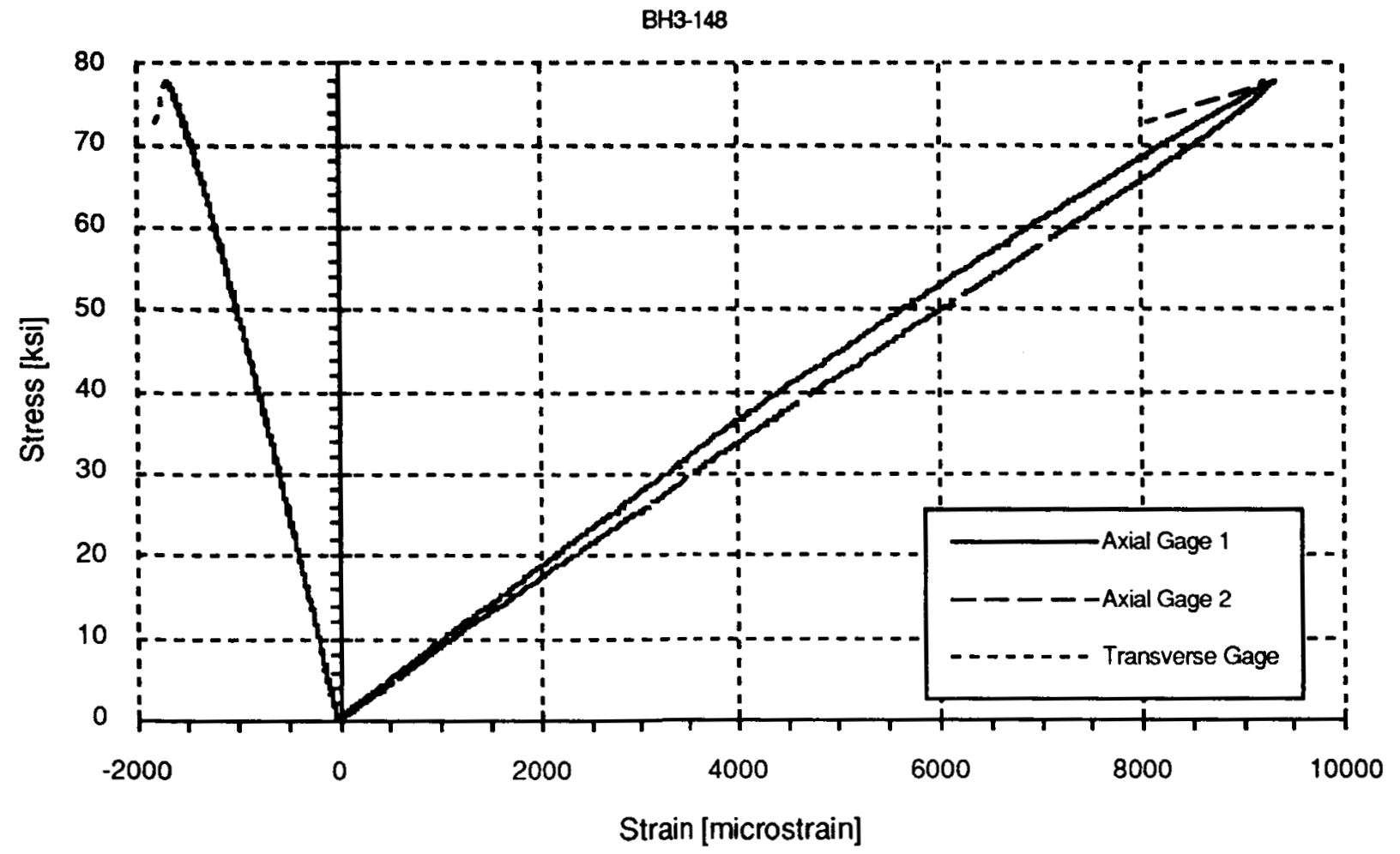

Figure B.10 Typical Longitudinal Compression Test Strain Data for Laminate L2. 
BH3-198

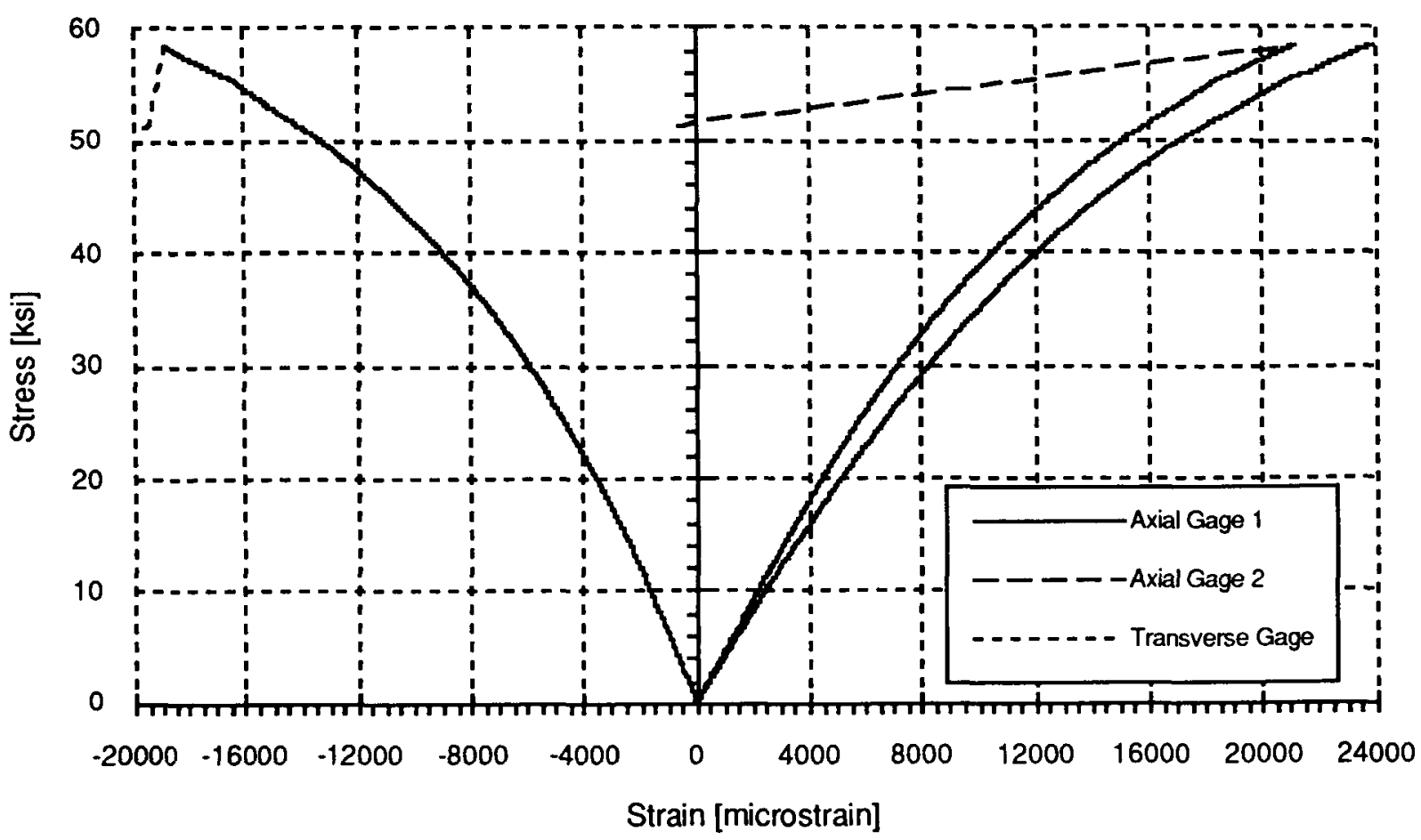

Figure B.11 Typical Longitudinal Compression Test Strain Data for Laminate L3.

BH3-172

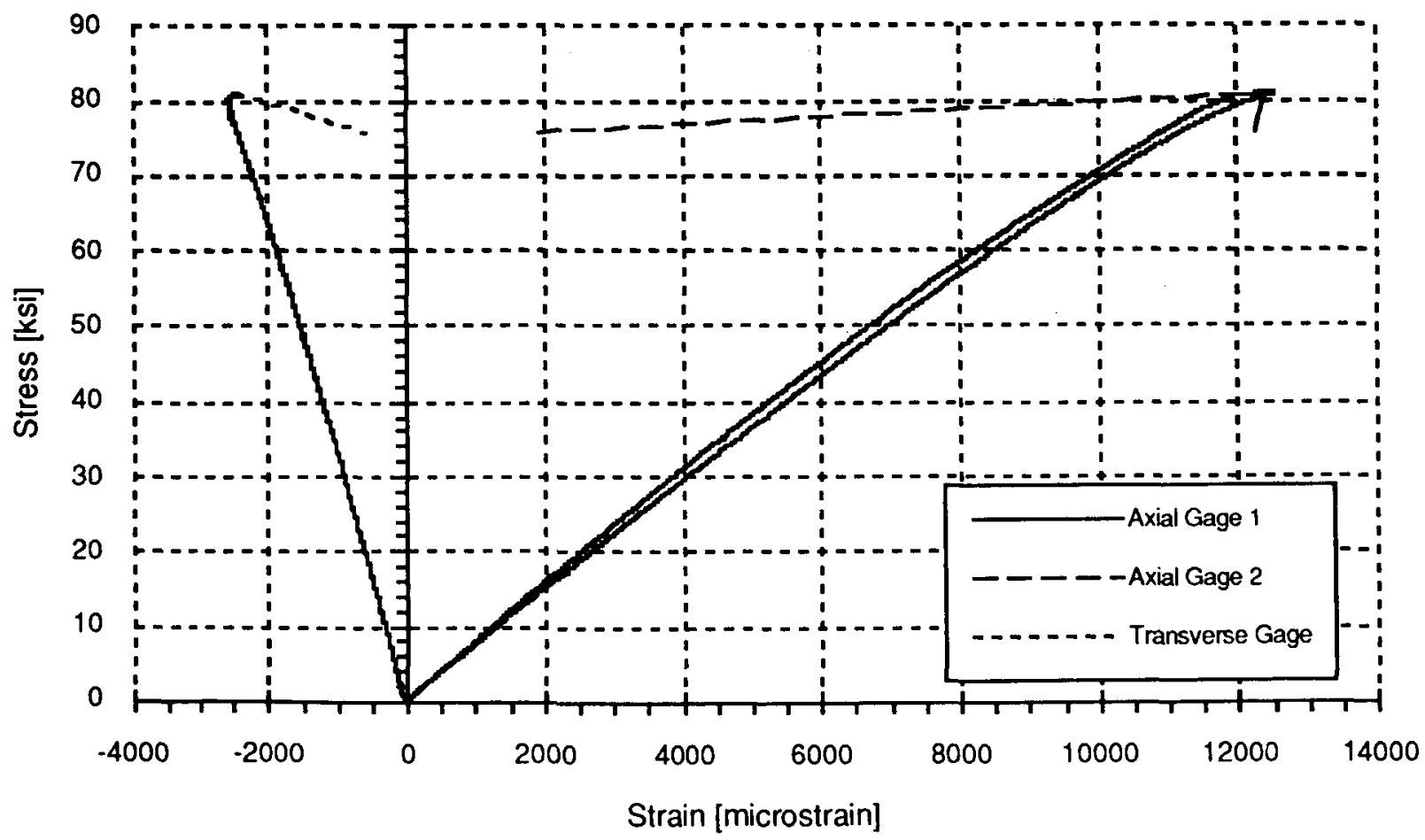

Figure B.12 Typical Longitudinal Compression Test Strain Data for Laminate L4. 
BH3-133

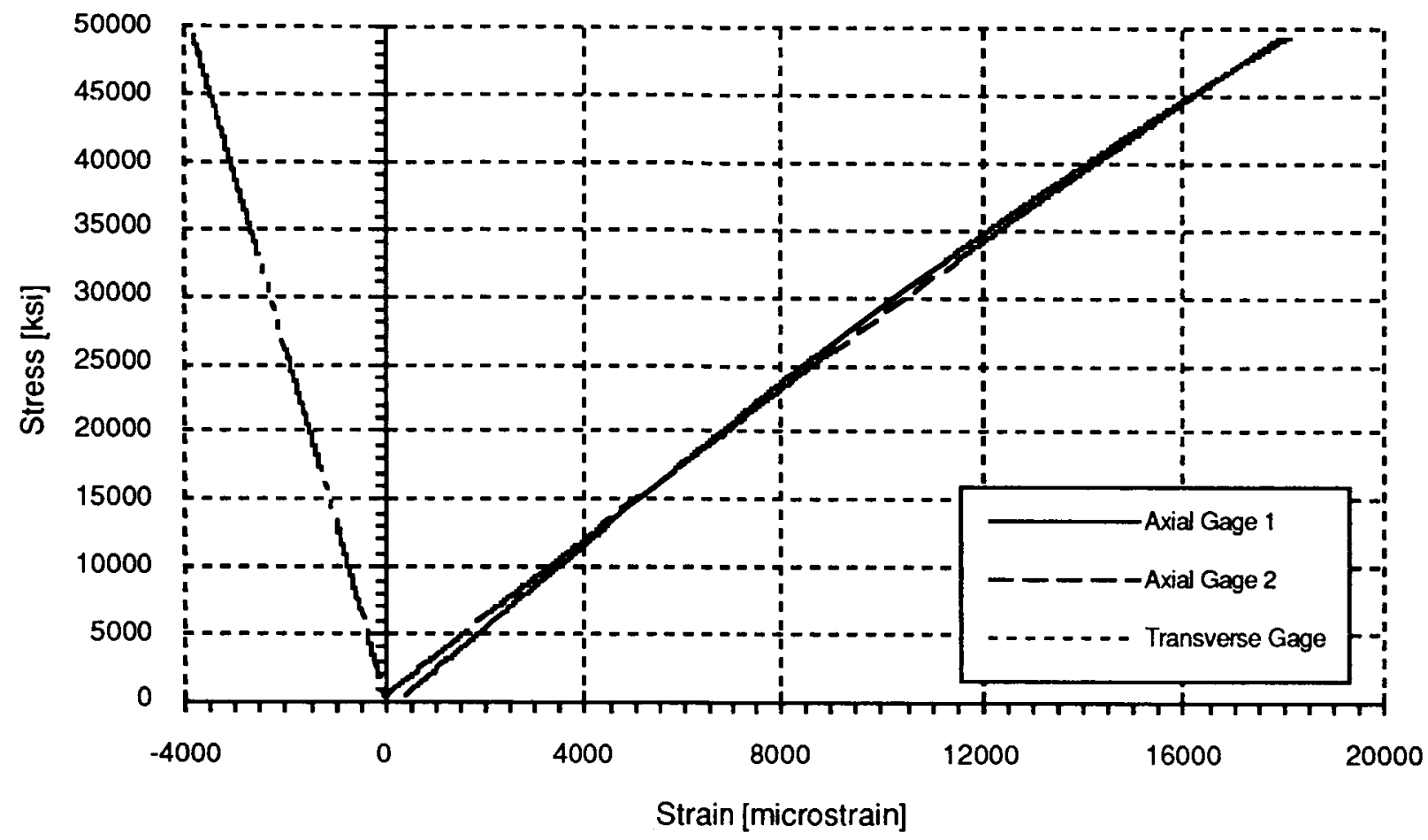

Figure B.13 Typical Transverse Compression Test Strain Data for Laminate L1.

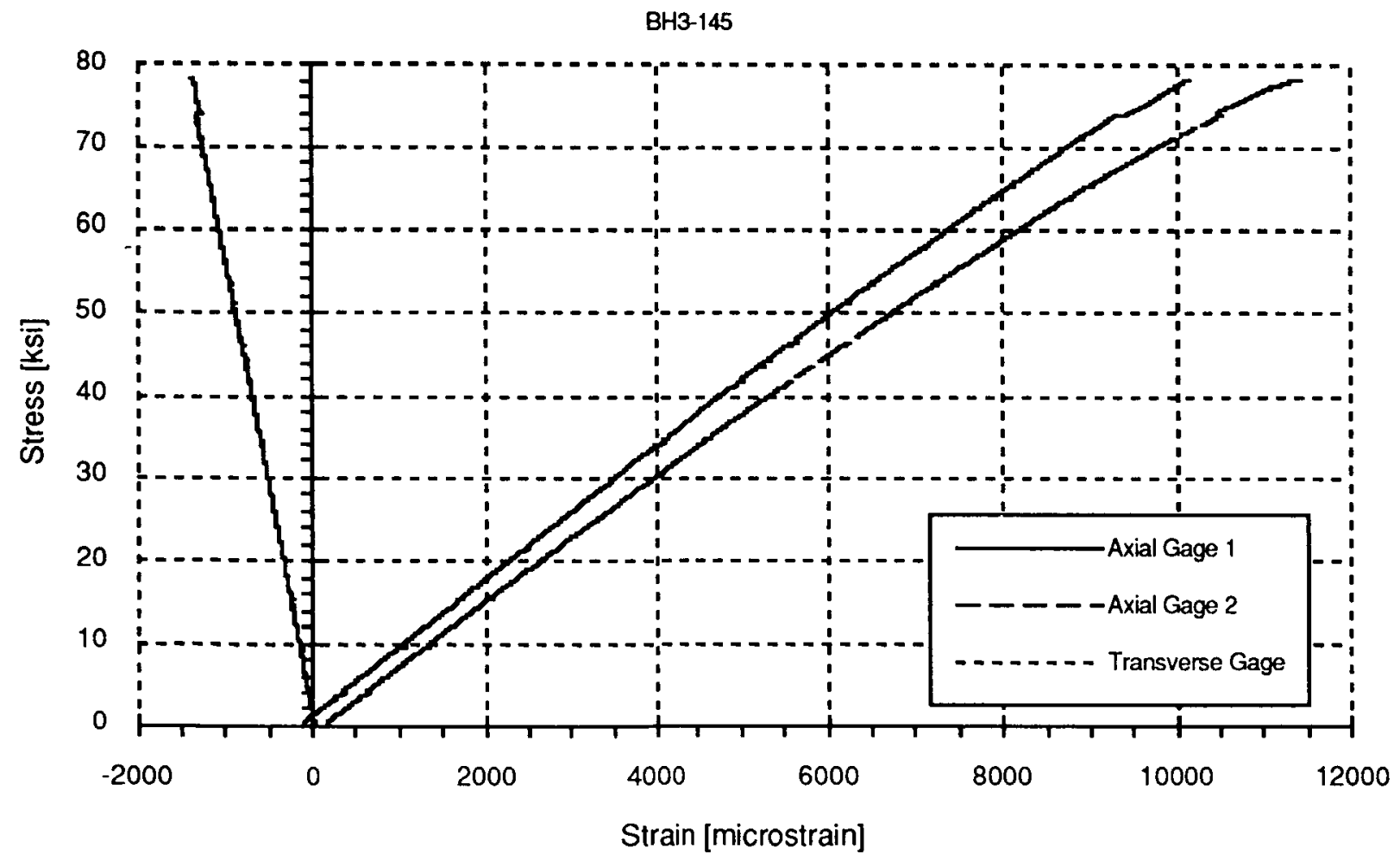

Figure B.14 Typical Transverse Compression Test Strain Data for Laminate L2. 


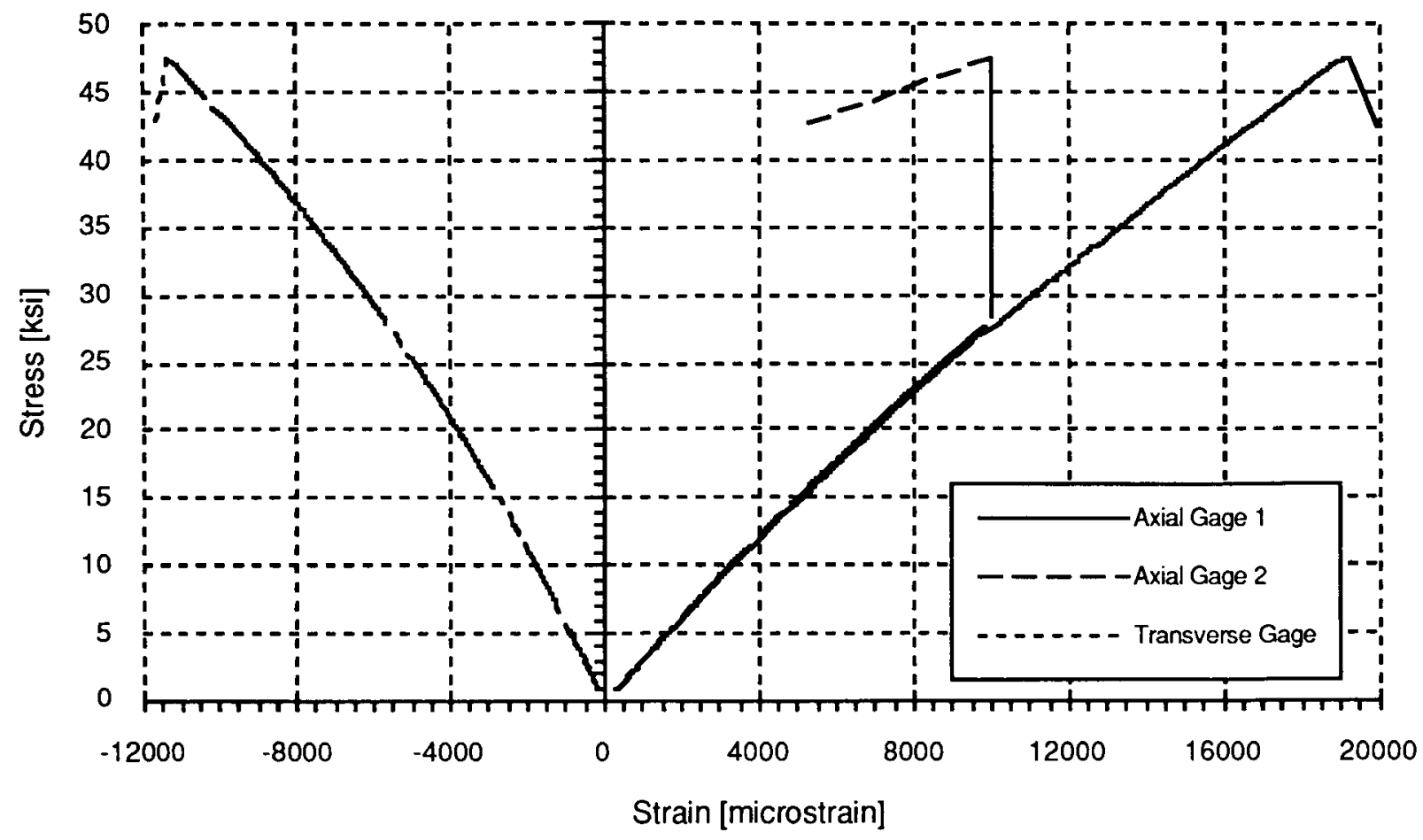

Figure B.15 Typical Transverse Compression Test Strain Data for Laminate L3.

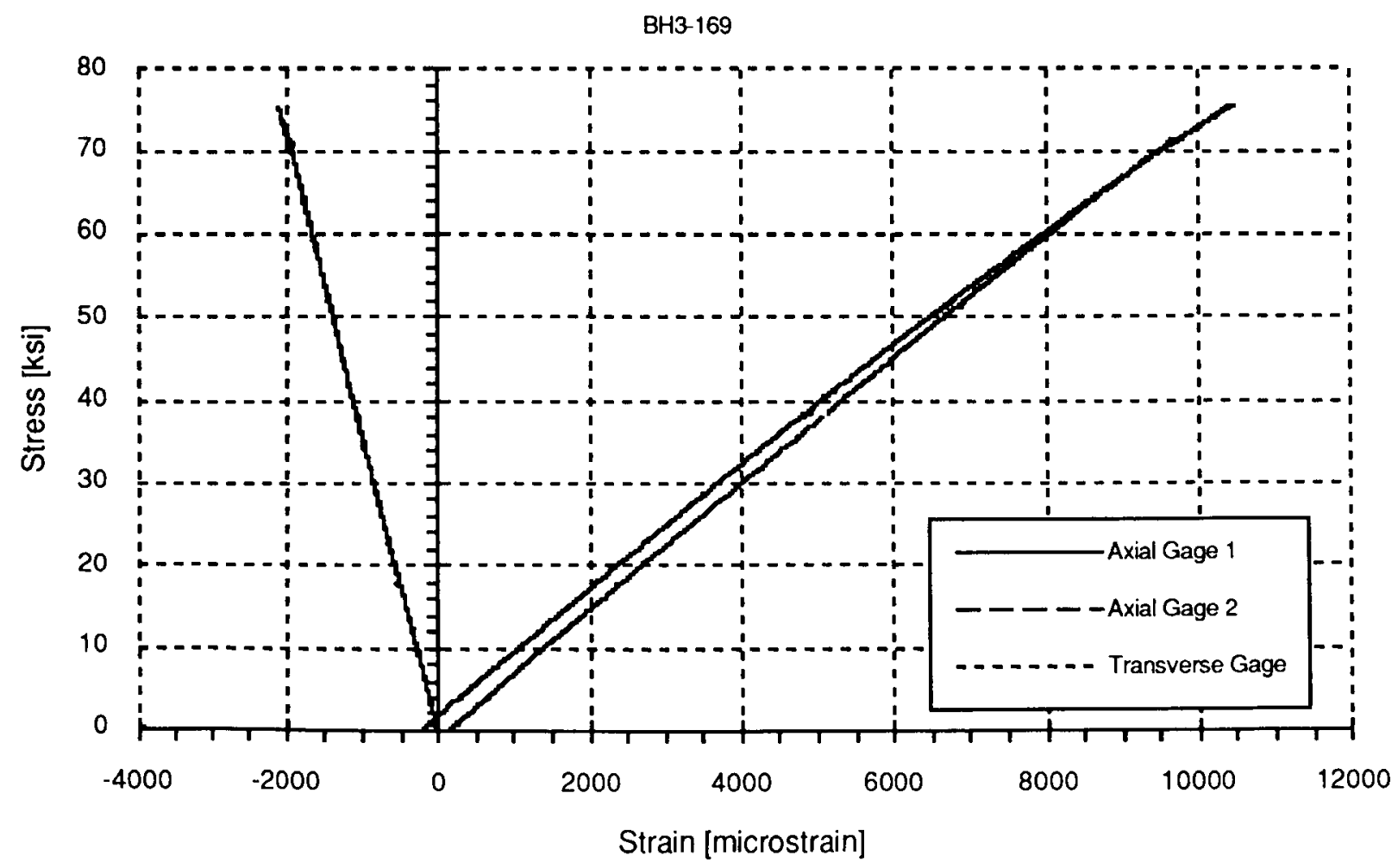

Figure B.16 Typical Transverse Compression Test Strain Data for Laminate L4. 


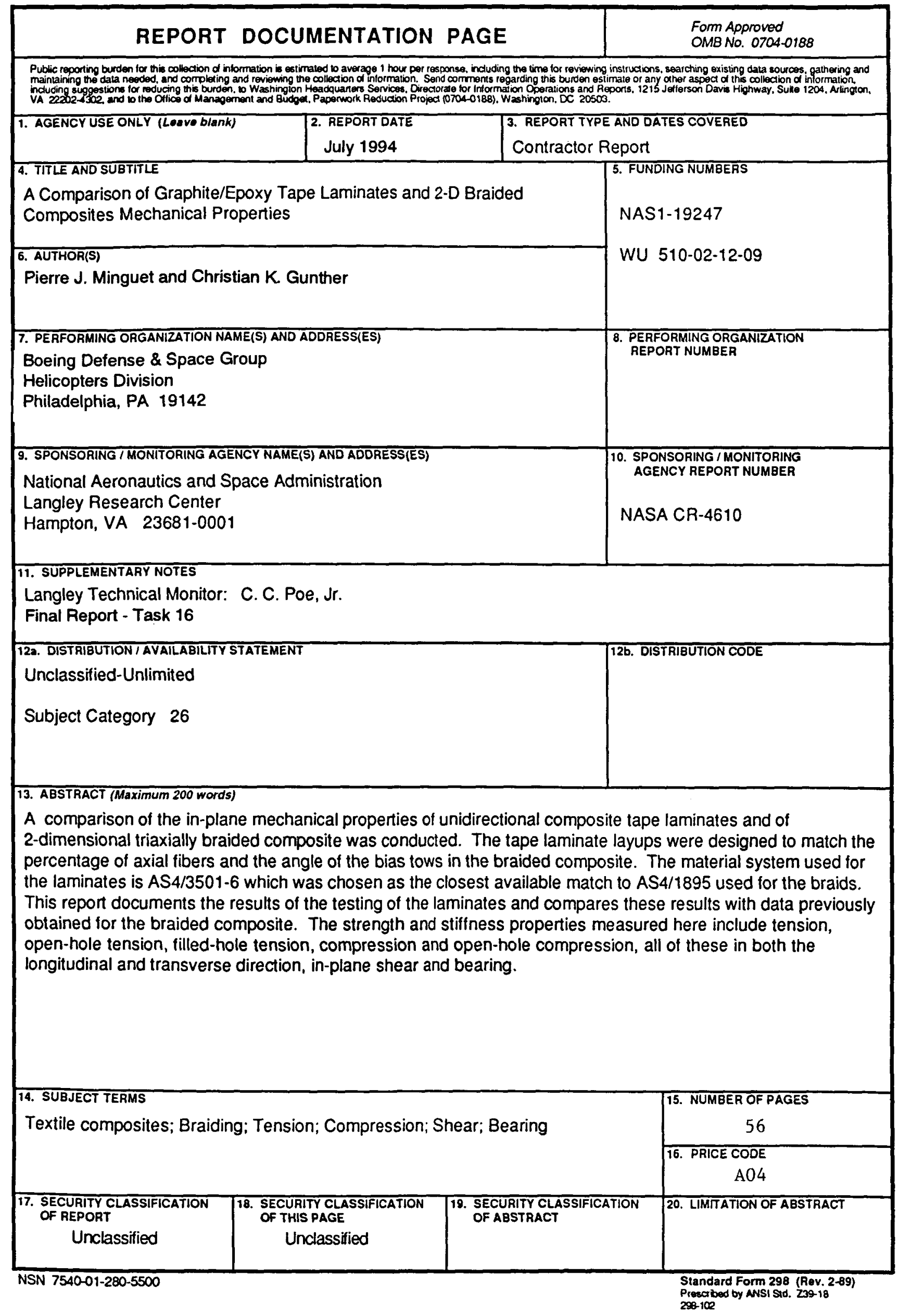

